\author{
Universidade de São Paulo \\ Faculdade de Filosofia, Ciências e Letras de Ribeirão Preto \\ Departamento de Psicologia e Educação
}

Mikael Cavallet

\title{
Distribuição da atenção visual em áreas não adjacentes do campo visual
}


Mikael Cavallet

\section{Distribuição da atenção visual em áreas não adjacentes do campo visual}

Tese apresentada à Faculdade de Filosofia, Ciências e Letras de Ribeirão Preto da Universidade de São Paulo, como parte das exigências para a obtenção do grau de Doutor em Ciências

Área de concentração: Psicobiologia

Orientador: Prof. Dr. Cesar Galera

Ribeirão Preto 
Autorizo a reprodução e divulgação total ou parcial deste trabalho, por qualquer meio convencional ou eletrônico, para fins de estudo e pesquisa, desde que citada a fonte.

FICHA CATALOGRÁFICA

Cavallet, Mikael

Distribuição da atenção visual em áreas não adjacentes do campo visual. Ribeirão Preto, 2010.

182 p. : il. ; $30 \mathrm{~cm}$

Tese de Doutorado, apresentada à Faculdade de Filosofia, Ciências e Letras de Ribeirão/USP - Área de concentração: Psicobiologia.

Orientador: Galera, César.

1. Atenção visual. 2. Divisão da atenção visual. 3. Dicas espaciais periféricas. 4. Tamanho da área. 


\section{FOLHA DE APROVAÇÃO}

\section{Mikael Cavallet}

Distribuição da atenção visual em áreas não adjacentes do campo visual

Tese apresentada à Faculdade de Filosofia, Ciências e Letras de Ribeirão Preto da Universidade de São Paulo para a obtenção do Título de Doutor em Ciências.

Área de concentração: Psicobiologia

Aprovado em:

\section{Banca Examinadora}

Prof. Dr.

Instituição: Assinatura:

Prof. Dr. Instituição: Assinatura:

Prof. Dr. Instituição: Assinatura:

Prof. Dr. Instituição: Assinatura:

Prof. Dr. Instituição: Assinatura: 


\section{AGRADECIMENTOS}

Agradeço em especial ao Professor Doutor César Galera pelos conselhos, idéias, paciência e oportunidades que me ofereceu durante estes anos de muito aprendizado. Obrigado pela convivência amiga desde os primeiros dias de estágio no laboratório.

Ao Professor Doutor Michael Von Grünau pela oportunidade de realizar o doutorado sanduíche em seu laboratório, pela chance de conhecer lugares incríveis, pela paciência e apoio. Obrigado a você e a sua querida família pela hospitalidade e principalmente pela amizade.

Ao Professor Doutor Aaron Johnson pela ajuda, equipamentos e conhecimento compartilhado e ao Professor Doutor Rick Gurnsey pela atenção, apoio e discussões.

Aos meus pais, Rita e Luiz Carlos Cavallet pelo apoio, educação, amor e incentivo aos estudos.

A Angelita Stabile, minha companheira e esposa, faça sol, chuva ou neve. Obrigado pelo incentivo e carinho.

Aos amigos: Douglas, Eduardo, Vitor e Leonardo pelos momentos de descontração e apoio.

Ao Professor Doutor Joaquim Carlos Rossini, pelas discussões, idéias, incentivo e amizade.

Aos atuais e ex-companheiros de laboratório pelas dicas importantes e pelas boas conversas.

Ao Igor e a Renata, pela alegria, dedicação e apoio técnico. 
Aos participantes dos experimentos que cederam parte do seu tempo e "atenção visual", sem os quais não seria possível a realização deste estudo.

A USP e a FFCLRP, pela oportunidade de realizar este estudo.

Ao CNPq e a CAPES pela concessão da bolsa de doutorado, doutorado sanduíche e pelo apoio financeiro para a realização desta pesquisa.

A todos àqueles que de alguma forma me ajudaram e esqueci-me de citar, desculpe a falha. 
The sober truth remains that vision requires far more than a functioning physical organ. Without an inner light, without a formative visual imagination, we are blind.

Zajonc Arthur 


\section{RESUMO}

Cavallet, M. (2010). Distribuição da atenção visual em áreas não adjacentes do campo visual. 182 p. Tese (Doutorado) - Faculdade de Filosofia, Ciências e Letras de Ribeirão Preto, Universidade de São Paulo, Ribeirão Preto, 2010.

A atenção visual é um conjunto de processos que permite processar preferencialmente uma informação visual em um dado momento. Muitos modelos de atenção visual propõem que a atenção pode ser destinada e focalizada a uma única localização no espaço por vez quando dicas espaciais são usadas para orientar esse deslocamento. Porém, diferentes estudos têm encontrado evidências de que em circunstâncias apropriadas, a atenção pode ser destinada a áreas não adjacentes do campo visual. O objetivo deste estudo foi investigar a distribuição da atenção por estas áreas quando o tamanho e a localização de dicas espaciais periféricas foram manipulados. Os resultados sugerem que a atenção visual pode ser destinada a mais de uma localização ao mesmo tempo como um gradiente com picos de processamento, mas que o tamanho das áreas indicadas não deve ser determinante para isso ocorrer. Os resultados indicam também que a habilidade para dividir a atenção pode depender da localização em que os eventos ocorrem em relação aos lados do campo visual. Eventos que ocorrem em lados opostos têm uma chance maior de serem beneficiados por focos independentes de atenção, enquanto eventos que ocorrem do mesmo lado do campo visual parecem ter mais chance de serem processados por um foco único de atenção, mas essa diferença parece ser relativa do que absoluta. Este estudo traz também contribuições para o entendimento do processo de focalização quando diferentes tarefas são solicitadas, revelando que o ajuste da atenção ao tamanho de uma área indicada é mais facilmente verificado em tarefas que requerem a detecção rápida de um alvo do que quando julgamentos de ordem temporal são solicitados.

Palavras-chave: 1. Atenção Visual, 2. Divisão da atenção visual, 3. Dicas espaciais,

4. Tamanho da área. 


\begin{abstract}
Cavallet, M. (2010). The distribution of visual attention on non-adjacent areas of the visual field. 182 p. Thesis (Doctorate) - Faculdade de Filosofia, Ciências e Letras de Ribeirão Preto, Universidade de São Paulo, Ribeirão Preto, 2010.

Visual attention is a set of processes which permits a preferential processing of visual information in a given moment. Several models of visual attention propose that attention might be allocated and focused in only one location by time when spatial cues are used to orient this displacement. However, different studies have been finding evidences that in appropriate circumstances, attention can be deployed to non-adjacent areas of the visual field. The main objective of the present study was to investigate the distribution of attention on these areas when the size and the localization of peripheral spatial cues were manipulated. The results suggest that visual attention can be deployed to more than one location simultaneously as a gradient with peaks in processing quality. The results also indicate that the ability to divide attention might depend on the localization in which the events occur in relation to each hemifield. Events that occur in different hemifields have more chance to take advantage of independent focus of attention while events that happen on the same hemifield have more chance to be processed by a single attentional focus but that this difference seems to be relative than absolute. This study have also contributions for the understanding of the focalization process when different tasks are requested revealing that the adjustment of the attentional focus to the size of a cued area is more easily verified in tasks that require fast detection of an target than when temporal order judgments are requested.
\end{abstract}

Key-words: 1. Visual attention, 2. Division of visual attention, 3. Spatial cues, 4. Size of an area. 


\section{SUMÁRIO}

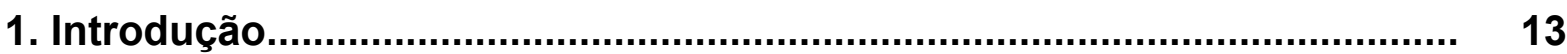

1.1. Atenção visual: definição e propriedades...................................... 16

1.2. Seleção espacial: orientação e controle dos recursos de atenção visual.

1.3. Foco de atenção: características espaciais......................................... 26

1.4. Distribuição espacial da atenção visual em áreas não-adjacentes do campo visual

1.5. Efeito de entrada prioritária e tarefa de julgamento de ordem temporal.

2. Experimentos

2.1. Experimento 1a - Orientação e focalização da atenção em um paradigma de julgamento de ordem temporal

Método

Resultados

Discussão

2.2. Experimento $1 \mathrm{~b}$ - Mais tempo para o ajuste do foco 66

Método

67

Resultados

68

Discussão. 70

2.3. Experimentos $2 a, 2 b$ e $2 c-$ Tarefas de tempo de reação e o efeito do tamanho da dica

Método

Resultados.

Discussão 
2.4. Experimentos $3 a, 3 b$ e $3 c-$ Ajuste do tamanho do foco

Método.

Resultados

Discussão.

2.5. Experimento 4 - Distribuição da atenção visual sobre regiões nãoadjacentes localizadas em lados opostos do campo visual.

Método 106

Resultados 109

Discussão.

2.6. Experimento 5 - Distribuição da atenção visual sobre regiões não adjacentes e não apresentadas do mesmo lado do campo visual.

Método

Resultados.

Discussão

2.7. Experimento 6 - A localização do alvo entre as duas dicas e a distribuição da atenção visual.

Método

Resultados

Discussão.

2.8. Experimento 7 - Alvo apresentado em diferentes excentricidades: tempo de reação para detectá-lo em provas com ou sem dicas

Método.

Resultados

Discussão. 
3. Discussão Geral.......................................................................... 145

3.1. Diferentes resultados entre tarefas para o efeito do tamanho da dica... 149

3.2. Distribuição da atenção por áreas não adjacentes do campo visual........ 155

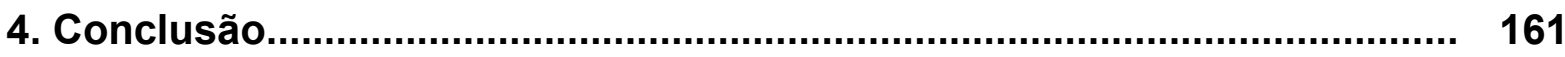

5. Referências Bibliográficas....................................................................... 163

Apêndices.................................................................................................... 173

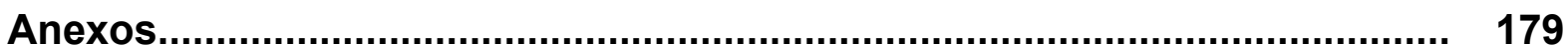


1. INTRODUÇÃO 

Enxergar o mundo como o enxergamos é uma tarefa complexa, que envolve desde a chegada da informação visual aos componentes sensoriais periféricos do sistema visual, até o processamento das características físicas dos estímulos visuais por áreas especializadas do sistema nervoso central. Durante esse processo, diferentes recursos cognitivos como a atenção e a memória são usados na medida em que a informação visual é processada, formando imagens coerentes da realidade externa. Uma idéia comumente aceita é de que a atenção é requerida porque o ambiente contém mais informação do que pode ser processada e compreendida em um dado momento (Vecera \& Rizzo, 2003). A atenção desempenharia a função de proteger o sistema de uma sobrecarga de informação. Assim, quando nossos olhos estão fixados em uma localização específica, o sistema visual não parece processar passivamente toda a informação disponível. Ao invés, aspectos diferentes da imagem são selecionados e recebem atenção em momentos diferentes. A atenção visual pode ser distribuída por toda a imagem ou dirigida a um objeto ou conjunto de objetos localizados nas diferentes coordenadas espaciais do campo visual, existindo ainda situações em que a atenção é dirigida para partes ou características desses objetos.

Além de ser importante em situações em que apenas um estímulo é o alvo de nossa ação, a atenção visual também é exigida em situações onde dois ou mais estímulos visuais, relevantes e localizados em áreas diferentes do campo visual, precisam ser processados simultaneamente. Essas situações são comuns e freqüentemente enfrentadas, por exemplo, no transito ou em atividades específicas como em esportes. É comum um motorista ter que prestar atenção em dois locais ao mesmo tempo, como no carro que está a sua frente, parado ou em movimento, e em um semáforo que está prestes a mudar. Da mesma maneira é comum um jogador de 
futebol, basquete ou voleibol enfrentar lances em que precisa prestar atenção simultaneamente na bola e no adversário, ambos, dentro do mesmo campo de visão. Essas situações levantam questões sobre a dinâmica da atenção visual. Como ocorre a seleção da informação nessas situações? A atenção é dividida simultaneamente em dois estímulos diferentes ou se distribui sobre os estímulos de maneira a englobá-los em um só foco de atenção?

Essas e outras questões referentes à distribuição da atenção visual foram investigadas nesse estudo e serão apresentadas de maneira mais detalhada nas próximas sessões da introdução, juntamente com a descrição de processos e características da atenção visual.

\subsection{Atenção visual: definição e propriedades}

A atenção visual pode ser definida como um conjunto de processos complexos, que seleciona e recruta recursos para o processamento da informação visual selecionada em relação à informação não selecionada (Palmer, 1999).

Essa definição engloba duas propriedades principais da atenção: a capacidade e a seletividade. Palmer (1999) definiu capacidade como a quantidade de recursos de percepção que estão disponíveis para uma dada tarefa, enquanto seletividade é a quantidade de atenção destinada aos diferentes subconjuntos de informação visual, podendo ser distribuída com certa flexibilidade. Essa propriedade permite que a atenção seja seletiva em termos do que será processado e do que não será processado (Palmer, 1999).

A seletividade pode ser entendida também, como uma mudança na distribuição dos recursos de atenção. Estudos sugerem que à medida que a informação é selecionada, os recursos de atenção mudam de um modo difuso de 
distribuição para um modo focalizado (Eriksen \& St. James, 1986; Jonides, 1983; Posner, Snyder \& Davidson, 1980), ou seja, conforme uma tarefa visual exige mais processamento da informação, os recursos de atenção deixam de ser distribuídos igualmente sobre todo o campo visual e passam a ser orientados para a informação relevante. A orientação e a focalização recrutam e concentram os recursos disponíveis, realizando a análise detalhada da informação visual selecionada. Esse mecanismo pode ocorrer também de um estímulo para outro, envolvendo diferentes etapas como a retirada dos recursos do estímulo inicialmente selecionado e o engajamento dos mesmos recursos no próximo estímulo a ser analisado (Posner, 1980; Posner et al., 1980).

\subsection{Seleção espacial: orientação e controle dos recursos de atenção visual}

$\mathrm{Na}$ maior parte do tempo a orientação dos recursos de atenção ocorre em conjunto com movimentos explícitos dos olhos para o estímulo selecionado, sendo chamada de orientação visual explícita. No entanto, a orientação da atenção também pode ocorrer de maneira encoberta, sem o ato físico de direcionar os olhos para o estímulo (Colegate, Hoffman \& Eriksen, 1973; Eriksen \& Hoffman, 1972; Posner et al., 1980). Esse tipo de seleção funciona como um ato interno de orientação dos recursos em volta dos objetos de interesse, sendo chamada de orientação visual encoberta. Ela pode ser exemplificada em uma situação onde fixamos o olhar em um objeto e prestamos atenção em outros que estão no campo visual, sem que os olhos mudem de posição. Como os olhos não estão em movimento explícito, a mudança é atribuída ao deslocamento da atenção visual que realiza a seleção espacial da informação. A seleção espacial pode ser entendida como o processo de concentração de recursos de atenção visual (focalização) sobre 
a informação de uma região restrita do campo visual. Ela pode ser pensada também como a seleção interna da informação localizada em porções específicas do mapa cortical, dada a organização retinotópica do córtex visual (Palmer, 1999).

Uma forma simples e muito utilizada em laboratório para estudar a seleção espacial e a orientação encoberta da atenção visual sobre diferentes localizações é apresentar rapidamente a um participante, estímulos visuais na tela de um monitor e solicitar que realize uma tarefa referente a estes estímulos, como ocorre no paradigma de dicas espaciais. Nesse tipo de paradigma, um estímulo visual ou instrução precede a apresentação do alvo da tarefa. Esse estímulo ou instrução é referido como dica e pode ou não predizer a localização em que o alvo aparecerá. Nos experimentos realizados por Posner e colaboradores (Posner, 1980; Posner \& Cohen, 1984; Posner, et al. 1980), por exemplo, em cada prova, uma dica foi apresentada com a intenção de orientar a atenção do participante para uma localização à direita ou à esquerda do campo visual, como mostrado na Figura 1. A dica podia ser uma mudança abrupta na luminosidade das bordas do quadrado (dica periférica), que marcava uma das possíveis localizações de apresentação do alvo (Figura 1A) ou um símbolo (uma seta) apresentado no centro do campo visual (dica central - Figura 1B), que apontava a localização onde o alvo poderia aparecer. Após um atraso, o alvo era apresentado e a tarefa do participante era detectá-lo o mais rápido possível, realizando assim, uma tarefa de tempo de reação (TR) simples. Em alguns experimentos uma tarefa de discriminação também foi usada (e.g., responder se o alvo era um "H" ou um "L"). 
A

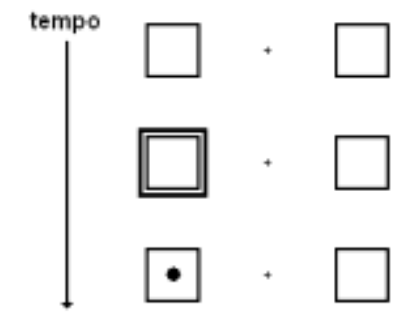

B

Dicas válidas

(1)

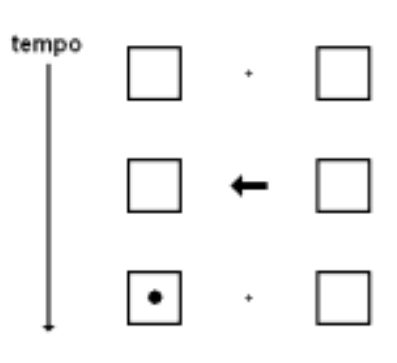

Dicas invalidas

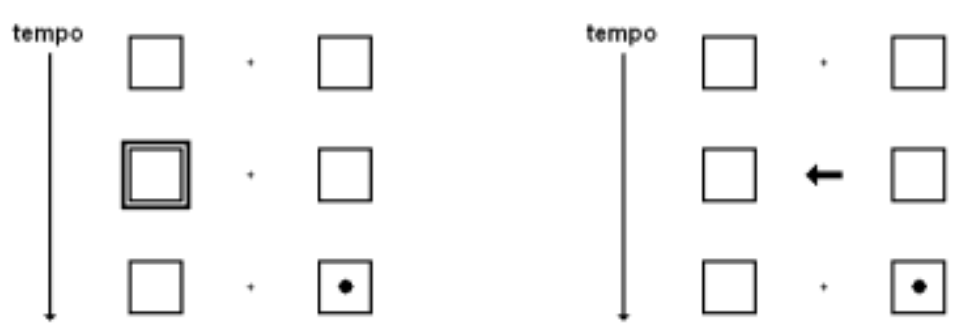

Figura 1. Seqüência de eventos em um paradigma de dicas espaciais. A tarefa dos participantes é detectar o aparecimento de um alvo que é corretamente indicado (provas de dica válida) ou incorretamente indicado (provas de dica inválida). (A) Dicas periféricas que automaticamente capturam a atenção visual para o local indicado. (B) Dicas centrais usadas para voluntariamente deslocar a atenção para a área indicada.

As dicas podiam informar corretamente a localização do alvo, ou seja, a dica e o alvo apareciam na mesma localização indicada (provas de dica válida) ou podiam aparecer em localizações diferentes (provas de dica inválida). Alguns experimentos incluíam também provas com dicas que não forneciam informação sobre a localização em que o alvo seria apresentado (provas de dica neutra). Para assegurar que os resultados fossem independentes de qualquer direcionamento dos olhos para os estímulos, os movimentos oculares dos participantes foram monitorados e somente as provas em que os olhos permaneceram sobre um estímulo de fixação foram analisadas. Os resultados mostraram que os participantes responderam mais rapidamente nas provas de dica válida e mais lentamente nas provas de dica inválida. Jonides (1981), de maneira semelhante a Posner e colaboradores, apresentou abruptamente uma barra na periferia do campo visual e 
próximo a provável localização de um alvo apresentado subseqüentemente. Os resultados também mostraram que a dica (barra) produziu um custo significativo no TR para identificar o alvo quando o alvo ocorreu em uma localização diferente a da barra e benefícios em desempenho quando ocorreu próximo a essa localização.

Resultados semelhantes também foram obtidos por Zimba e Hughes (1987), que apresentaram dez quadrados ao redor do centro da tela para demarcar possíveis localizações onde os eventos ocorreriam. Os resultados mostraram um aumento rápido do TR dos participantes conforme a distância aumentava entre o quadrado indicado e a localização em que o alvo era apresentado.

O aumento em TR encontrado nesses estudos é explicado pela idéia de que a apresentação da dica espacial leva ao deslocamento espacial da atenção visual para a região indicada. Quando o alvo da tarefa é apresentado em um local não indicado, a atenção precisa ser deslocada para o local em que o alvo foi apresentado, aumentando o tempo de processamento dessa informação, pois o movimento da atenção presumivelmente leva tempo e os TR's mais lentos nos locais não indicados são atribuídos ao tempo que a atenção leva para percorrer a distância entre o local indicado e a informação relevante para a tarefa. Por outro lado, quando o alvo da tarefa é apresentado no local indicado, a atenção não precisa ser reorientada para processar a informação, produzindo TR's mais rápidos. Essa diferença tem sido considerada como um efeito provocado pela orientação encoberta da atenção espacial para uma área indicada (Jonides, 1981; Posner, 1980; Posner \& Cohen, 1984; Posner, et al. 1980; Wright \& Ward, 1998).

Posner (1980) e Jonides (1981) assumem de maneira semelhante que a orientação da atenção iniciada por dicas periféricas ou centrais é o resultado de um mecanismo de ativação dos recursos de atenção, guiado por um controle 
automático ou voluntário. Dois fatores determinariam esse controle: (1) as propriedades físicas dos estímulos do campo visual, que predominantemente iniciariam a orientação automática da atenção e (2) os objetivos do observador, que guiariam o deslocamento da atenção de maneira voluntária (Egeth \& Yantis, 1997; Pashler, Johnston \& Ruthruff, 2001). Em outras palavras, algumas vezes o deslocamento da atenção pode depender quase exclusivamente das propriedades da imagem (conduzido pelos estímulos), como uma mudança que ocorre em intervalos curtos de tempo (e.g., o aparecimento abrupto de um estímulo) e em outros momentos pode estar sob supervisão do indivíduo, de acordo com os seus objetivos ou instruções (direcionado pelos seus objetivos), ocorrendo por meio de processos controlados de distribuição dos recursos de atenção.

Estímulos com características específicas, como um estímulo de início abrupto, são relatados para capturar a atenção automaticamente, ou seja, de maneira involuntária (sem o controle consciente). Uma explicação para isso é a de que estímulos de início abrupto possuem um valor ecológico alto, pois podem representar uma importante ameaça a ser evitada (como um predador) ou uma oportunidade a ser agarrada (como uma presa, Yantis \& Hillstron, 1994), requerendo uma resposta rápida do indivíduo que deve processá-los imediatamente. Estudos usando diferentes tarefas têm apontado nesse sentido, mostrando que o desempenho dos participantes é melhor quando o alvo da tarefa é apresentado abruptamente no campo visual do que quando ele não é apresentado dessa maneira, sugerindo que o seu aparecimento captura a atenção de maneira reflexa, involuntária e automática (Jonides \& Yantis, 1988; Theeuwes, 1995; Yantis \& Jones, 1991; Yantis \& Jonides, 1984). 
Devido às dicas periféricas serem estímulos apresentados abruptamente no campo visual, elas também têm sido usadas para investigar a orientação automática da atenção. Remington, Johnston e Yantis (1992) mostraram que uma dica apresentada abruptamente na periferia do campo visual pode reorganizar de maneira involuntária a atenção, mesmo quando a dica não informava aos participantes o local de apresentação do alvo (dica não preditiva). Baseados em diferentes resultados comportamentais e neurofisiológicos, Serences e Yantis, (2006) sugerem que a orientação da atenção deve ocorrer de maneira automática, pois o início abrupto de uma dica periférica pode ativar circuitos neurais de um mapa de representação espacial da área indicada, facilitando a detecção do alvo apresentado nessa localização. Além disso, a capacidade de uma dica periférica atrair a atenção não parece ser restrita apenas a um tipo de dica usada, sendo mostrada com diferentes dicas periféricas, por exemplo, com a apresentação de um ponto (Nakayama \& Mackeben, 1989), um quadrado (Von Grünau \& Faubert, 1994), e uma linha horizontal pequena (Kröse \& Julesz, 1989).

Já a orientação voluntária requer o desenvolvimento de uma expectativa espacial baseada na informação probabilística fornecida pela dica, como ocorre com a apresentação de uma seta no centro do campo visual (Müller \& Rabbitt, 1989). Esse tipo de orientação deve ocorrer de acordo com instruções ou estímulos que induzem o observador a interpretá-los, conduzindo-o a realizar a orientação da atenção de acordo com um controle consciente.

Uma variável importante na determinação do tipo de controle da orientação da atenção é o tempo, pois pode revelar a dinâmica temporal desse controle. Posner e Cohen (1984) verificaram que em situações específicas, a ativação automática da atenção pode produzir um efeito inibitório, que pode ser substituído pela orientação 
voluntária da atenção conforme a manipulação do tempo entre a apresentação da dica e a apresentação do alvo. Em seu estudo, a dica periférica foi apresentada por 150 milissegundos (ms) à direita ou à esquerda do campo visual e após um intervalo variável de $0,50,100,200,300$ ou 500 ms, o alvo foi apresentado. O alvo podia aparecer no centro do campo visual (probabilidade de $60 \%$ ) ou à direita ou à esquerda do centro no mesmo local indicado (probabilidade de 10\% para cada lado), portanto, a dica não era preditiva. Provas sem o alvo (probabilidade de $20 \%$ ) foram apresentadas para que os participantes não respondessem de forma displicente. Os participantes realizaram uma tarefa de TR simples e os resultados revelaram respostas mais rápidas quando o alvo apareceu no lado indicado nos primeiros 150 ms após a apresentação da dica. Essa facilitação foi substituída por uma inibição, aproximadamente 300 ms após a apresentação da dica, ou seja, o TR foi mais lento para o alvo apresentado no local indicado do que no local não indicado quando o intervalo entre dica e alvo foi maior. No entanto, nas provas em que o alvo apareceu no centro, o TR foi rápido com todos os intervalos de tempo usados. O mesmo padrão de resultados também foi replicado em outro experimento quando eles usaram um intervalo maior do que $500 \mathrm{~ms}$ e um controle sobre a luminosidade dos estímulos. Com dicas centrais o desempenho foi um pouco diferente, revelando uma facilitação após a apresentação da dica central, mas sem a inibição após intervalos maiores de tempo. Os resultados sugerem que dicas periféricas e centrais ativam de maneira diferente, ao longo do tempo, os recursos de atenção.

Outros estudos também têm encontrado a inibição com intervalos longos, seguida sempre pela facilitação com intervalos curtos de exposição de dicas periféricas não preditivas (Lambert \& Hockey, 1991; Rafal, Calabresi, Brennan \& Sciolto, 1989). Esses estudos sugerem que o TR mais rápido para os intervalos 
curtos de tempo ocorrem devido ao alinhamento automático da atenção para o local indicado, enquanto a inibição ocorreria devido ao deslocamento da atenção para o centro do campo visual, provavelmente guiado por um controle voluntário (Maruff, Hay, Malone \& Currie, 1995; Pratt \& Abrams, 1995). No entanto, a dica periférica parece produzir um benefício máximo, apenas quando a dica permanece na tela juntamente com o alvo até que o indivíduo realize a sua resposta (Maruff, Yucel, Danckert, Stuart \& Currie, 1999) e pode ser ainda mais eficiente se for preditiva, ou seja, se informar a localização do alvo em mais de $50 \%$ das provas. Nesse caso, a facilitação é significativamente maior do que a inibição mesmo que o intervalo entre a dica e o alvo seja maior do que 500 ms e mesmo que a dica tenha sido exposta por apenas 50 ms durante esse intervalo (Maruff et al., 1995; Maruff, Currie, McArthur \& Malone, 1995).

O melhor desempenho encontrado quando dicas periféricas são apresentadas por períodos de tempo maiores do que 150 ms pode estar relacionada a ativação conjunta de um mecanismo automático e outro voluntário de orientação da atenção. Müller e colaboradores (Müller \& Findlay, 1988; Müller \& Rabbitt, 1989) propõem que dicas periféricas ativam tanto um mecanismo automático, rápido, quanto um mecanismo lento, voluntário de orientação da atenção. Esses dois mecanismos seriam iniciados em diferentes momentos após o início da dica. O mecanismo automático produziria uma ativação inicial rápida e forte, mas transitória, diminuindo após 100-300 ms do início da apresentação de dicas periféricas, enquanto o mecanismo voluntário produziria uma ativação de aumento lento, mas prolongado. Dicas centrais, por outro lado, iniciariam apenas o mecanismo de orientação voluntário da atenção. Os resultados desses estudos parecem confirmar essa idéia mostrando uma facilitação máxima entre 100 e 150 ms após a exposição de dicas 
periféricas, diminuindo rapidamente após esse intervalo, mas ainda produzindo uma vantagem para a informação indicada, sendo verificado também em outro estudo (Cheal \& Lyon, 1991).

Resultados semelhantes foram encontrados também por Nakayama e Mackeben (1989) com uma tarefa de busca visual. Eles verificaram que os participantes tiveram um desempenho melhor quando a dica periférica indicou a localização do alvo, durante intervalos curtos de tempo entre a dica e o alvo apresentado junto com outros estímulos de busca visual. O pico no desempenho ocorreu entre 50 e 150 ms e intervalos maiores levaram a um decréscimo significativo em desempenho. Semelhante a Müller e Rabbitt (1989), Nakayama e Mackeben sugeriram uma fase inicial transitória e automática de orientação da atenção, seguida por uma fase voluntária.

Em resumo, esses estudos revelam um desempenho melhor em áreas indicadas do que em áreas não indicadas e sugerem que essa facilitação seja atribuída em maior parte a orientação da atenção para as localizações indicadas. Além disso, a orientação parece ser predominantemente automática quando dicas periféricas preditivas são apresentadas, mas após um determinado tempo, essa ativação perde força e a atenção pode ser mantida de maneira voluntária no local indicado. Embora mais fraca, a manutenção voluntária da atenção nessas situações, dependerá da probabilidade de o alvo aparecer no local indicado. Caso a probabilidade seja baixa, os recursos de atenção podem deixar rapidamente o local indicado para selecionarem outras localizações. Caso seja alta, um benefício mais prolongado pode ocorrer. 


\subsection{Foco de atenção: características espaciais}

Além de os estudos mostrarem que a atenção visual pode ser orientada para diferentes localizações no espaço, uma idéia amplamente aceita é a de que durante a orientação, os recursos de atenção também sejam concentrados e focalizados no local selecionado (Eriksen \& St. James, 1986; Jonides, 1983; Posner et al. 1980). Deferentes modelos têm tentado explicar como esse mecanismo funciona e propostas que consideram a atenção visual como um foco que se desloca pelo espaço têm sido amplamente investigadas e suportadas por diferentes estudos, incluindo correlatos neurais desse foco de atenção em áreas corticais visuais no estriado e extra-estriado; representações retinotópicas da área que recebeu atenção exibem ativação maior, verificada por meio de imagens por ressonância magnética funcional (fMRI) (Kastner, Weerd, Desimone \& Ungerleider, 1998; Brefczynski \& DeYoe, 1999; McMains \& Somers, 2005).

Uma dessas propostas é a analogia do foco da lanterna (Posner et al. 1980). De acordo com esse modelo, os recursos de atenção não podem ser distribuídos livremente pelas localizações no espaço, mas parecem formar um foco único, de forma circular e que pode variar em tamanho de acordo com os requerimentos do experimento (Posner et al. 1980). O foco pode ser orientado ou deslocado para os diferentes locais ocupados pelos objetos e o objeto abrangido pelo foco, levaria vantagem em processamento (i.e, TR's rápidos e maior número de acertos nas tarefas realizadas) em relação aos objetos que estão fora de sua extensão. Portanto, quando uma dica periférica é apresentada no campo visual, o foco de atenção seria automaticamente deslocado para o local indicado, abrangendo toda a área indicada e promovendo uma vantagem em processamento para a informação apresentada nesse local. De acordo com os resultados de LaBerge (1983), o foco também teria a 
capacidade de diminuir de tamanho para uma extensão menor do que $0,3^{\circ}$ de ângulo visual e expandir para uma área de aproximadamente $2,0^{\circ}$.

Uma analogia um pouco diferente, mas que complementa a proposta do foco da lanterna é a proposta do zum de uma lente (Eriksen \& St. James, 1986). De acordo com esse modelo o foco tem uma forma mais ou menos circular ou elíptica e pode mudar de tamanho (Eriksen \& Yeh, 1985), mas essa mudança, conseqüentemente, altera a concentração dos recursos de atenção distribuídos dentro do foco (Eriksen \& Yeh, 1985; Eriksen \& St. James, 1986). Essa alteração seria estabelecida por uma relação inversa entre a extensão do foco e a eficiência de processamento dentro do seu contorno. Análises da atividade neural por meio de fMRI em várias áreas visuais em função do tamanho da região indicada no campo visual, parecem confirmar essa relação inversa, mostrando que enquanto a extensão ativada de áreas retinópicas do córtex visual aumenta com o aumento da região indicada, o nível da atividade neural em uma sub-região diminui (Müller, Bartelt, Donner, Villringer \& Brandt, 2003). Em estudos que têm manipulado o tamanho de uma dica periférica (e.g. um quadrado), essa relação inversa tem sido verificada por TR's mais rápidos para detectar um alvo apresentado dentro de uma dica pequena do que dentro de um quadrado grande, sugerindo que a concentração de recursos de atenção dentro de uma dica pequena é maior do que dentro de uma dica grande. Esse efeito é chamado de efeito do tamanho da dica e foi encontrado em vários estudos com tarefas diferentes como a detecção simples de um alvo, tarefa de reconhecimento, ou em uma tarefa de discriminação (Benso, Turato, Mascetti \& Umiltà, 1998; Castiello \& Umiltà, 1990, 1992; Eriksen \& St. James, 1986, Eriksen \& Yeh, 1985; Maringelli \& Umiltà, 1998; Mizuno, Umiltà \& Sartori, 1998; Turatto et al. 2000). 
Estudos mais recentes têm considerado a possibilidade de o foco de atenção ser mais flexível em relação a sua extensão e forma. O fato de os objetos que vemos todos os dias possuírem diferentes formas e tamanhos torna plausível a idéia de que uma vez que a atenção tenha sido orientada para um objeto, ela seja também ajustada ao tamanho e forma desse estímulo (Turatto et al. 2000). Esse ajuste do foco foi chamado de focalização por Turatto et al. (2000) e embora grande parte dos estudos não tenha considerado a orientação e a focalização como processos independentes, algumas evidências apontam que o foco pode se ajustar tanto ao tamanho quanto forma de uma área indicada (Castiello \& Umiltà, 1990; Galera, von Grünau \& Panagopoulos, 2005; Panagopoulos, von Grünau \& Galera 2004; Turatto et al. 2000). Castiello e Umiltà, (1990), por exemplo, verificaram que apresentar uma dica periférica (moldura quadrada) por 40, 50 ou 500 ms antes do alvo e manipular o seu tamanho, que poderia ser de $1.0^{\circ}, 2.0^{\circ}$ ou $3.0^{\circ}$ de ângulo visual de lado, não produziu o efeito do tamanho da dica quando a dica foi apresentada por 40 ou 50 ms. Durante esse intervalo ocorreu apenas o benefício em TR para as provas de dica válida. No entanto, com 500 ms de intervalo entre a dica e o alvo, um efeito do tamanho da dica confiável ocorreu junto com o benefício nas provas de dica válida. Esses resultados sugerem que durante o intervalo curto de tempo entre a dica e o alvo, ocorreu apenas o processo de orientação ou parte dele, mas quando o tempo foi maior, a orientação e a focalização dos recursos de atenção também teriam ocorrido. Além disso, são coerentes com resultados mais recentes mostrando que a localização neural da atenção pode ser ajustada para refletir a escala espacial de um alvo entre 250 e 300 ms após o início da exposição de um conjunto de estímulos (Hopf et al., 2006). 
Maringelli e Umiltà (1998) realizaram uma tentativa de estudar a orientação e a focalização separadamente, apresentando a dica de início abrupto e o alvo sempre em uma mesma posição no centro da tela. Os resultados revelaram um efeito do tamanho da dica com um intervalo de 100 ms entre a dica e o alvo, sugerindo que o processo de focalização pode ocorrer de maneira automática. Benso et al. (1998) também investigaram o ajuste do foco ao tamanho dos estímulos, manipulando o intervalo entre a dica e o alvo, e com base em seus resultados sugeriram duas fases, uma inicial, na qual o foco é automaticamente ativado pelo início abrupto de um objeto, e uma fase posterior, na qual o tamanho do foco é mantido de maneira voluntária.

Uma maneira encontrada por Turatto et al. (2000) para estudar a focalização foi apresentar duas dicas de início abrupto e de tamanhos diferentes (diferença de $5^{\circ}$ em tamanho entre a menor e a maior dica) em seqüência e no mesmo local. Os resultados revelaram que o tamanho da segunda dica (irrelevante para a tarefa) interferiu nos TR's produzindo um efeito do tamanho da dica. Isso foi interpretado como evidência de que o foco pode ser reajustado automaticamente ao tamanho de outro objeto apresentado abruptamente dentro ou ao redor de um objeto inicialmente focalizado. De maneira semelhante, estudos que tem manipulado a forma de dicas periféricas, indicam que o foco de atenção também pode se moldar de maneira automática a regiões com formas específicas como a de um retângulo (Galera et al., 2005; Panagopoulos et al., 2004).

Apesar de existirem diferenças entre essas propostas, de maneira geral esses estudos suportam a idéia de um foco único e indivisível de atenção, que pode ser ajustado ao tamanho e forma dos estímulos apresentados no campo visual. A flexibilidade desse ajuste deve depender de características físicas e espaciais dos 
estímulos visuais e da dinâmica temporal em que esses eventos ocorrem. O controle voluntário, regido pelos objetivos do observador, deve interagir com a ativação automática da atenção para que a orientação e a focalização utilizem da melhor forma possível os recursos de atenção disponíveis, até que toda a informação relevante para o observador seja processada. Situações onde dois ou mais objetos não adjacentes precisam ser processados ao mesmo tempo, levariam a expansão do tamanho do foco, funcionando como o zum de uma lente, que abarcaria todos os objetos dentro de um foco único e grande. Esse aumento do foco teria um custo para o sistema, visto que os recursos de atenção são limitados e áreas maiores abrangidas pelo foco levariam a uma dispersão desses recursos por toda essa área. É interessante ressaltar que ao abranger os objetos não adjacentes, o modelo do zum prevê ainda que regiões que estão entre esses objetos, também estarão dentro do foco e eventos que venham a ocorrer nessas regiões receberão os benefícios da atenção visual, pois a sua configuração permite apenas duas possibilidades para o processamento de qualquer estímulo, estar dentro ou fora dos seus limites.

No entanto, diferentes resultados mostram que a distribuição da atenção é um pouco mais complexa. Nos experimentos de Egly e Homa (1984), por exemplo, a tarefa dos participantes foi identificar ou localizar uma letra apresentada em uma de oito localizações dentro de uma de três circunferências (anéis) apresentadas ao redor do estímulo de fixação. Contrário a proposta de um foco único de atenção, os resultados indicaram que os recursos de atenção foram destinados e concentrados ao longo do anel indicado. Isso sugere que a atenção visual foi capaz de ser distribuída dentro de uma configuração complexa, com regiões espacialmente separadas e sem incluir regiões intermediárias. Embora esses resultados não tenham sido confirmados por Juola, Crouch e Cocklin (1987), outros estudos (Juola, 
Bouwhuis, Cooper \& Warner, 1991; Muller \& Hübner, 2002) têm encontrado resultados semelhantes aos apresentados por Egly e Homa (1984).

Resultados contrários a idéia de um foco único também foram encontrados por Galera, Cavallet, von Grünau e Panagopoulus (2005), que apresentaram um alvo e três estímulos irrelevantes para a tarefa ao redor de um estímulo de fixação a uma mesma excentricidade (Experimento 2). Os estímulos foram apresentados dentro de quatro localizações indicadas ou entre estas localizações. Os resultados revelaram um custo (TR's mais lentos) quando os estímulos foram apresentados entre as quatro localizações indicadas e um desempenho melhor quando o alvo apareceu dentro de uma destas localizações. Esses resultados não são compatíveis com o modelo do foco da lanterna e zum de uma lente, pois mesmo sendo apresentados entre as dicas, os estímulos estariam dentro da zona abrangida pelo foco único de atenção.

Estudos têm demonstrado também que a concentração dos recursos de atenção pode diminuir gradualmente conforme o aumento da distância entre o local em que a atenção foi inicialmente destinada e o estímulo apresentado fora desse local (Laberge, 1983; Laberge \& Brown, 1989; Laberge, Carlson, Williams \& Bunney, 1997; Shulman, Sheehy \& Wilson, 1986). Esses resultados são explicados pela idéia de que os recursos de atenção podem ser distribuídos como um gradiente de atenção espacial. LaBerge e Brown (1989) propõe claramente que o gradiente de atenção pode formar dois picos de ativação de recursos de atenção, correspondendo às localizações de dois alvos apresentados ao mesmo tempo e em locais diferentes do campo visual. Devido a essa proposta considerar o foco de atenção como o pico de ativação dos recursos de atenção, é evidente a idéia de que o foco possa operar simultaneamente em mais de uma localização não adjacente. 
Além disso, alguns estudos têm adicionado ao modelo de gradiente de atenção, evidências de que existem regiões de supressão perceptual ao redor dos locais de processamento aumentado, que melhoram o desempenho quando vários estímulos dispostos muito próximos uns aos outros competem pelos recursos (Bahcall \& Kowler, 1999; Eriksen, Pan \& Botella, 1993; Müller \& Kleinschmidt, 2004; Muller, Mollenhauer, Rösler \& Kleinschmidt, 2005). Essa proposta vai ao encontro de evidências favoráveis ao processamento simultâneo de estímulos visuais localizados em áreas separadas do campo visual e que sugerem que os recursos de atenção possam ser divididos (Awh \& Pashler, 2000; Bichot, Cave \& Pashler, 1999; Castiello \& Umiltà, 1992; Hahn \& Kramer, 1995, 1998; Kramer \& Hahn, 1995; Kraft et al. 2005; Müller \& Findlay, 1987; Müller, Malinowski, Gruber \& Hillyard, 2003; McMains \& Somers, 2004, 2005; Silva \& Ribeiro-do-Valle, 2008). De acordo com essa idéia, o sistema visual pode codificar e manter informações de duas ou mais localizações do campo visual de uma só vez, mesmo que uma dessas localizações já esteja recebendo atenção (Wright, 1994). Portanto, essas propostas vão contra os modelos de foco único da atenção e adicionam novas informações sobre a distribuição da atenção visual pelos estímulos.

\subsection{Distribuição espacial da atenção visual em áreas não adjacentes do campo visual}

As diversas situações em que realizamos mais de uma tarefa visual ao mesmo tempo como, por exemplo, ver uma placa de trânsito enquanto prestamos atenção na rua movimentada a nossa frente, parecem coerentes com a idéia de que possamos dividir a nossa atenção visual em dois ou mais locais ao mesmo tempo. Porém, testes empíricos têm revelado tanto resultados contrários quanto favoráveis 
a essa suposição. A maior parte dos estudos tem investigado a divisão do foco usando duas dicas centrais ou periféricas enquanto apresentam o alvo em um dos locais indicados ou entre esses locais. A comparação entre o desempenho nessas condições tem permitido pressupor se o foco é dividido entre os diferentes locais indicados ou expandido para abarcá-los em um só foco. Um dos primeiros estudos com dicas espaciais a pesquisar esse assunto e sugerir a divisão espacial da atenção visual sobre duas áreas indicadas foi o estudo de Müller e Findlay (1987). Eles apresentaram um alvo em uma de quatro localizações demarcadas por quadrados dispostos um em cada canto do campo visual (i.e., superior esquerdo, direito, inferior esquerdo e direito) e com a mesma excentricidade. Uma ou duas localizações foram indicadas ao mesmo tempo entre provas por setas apresentadas no centro do campo visual e o alvo foi apresentado nas localizações indicadas em uma proporção maior do que nas localizações não indicadas. Os resultados mostraram que os participantes foram mais sensíveis para detectar o alvo apresentado nos dois locais indicados simultaneamente do que nas localizações não indicadas. Embora o alvo não tenha sido apresentado em localizações intermediárias àquelas indicadas, os resultados foram interpretados como indícios de que a atenção visual possa ser dividida de maneira voluntária em duas localizações separadas no espaço.

Por outro lado, McCormick e Klein (1990) investigaram se localizações intermediárias àquelas indicadas também recebiam atenção, apresentando o alvo em seis possíveis localizações, três à direita e três à esquerda do centro do campo visual. Todas eqüidistantes e alinhadas com o meridiano horizontal. Eles também usaram dicas centrais para orientar a atenção dos participantes para uma ou duas localizações não-adjacentes e em $56 \%$ das provas o alvo foi apresentado na localização indicada e em $24 \%$ não. O TR para detectar o alvo apresentado entre 
duas localizações indicadas foi igual ao TR da condição em que essa mesma localização foi indicada. Esses resultados sugerem que a atenção não foi dividida, mas que os participantes orientaram a atenção para a localização entre as outras duas indicadas.

Castiello e Umiltá (1992) obtiveram resultados que parecem apontar para a divisão do foco quando associaram o efeito do tamanho da dica com a apresentação de duas dicas periféricas de cada lado do campo visual. Baseados na informação de que os recursos de atenção são constantes e que a variação do tamanho de uma dica periférica deve interferir na concentração desses recursos (Eriksen \& St. James, 1986), Castiello e Umiltá levantaram a hipótese de que a divisão do foco em duas dicas de tamanhos diferentes, também deveria revelar a variação em concentração de acordo com o tamanho de cada dica apresentada. Assim, duas dicas periféricas (molduras quadradas) foram apresentadas simultaneamente por $500 \mathrm{~ms}$. Cada moldura foi apresentada a $10^{\circ}$ de ângulo visual à direita e à esquerda do estímulo de fixação. Três tamanhos diferentes de moldura (pequena, intermediária ou grande) foram usados e em cada prova, cada moldura poderia ser apresentada com um tamanho diferente ao tamanho da outra. A tarefa dos participantes foi detectar o mais rápido possível um alvo apresentado sempre dentro de uma das dicas, mantendo o olhar sempre sobre o estímulo de fixação. Em $20 \%$ das provas o alvo não foi apresentado para desencorajar respostas antecipadas. Os resultados mostraram que o TR para detectar o alvo dentro de cada dica aumentou conforme o aumento do tamanho da moldura. Essa relação inversa entre o tamanho de cada área indicada e a eficiência do processamento foi interpretada como evidência de que dois focos independentes de atenção, um para cada moldura, ajustaram-se ao tamanho das molduras apresentadas simultaneamente em lados opostos do campo visual. 
No entanto, esses resultados podem ser explicados também pelo deslocamento de um foco único de atenção para uma dessas localizações de cada vez e não pela divisão do foco (Posner et al., 1980). Isso ocorreria se o participante prestasse atenção em uma localização indicada por prova, produzindo TR's mais rápidos em média nos locais indicados. Castiello e Umiltà (1992) argumentaram contra essa estratégia, apresentando a distribuição do TR e comparando as variâncias entre as diferentes condições.

Em um estudo subseqüente, McCormick, Klein e Johnston (1998) usaram um delineamento experimental muito semelhante ao usado por Castiello e Umiltá (1992) e não encontraram evidências de que o foco de atenção tenha sido dividido. Seu estudo é interessante porque além de manipular o tamanho das dicas apresentadas em lados opostos do campo visual, o alvo foi apresentado também entre as duas molduras. Isso permitiu verificar se a área entre as duas dicas periféricas também receberia recursos de atenção e conseqüentemente, conferir se os resultados poderiam ser explicados pela expansão de um foco único de atenção como sugerido pelo modelo do zum. Os resultados revelaram um aumento gradual geral do TR conforme o aumento do tamanho das dicas e TR's igualmente rápidos para detectar o alvo apresentado entre as duas dicas e dentro das dicas. Além disso, eles compararam o desempenho entre provas válidas e inválidas com apenas uma dica e verificaram uma vantagem para detectar o alvo dentro da dica do que fora dela nas mesmas localizações usadas nas provas com duas dicas. Esses resultados não suportam a idéia de divisão da atenção, mas sim a expansão de um foco único de atenção que abrangeu os dois estímulos apresentados em áreas não adjacentes, incluindo a zona entre as duas dicas. 
Resultados contrários à divisão do foco também foram obtidos com potenciais evocados do cérebro relacionados a eventos, coletados durante a realização de uma tarefa de TR em que os participantes foram instruídos verbalmente a prestar atenção em duas de quatro localizações (Heinze, Luck, Münte, Gös, Mangun \& Hillyard, 1994). Os resultados mostraram que o alvo apresentado entre duas localizações monitoradas, evocou respostas semelhantes às evocadas pela apresentação do alvo exatamente nos locais monitorados e, maior do que àquelas evocadas em provas em que o alvo foi apresentado em locais não monitorados, mas fora da zona entre as dicas. Os resultados novamente sugeriram que os participantes não foram capazes de dividir o foco de atenção, mas sim, que um foco único incluiu toda a área com as duas localizações relevantes e a área entre elas. Outros resultados comportamentais também apontam no mesmo sentido, revelando que apesar de saber que um estímulo competidor é um estímulo com características semelhantes ao do alvo e que a sua função é competir pelos recursos de atenção, o participante não consegue ignorá-lo, produzindo TR's mais lentos e um desempenho pior (Pan \& Eriksen, 1993). Esses resultados colocam dúvidas sobre a capacidade de dividirmos o foco de atenção.

Outros estudos encontraram evidências favoráveis a divisão da atenção apenas em condições específicas, isto é, quando os estímulos visuais foram apresentados de maneira não abrupta (Hahn \& Kramer, 1995, 1998; Kramer \& Hahn, 1995). Nesses estudos, duas dicas periféricas (molduras quadradas) foram apresentadas acima ou abaixo do campo visual, mas sempre em lados opostos. Após um curto intervalo de tempo, dois estímulos que deveriam ser comparados foram apresentados ao mesmo tempo dentro das duas dicas. Estímulos que competiam pela atenção, mas irrelevantes para a tarefa, foram apresentados entre 
as duas dicas e os resultados mostraram que os participantes foram capazes de suprimir a influência desses estímulos competidores, apenas quando os estímulos foram apresentados de maneira não abrupta, ou seja, removendo partes de um estímulo que os cobria (mascarava). Quando os estímulos competidores foram apresentados abruptamente no campo visual, o desempenho foi prejudicado, sugerindo que os participantes não conseguiram ignorá-los, portanto, processando as duas áreas indicadas e a região intermediária entre as duas dicas periféricas.

Por outro lado, estudos mais recentes têm encontrado evidências de que a atenção pode ser dividida mesmo quando os estímulos são apresentados de maneira abrupta (Awh \& Pashler 2000; Bichot et a., 1999). Awh e Pashler (2000), por exemplo, usaram uma tarefa de identificação e encontraram uma vantagem clara em desempenho para áreas indicadas por dicas periféricas em comparação às áreas intermediárias, mesmo quando os estímulos apareceram de maneira abrupta entre as duas localizações indicadas. Embora seus resultados tenham revelado que os estímulos apresentados de maneira abrupta entre as dicas não tenham sido completamente ignorados, esses estímulos não excluíram a vantagem em processamento das áreas indicadas. Esse padrão de resultado foi interpretado como indícios de que os recursos de atenção possam ser divididos em forma de gradientes que produzem picos de ativação nos locais indicados, diminuindo nas áreas intermediárias às dicas.

De maneira semelhante e apenas com instruções verbais sobre as localizações que deveriam monitorar, ou seja, sem usar dicas espaciais, Müller et al. (2003) encontraram resultados comportamentais e eletrofisiológicos (potencial evocado visual), que confirmam a possibilidade de o foco ser dividido entre localizações espacialmente separadas por períodos de tempo maiores do que 100 
ms, excluindo localizações intervenientes. Estudos usando fMRI também têm revelado resultados parecidos (McMains \& Somers, 2004, 2005). Em McMains e Somers (2004) os participantes realizaram uma tarefa na qual foram instruídos a prestar atenção simultaneamente em dois alvos apresentados rapidamente em duas localizações separadas. Estímulos competidores foram apresentados entre as duas localizações monitoradas ao mesmo tempo em que os alvos apareceram. Os resultados mostraram um aumento específico da ativação retinotópica das representações dos dois alvos no córtex visual estriado e extra-estriado e nenhum aumento para as representações intervenientes dos estímulos competidores. Os resultados foram interpretados como indício de que dois focos separados de atenção foram mantidos de maneira voluntária sobre duas localizações não adjacentes. Em seguida, McMains e Somers (2005) questionaram se (1) a divisão do foco de atenção produz algum custo que diminui a eficiência da atenção, comparado a proposta de um foco que expanda em tamanho como proposto pelo modelo do zum ou (2) se a divisão do foco produz um benefício em relação ao modelo do zum, por conservar os recursos de atenção que de outra forma seriam destinados a estímulos irrelevantes para a tarefa e localizados nas localizações intervenientes. Os participantes foram instruídos a monitorar de maneira encoberta diferentes localizações em quatro condições: (1) orientar a atenção para apenas uma localização; (2) duas localizações adjacentes; (3) duas localizações não adjacentes (com uma localização entre elas); ou (4) três localizações adjacentes. O alvo foi apresentado nas localizações monitoradas em $50 \%$ das provas e a tarefa foi detectar o alvo apresentado. Um desempenho em TR pior e a diminuição do sinal que reflete a dependência do nível de oxigenação sanguínea (BOLD em Inglês), mostraram que monitorar várias localizações diminuiu a eficiência do processamento em relação às 
provas em que apenas uma localização deveria ser monitorada. Além disso, quando os participantes deveriam monitorar uma área de mesma extensão, ou seja, quando foram instruídos a monitorar duas localizações não adjacentes (com uma localização entre elas) ou três localizações adjacentes, um desempenho melhor e um sinal BOLD maior foi verificado para a condição em que os participantes foram instruídos a monitorar duas localizações não adjacentes (com uma localização entre elas). Quando os participantes tiveram que monitorar a mesma quantidade de localizações, isto é, condição com duas localizações adjacentes e duas localizações não adjacentes, tanto o desempenho comportamental quanto o sinal BOLD foram iguais entre as duas condições. Esses resultados sugerem que um mecanismo de focos múltiplos, que ignora estímulos apresentados em localizações intervenientes, é tão eficiente quanto um mecanismo de expansão do foco e em algumas situações pode produzir um desempenho até melhor. Além disso, sugerem que os dois mecanismos podem coexistir, sendo usados de acordo com as demandas da tarefa.

Uma posição semelhante é defendida por Kraft et al. (2005) ao mostrarem que a localização dos estímulos em relação a metade esquerda ou direita do campo visual, assim como a dificuldade da tarefa usada, podem ser importantes para a divisão ou não da atenção visual. Em seu estudo, dois estímulos competidores foram apresentados junto com dois alvos em quatro localizações dispostas em uma linha diagonal e próximas uma da outra, acima, abaixo, à direita ou à esquerda do estímulo de fixação. As localizações foram demarcadas por molduras quadradas. Três localizações foram posicionadas dentro da mesma metade do campo visual (e.g., do lado esquerdo) enquanto a quarta localização foi posicionada na outra metade (e.g., lado direito). Os alvos foram apresentados em localizações adjacentes ou em localizações separadas, que poderiam estar dentro do mesmo lado do campo 
visual ou em lados diferentes. A localização dos alvos foi sempre indicada por duas dicas centrais e a tarefa foi comparar a identidade dos dois alvos. A dificuldade da tarefa foi manipulada entre experimentos pela mudança das características dos estímulos apresentados junto com os alvos e alterando o contraste entre eles. Quando o alvo foi apresentado dentro da mesma metade do campo visual, o desempenho nas tarefas consideradas fáceis, mensurado pelo TR e respostas erradas, foi melhor para alvos adjacentes do que separados, mas quando os alvos foram apresentados em metades diferentes do campo visual, o desempenho foi semelhante entre as duas condições. Nas tarefas difíceis o desempenho foi sempre melhor quando os alvos foram apresentados em metades diferentes do campo visual. Esses resultados foram interpretados como indícios de que dentro do mesmo lado do campo visual os recursos de atenção não foram divididos, mas quando os estímulos foram apresentados em lados opostos, uma vantagem bilateral para cada lado do campo ocorreu, sugerindo que os recursos de atenção foram divididos.

Devido aos resultados não serem explicados nem por modelos de foco único de atenção nem por modelos que sugerem a divisão da atenção, Kraft et al. (2005) apresentaram um modelo modificado de atenção visual, no qual cada hemisfério cerebral pode manter e controlar focos de atenção simultaneamente. De acordo com esse modelo, a atenção visual pode ser dividida entre dois lados do campo visual, mas formar um foco único dentro do mesmo lado. Assim, quando a atenção é dividida em lados opostos, ocorreria um aumento dos recursos de atenção, pois os hemisférios contribuiriam com o controle de sistemas de atenção parcialmente independentes, que seriam unidos por processos que controlam os movimentos dos olhos.

Diferentes estudos, incluindo estudos que investigaram movimentos oculares (Corbetta et al., 1998; Sereno \& Kosslyn, 1991) e estudos com indivíduos com o 
corpo caloso seccionado (Banich, 1998; Holtzmann, 1981; Luck, Hillyard, Mangun \& Gazzaniga, 1989; Mangun et al. 1994) parecem suportar esse modelo. Luck et al. (1989), por exemplo, compararam o desempenho em uma tarefa de busca visual com indivíduos normais e com pacientes com secção do corpo caloso e verificaram que conjuntos de estímulos bilaterais foram processados em uma taxa mais rápida pelos pacientes seccionados do que pelo grupo controle de participantes normais. Os resultados foram interpretados como evidência de que cada hemisfério dos participantes seccionados pode ter controlado seu próprio foco de atenção, que poderia esquadrinhar independentemente seu respectivo campo visual contralateral, enquanto indivíduos com a comunicação entre os hemisférios intacta teriam um sistema integrado de foco de atenção para ambos os conjuntos de estímulos apresentados de cada lado do campo visual. Apesar desses resultados suportaram o modelo proposto por Kraft et al., mais informações precisam ser coletadas para entender como a atenção visual pode ser dividida nessas circunstâncias, pois alguns resultados sugerem que a atenção possa ser dividida do mesmo lado do campo visual (Awh \& Pashler 2000; Hahn \& Kramer, 1998; Silva \& Ribeiro-do-Valle, 2008), enquanto outros demonstram que indivíduos normais não são capazes de dividir a atenção de maneira voluntária entre lados opostos do campo visual, mas indivíduos com o corpo caloso seccionado, sim (Arguin, Lassonde, Quattrini, Del Peste, Foschi \& Papo, 2000).

Resultados recentes de Silva e Ribeiro-do-Valle (2008) indicam que a atenção pode ser automaticamente e simultaneamente dirigida a duas localizações nãoadjacentes e posicionadas do mesmo lado do campo visual. Embora seu estudo seja diferente do estudo de Kraft et al. (2005), por não ter usado estímulos competidores e ter usado dicas periféricas ao invés de centrais, bem como, apresentado apenas 
um alvo ou invés de dois, seus resultados mostraram que a região entre duas dicas periféricas pode ser ignorada quando as dicas foram apresentadas rapidamente (50 ms de exposição +50 de intervalo sem dica $=100$ ms de intervalo entre estímulos) do mesmo lado do campo visual. Isso pode ser um indício de que a orientação automática da atenção para duas dicas separadas não depende tanto da localização que elas ocupam em relação ao lado do campo visual. Resultados de Hahn e Kramer (1998) usando dicas periféricas apresentadas por 150 ms e do mesmo lado do campo visual (Experimento 5), também parecem apontar nesta direção. Enquanto resultados de Awh e Pashler (2000), que usaram dicas periféricas expostas por 750 ms e apresentaram os alvos do mesmo lado e em lados opostos do campo visual, sugerem que a divisão da atenção em um mesmo lado do campo visual deve ser relativa e não absoluta.

Uma interpretação diferente para esses resultados também pode ser a de que a atenção seleciona os objetos ou grupos de objetos e não suas localizações (Baylis \& Driver, 1993; Duncan, 1984; Gibson, 1994; Kahneman, Treisman \& Gibbs, 1992; Kramer \& Jacobson, 1991). De acordo com esses estudos, o processo de focalização pode ocorrer baseado apenas nas características dos objetos. O sistema visual seria forte o bastante para classificar ou identificar muitos objetos visuais rapidamente e em paralelo em estágios primários de processamento. A seleção ocorreria em um estágio posterior, onde as características do objeto selecionado seriam analisadas mais detalhadamente. Assim, segundo essa proposta, a atenção pode ser dividida em regiões não contíguas do espaço quando objetos com características semelhantes ocorrerem um uma cena, como por exemplo, objetos que se movem na mesma direção e com a mesma velocidade.

Apesar de esses diferentes estudos terem revelado informações importantes sobre a distribuição da atenção em regiões não adjacentes e encontrado evidências 
de que a atenção visual possa ser dividida, algumas questões ainda precisam ser mais bem investigadas. Os resultados conflitantes mostram que ainda faltam informações para entendermos como e em que situações a atenção visual pode ser dividida. Um ponto importante e investigado em apenas alguns estudos (Castiello \& Umiltà, 1992; McCormick et al. 1998; McMains \& Somers, 2005), refere-se ao papel do tamanho das áreas indicadas sobre a divisão do foco. O que ocorre quando o tamanho de duas dicas é manipulado? (1) A existência de dois focos independentes de atenção, ajustados ao tamanho de cada dica ou (2) o ajuste do tamanho de um foco único que engloba as duas dicas e a área entre elas? Além disso, esse ajuste do tamanho do foco, revelado pelo efeito do tamanho da dica, seria observado quando duas dicas são apresentadas do mesmo lado do campo visual ou apenas quando são apresentadas em lados opostos? De maneira semelhante, estímulos apresentados de maneira abrupta em localizações indicadas por dicas periféricas e apresentados do mesmo lado do campo visual revelariam resultados que sugerem a divisão do foco como mostrado por Silva e Ribeiro-do-Valle (2008) ou mostrariam um foco único como sugerido por Kraft et al. (2005) com dicas centrais?

O presente estudo investigou essas questões, manipulando o tamanho de duas dicas periféricas apresentadas em lados opostos do campo visual ou deslocadas para um dos lados. Verificar se o efeito do tamanho da dica ocorre nessas condições forneceria evidências de que a atenção visual foi focalizada ao mesmo tempo em duas áreas separadas como observado por Castiello e Umiltà (1992). Além disso, um alvo apresentado entre as dicas poderia informar se esse ajuste ocorre em cada área indicada ou se engloba toda a região entre as duas dicas. Isso contribuiria para entender os resultados contrários encontrados por Castiello e Umiltà (1992) e McCormick, et al. (1998). Também permitiria conferir se a 
diferença entre o mesmo lado e lados opostos do campo visual, obtida por Kraft et al. (2005) com dicas centrais, também se repete quando dicas periféricas são apresentadas. Por fim, investigar como ocorre a distribuição da atenção em áreas próximas às duas dicas pode ser relevante para modelos como o do gradiente de atenção, que propõe picos de ativação dos recursos dentro das áreas indicadas, mas com uma diminuição gradual desses recursos fora das áreas que recebem os recursos. Portanto, o objetivo principal desse estudo foi investigar a distribuição da atenção em áreas não adjacentes do campo visual quando o tamanho dessas áreas foi manipulado.

Além disso, o estudo investigou a possibilidade de obter o efeito do tamanho da dica com uma tarefa menos convencional, conhecida como tarefa de julgamento de ordem temporal (JOT). Apesar de um grande número de estudos utilizarem tarefas de TR para investigar a divisão da atenção visual, a tarefa de JOT pode fornecer uma estimativa da concentração de atenção destinada a uma ou duas regiões específicas do campo visual, comparando a facilitação em desempenho obtida entre dois estímulos localizados em áreas diferentes de uma cena. Uma série de estudos tem investigado a seleção da informação, explorando a influência da atenção sobre a percepção de ordem temporal (Hikosaka, Miyauchi \& Shimojo, 1993; Park, Rey \& Schlag, 2003; Scharlau, 2004a; Scharlau, 2004b), revelando que a atenção pode produzir um efeito chamado de entrada prioritária (Titchener, 1908), que pode ser usada para medir a facilitação relativa de dois estímulos ou localizações. Assim, encontrar o efeito do tamanho da dica em uma tarefa de JOT permitiria verificar diferentes concentrações de atenção em duas áreas indicadas. 


\subsection{Efeito de entrada prioritária e a tarefa de julgamento de ordem temporal}

A percepção de ordem temporal entre dois estímulos apresentados simultaneamente ou em seqüência é atribuída ao tempo que a informação sensorial de cada estímulo chega a um sistema central de comparação (Sternberg \& Knoll, 1973). A distribuição desigual da atenção sobre os estímulos pode interferir na velocidade de transmissão da informação, produzindo o efeito de entrada prioritária. A idéia subjacente a esse fenômeno é comum a outros modelos de atenção, descritos anteriormente, onde estímulos que recebem atenção ganham alguma vantagem em processamento. No caso da hipótese da entrada prioritária, a atenção encurta a latência do estímulo que recebeu atenção, ou seja, eventos que recebem atenção devem ser percebidos antes do que estímulos que não receberam atenção (Titchener, 1908).

Esse efeito tem recebido respaldo de diferentes estudos psicofísicos (Scharlau, 2004a; Shore, Spence \& Klein, 2001; Stelmach \& Herdman, 1991), e eletrofisiológicos (McDonald, Teder-Sälejärvi, Di Russo \& Hillyard, 2005; Vibell, Klinge, Zampini, Spence \& Nobre, 2007). Os últimos têm mostrando que a distribuição desigual de atenção sobre os estímulos pode interferir na força do sinal neural do estímulo que recebe atenção em áreas occipitais ventrais, responsáveis pela percepção visual dos objetos (Mcdonald et al., 2005) e na velocidade de processamento da informação (Vibell et al., 2007). Essa alteração na percepção temporal parece ser um processo que se estende de estágios inicias, sensoriais e automáticos, a estágios posteriores, que envolvem processos cognitivos controlados. Isto foi verificado por Vibell et al., que encontraram antecipações no tempo dos potenciais $\mathrm{P} 1$ e $\mathrm{N} 1$ relacionados a modalidade que recebeu atenção, e maior 
modulação do potencial $\mathrm{P} 300$ em relação a $\mathrm{P} 1$ e N1, sugerindo que o efeito de entrada prioritária aumenta conforme o prosseguimento do processamento neural de estágios perceptuais iniciais para estágios cognitivos e motores posteriores.

Todos esses estudos têm estimado o efeito de entrada prioritária por meio do JOT de dois estímulos. Em uma típica tarefa de JOT, a atenção é deslocada para uma determinada região do campo visual por meio de dicas espaciais ou instruções, o intervalo entre a apresentação dos dois estímulos relevantes à tarefa (intervalo entre estímulos - IEE) é manipulado e os participantes devem relatar a ordem em que os dois estímulos foram apresentados (e.g., qual estímulo foi apresentado primeiro). Em geral, o alvo que recebe atenção é julgado como apresentado primeiro do que o outro que não recebe atenção. Isso ocorre mesmo quando o alvo que recebe atenção é apresentado muitos milissegundos depois do que o outro. Essa ilusão temporal tende a desaparecer quando o intervalo entre os dois estímulos aumenta. Os julgamentos são analisados em função do IEE e uma função psicométrica ajustada a quantidade de respostas, permite estimar a vantagem relativa da informação indicada em relação à informação não indicada. Essa vantagem é comumente verificada por meio do ponto de simultaneidade subjetiva (PSS), obtido por meio de uma função psicométrica ajustada aos dados empíricos (i.e., quantidade de julgamentos para cada estímulo), sendo um indicador de desempenho (Spence \& Parise, 2009; Sternberg \& Knoll, 1973). O PSS reflete uma estimativa do IEE no qual os participantes responderam com a mesma freqüência (50\% das respostas) que um dos estímulos foi apresentado primeiro. Por meio da metade da diferença entre o PSS do estímulo apresentado no local indicado e o PSS obtido para o estímulo apresentado em um local não indicado, é possível calcular a facilitação perceptual (FP) relativa. A FP pode ser entendida como o efeito de 
entrada prioritária, visto que é estimada a partir da vantagem da informação que recebeu atenção e do custo da informação que não recebeu atenção inicialmente. Assim, os pesquisadores podem verificar o quanto a manipulação de parâmetros espaciais e temporais interfere nos valores do PSS e da FP de cada condição, permitindo estudar a distribuição de atenção entre uma única modalidade de estímulos, como por exemplo, a visual (Shore et al., 2001; Stelmach \& Herdman, 1991), ou entre modalidades diferentes, como a visual e a auditiva (Spence, Shore \& Klein, 2001; Zampini, Shore \& Spence, 2005).

Um dos primeiros estudos a demonstrar resultados consistentes utilizando um paradigma de JOT para examinar o efeito de entrada prioritária visual, foi o de Stelmach e Herdman (1991). Em seus experimentos, três localizações foram demarcadas: à esquerda, à direita e uma ao centro do campo visual. Os alvos foram apresentados sempre nas localizações demarcadas, mas nunca ao centro do campo visual. Pontos movendo-se rapidamente em direção a uma das três marcas foram usados para indicar uma das localizações onde o primeiro alvo (ponto) poderia aparecer. Em seguida, os dois alvos foram apresentados rapidamente, um no lado indicado e outro no lado oposto ao indicado. O IEE usado foi de 0, 20, 40, 60, 80 e $100 \mathrm{~ms}$ e os participantes julgavam em qual lado o ponto aparecia primeiro. Os resultados demonstraram que o alvo apresentado no lado indicado foi percebido em média $40 \mathrm{~ms}$ antes do que o lado não indicado. Quando a localização central foi indicada (condição neutra), não existiu vantagem para a latência perceptual para qualquer um dos pontos apresentados nos lados do campo visual. Resultados semelhantes foram obtidos quando dicas centrais foram usadas, demonstrando que o efeito obtido deveria ser em grande parte atribuído a orientação da atenção para o local indicado. 
Em um estudo mais recente, Shore et al. (2001) usaram um método em que as dicas espaciais (periférica ou central) e as dimensões das respostas foram ortogonais, ou seja, orientaram a atenção dos participantes para a direita ou esquerda do campo visual enquanto a tarefa era julgar se uma linha vertical ou horizontal havia sido apresentada primeiramente. Eles argumentaram que não existiu razão para acreditar que a resposta "horizontal" ou "vertical" primeiro deveria ser preferencialmente escolhida devido às localizações indicadas (direita ou esquerda). Isso diminuiria algum possível viés de resposta associado à localização indicada, amenizando argumentos de que o efeito de entrada prioritária seria causado por outros processos e não pela atenção. Os resultados mostraram que tanto a dica periférica, que foi uma mudança brusca na luminosidade das bordas de uma moldura quadrada (60 ms), quanto a dica central, produziram uma vantagem significativa para a informação apresentada no local indicado. Esse método revelouse adequado para investigar o efeito de entrada prioritária, por exercer um controle maior sobre um possível viés de resposta.

Embora o efeito de entrada prioritária tenha sido encontrado tanto pela orientação voluntária quanto pela orientação automática da atenção visual, dicas periféricas levam certa vantagem (Shore et al., 2001; Stelmach \& Herdman, 1991). Alguns estudos têm mostrado que os efeitos obtidos pela orientação voluntária da atenção podem mudar conforme o critério de julgamento (Shore et al. 2001) ou pode desaparecer se o número de alternativas de julgamento aumentar (Jaskowski, 1993). Por outro lado, o efeito de entrada prioritária obtido com a apresentação de dicas periféricas, é afetado apenas marginalmente por mudanças de critério de julgamento, isto é, quando outro tipo de julgamento de ordem temporal é solicitado como, por exemplo, "qual foi o segundo estímulo apresentado?" (Scharlau, 2004a; Shore et al., 2001), ou o número de alternativas de resposta aumentar (Scharlau, 2004a). 
Nossos resultados de experimentos usando o JOT e um método semelhante ao de Shore et al. (2001), mostraram que a percepção de ordem temporal dos participantes foi alterada quando estímulos (letras) foram apresentados dentro de uma moldura retangular $\left(8,0^{\circ} \times 1,4^{\circ}\right.$ de ângulo visual) não relatada para os participantes e apresentada abruptamente na periferia do campo visual (Cavallet, Galera, Von Grünau \& Afroditi, no prelo). Os experimentos foram baseados no princípio de que o aparecimento abrupto de um estímulo deve capturar a atenção de maneira automática (Jonides \& Yantis, 1988; Remington et al., 1992; Theeuwes, 1995; Yantis \& Jones, 1991; Yantis \& Jonides, 1984), assim como nas evidências de que a atenção pode sofrer uma reorganização na distribuição dos seus recursos quando uma figura de forma geométrica específica é apresentada (Castiello \& Umiltà, 1990; Egly \& Homa, 1984; Galera et al., 2005; Panagopoulos et al., 2004). O método usado consistiu na apresentação de duas letras em seqüência, uma dentro da moldura e a outra fora, para estimarmos a vantagem relativa da letra apresentada dentro da forma geométrica em relação à letra apresentada fora. A tarefa dos participantes foi responder qual letra havia sido apresentada primeiro. Apesar de a moldura não ter sido relatada para os participantes e em $50 \%$ das provas a primeira letra ter sido apresentada dentro e na outra metade fora da moldura, a moldura pode ser considerada como uma dica periférica, que atraiu a atenção de maneira automática, pois os resultados mostraram que as letras apresentadas dentro da moldura foram percebidas antes do que as letras apresentadas fora. Essa vantagem foi maior quando a moldura foi apresentada por 100 ms antes da exposição da primeira letra, diminuindo com intervalos maiores de tempo (400 ms), mesmo assim produzindo um efeito de entrada prioritária significativo. 
Portanto, a possibilidade de investigar a divisão do foco de atenção com o paradigma de JOT pode ser realizada, apresentando-se duas dicas periféricas para verificar qual área indicada recebe maior facilitação ou se a facilitação é igual nas duas áreas, como foi realizado no estudo de Scharlau (2004b). Como a tarefa de JOT pode mensurar a facilitação relativa de dois estímulos ou localizações, encontrar a vantagem para um estímulo indicado garante a conclusão de que esse estímulo recebeu atenção, mas quando dois estímulos recebem a mesma vantagem, nenhum efeito de entrada prioritária deve ser observado. Deste modo, Scharlau (2004b) apresentou duas dicas periféricas em volta do ponto de fixação e em seqüência apresentou dois estímulos a serem julgados com um intervalo variável entre eles. Ao longo dos experimentos realizados, três combinações foram possíveis entre a localização em que os estímulos foram apresentados e a localização das duas dicas: (1) um estímulo dentro de uma dica e outro entre as duas dicas; (2) um estímulo dentro de uma dica e outro fora das dicas e da zona entre as dicas; e (3) cada estímulo dentro de uma dica. Por meio do PSS de cada condição, Scharlau (2004b) comparou a facilitação relativa de duas localizações: uma indicada e outra não ou duas indicadas. Os resultados mostraram que os estímulos apresentados nas duas regiões indicadas foram beneficiados de maneira semelhante, não existindo vantagem ou efeito de entrada prioritária para um dos estímulos, mas quando um estímulo foi apresentado dentro de uma das dicas e o outro fora, independente da localização (entre as duas dicas ou fora dessa área), ocorreu uma vantagem semelhante na latência temporal do estímulo indicado, sugerindo que a região entre as duas dicas não recebeu atenção inicialmente. Portanto, uma idéia do presente estudo é manipular o tamanho da dica para verificar se este fator influencia 
a vantagem em latência temporal do estímulo apresentado dentro de uma dica em relação ao estímulo apresentado fora.

Alguns estudos têm encontrado também uma dissociação entre tarefas de JOT e tarefas de TR (Jaskowski, 1992, 1993; Neumann \& Esselmann, 1992, Neumann, Esselmann \& Klotz, 1993; Roufs, 1974; Tappe, Niepel \& Neumann, 1994), revelando que a tarefa de JOT é menos sensível a manipulação de características físicas dos estímulos do que as tarefas de TR. Isso indica que o efeito do tamanho da dica, relatado até o momento em estudos que usaram tarefas de TR relativamente simples, necessita ser confirmado em um paradigma de JOT. Portanto, antes de investigar a divisão da atenção visual manipulando o tamanho de duas áreas indicadas, o objetivo secundário desse estudo foi verificar se o processo de focalização revelado pelo efeito do tamanho da dica ocorre em um paradigma de JOT. Essa verificação é importante, pois além de existir uma dissociação entre tarefas de JOT e TR, alguns estudos têm mostrado que a focalização pode não ser tão sensível ao tamanho de uma área, podendo ser influenciada pelas demandas da tarefa e por um controle voluntário do observador (Greenwood \& Parasuraman 2004; Yeshurun \& Carrasco, 2008).

Por fim, além do interesse teórico, este estudo pode apresentar também implicações práticas, pois lidamos constantemente com tarefas que exigem o monitoramento simultâneo de diferentes localizações em uma cena como no controle de painéis de aviões, de equipamentos industriais ou quando estamos dirigindo. Verificar como a atenção pode ser dividida nestas situações é importante para a realização destas tarefas com segurança, pois a atenção permite uma relação objetiva e eficiente do indivíduo com o ambiente em que vive. Problemas nesse mecanismo de seleção podem afetar outros processos cognitivos como a memória, 
a fala e a resolução de problemas, além de estarem relacionados diretamente ou indiretamente a transtornos como o Transtorno do Déficit de Atenção com Hiperatividade (TDAH) e a doenças psiquiátricas como a esquizofrenia. Investigar o seu funcionamento e seleção da informação em indivíduos neurologicamente normais pode ajudar a identificar os processos de atenção prejudicados nesses casos e em casos de pacientes com danos cerebrais, sendo útil, também, para o desenvolvimento de estratégias de cuidado e reabilitação (Vecera \& Rizzo, 2003). 


\section{EXPERIMENTOS}





\subsection{Experimento 1a - Orientação e focalização da atenção em um paradigma de julgamento de ordem temporal.}

A proposta desse primeiro experimento foi investigar se o efeito do tamanho da dica encontrado nos estudos com tarefas de TR, também ocorre quando os participantes realizam uma tarefa de JOT entre dois estímulos. O método foi o mesmo usado em Cavallet et al. (no prelo), onde duas letras foram apresentadas em seqüência, uma dentro e a outra fora de uma moldura quadrada, não relatada para os participantes, permitindo estimar a vantagem relativa da letra apresentada dentro em relação à letra apresentada fora. A tarefa foi responder qual letra foi apresentada primeiro e a moldura foi apresentada abruptamente na periferia do campo visual por $100 \mathrm{~ms}$ antes da exposição da primeira letra. O intervalo de tempo de $100 \mathrm{~ms}$ foi escolhido por mostrar um desempenho máximo com esse tipo de paradigma quando o intervalo entre uma moldura e a primeira letra foi manipulado (Cavallet et al., no prelo). Esse pico em 100 ms deve ocorrer devido a ativação de um mecanismo automático de orientação da atenção para o local delimitado (Müller \& Findlay, 1988; Müller \& Rabbitt, 1989; Nakayama \& Mackeben, 1989; Remington et al., 1992; Von Grünau \& Faubert, 1994; Kröse \& Julesz, 1989). Embora 100 ms de exposição da moldura pareça um intervalo curto para investigar o efeito do tamanho da dica, comparado aos 500 ms de exposição usados por Castiello e Umiltà (1990, 1992), esse intervalo produziu um efeito de entrada prioritária ao longo de toda uma moldura retangular de $8.0^{\circ}$ de ângulo visual (Cavallet et al., no prelo), sugerindo que o foco de atenção tenha sido ajustado à forma e tamanho dessa figura geométrica. 
Além disso, o tamanho da moldura foi manipulado entre provas para verificarmos se o ajuste do tamanho do foco, sugerido pelo efeito do tamanho da dica, seria encontrado.

O efeito do tamanho da dica foi verificado por meio da vantagem relativa, obtida por meio do PSS da função ajustada à proporção de respostas de cada condição experimental. Assim, se a manipulação do tamanho da dica alterar a concentração inicial de recursos de atenção dentro da moldura, uma vantagem maior será obtida para a letra apresentada dentro da moldura menor em relação a letra apresentada dentro da moldura maior. Isso será verificado pela variação do PSS, que deverá ter magnitude maior nas provas em que a moldura menor for apresentada. Variação semelhante deverá ser observada também para a FP relativa, que mostrará se o efeito de entrada prioritária variará conforme o tamanho da área indicada.

\section{Método}

\section{Participantes}

Dezessete voluntários (7 mulheres), estudantes do Campus da Universidade de São Paulo em Ribeirão Preto, com idade média de 24 anos, sem conhecimento prévio da proposta do estudo, participaram de uma sessão experimental de aproximadamente 45 minutos. Todos os participantes relataram ter visão normal ou corrigida e assinaram um termo de consentimento livre e esclarecido (Apêndice A) antes de iniciar a sessão experimental. O estudo foi aprovado pelo Comitê de Ética em pesquisa do Departamento de Psicologia e Educação da Faculdade de Filosofia, Ciências e Letras de Ribeirão Preto (Anexo A). 


\section{Material e estímulos}

O experimento foi montado e executado pelo pacote de programas E`Prime® 1.0 Psychology Software Tools, Inc. (disponível em http://www.pstnet.com). Os estímulos foram apresentados em um monitor Flatron ez T930B, com resolução de 1024 x 768 pixels e taxa de atualização vertical de $100 \mathrm{~Hz}$. Os participantes permaneceram sentados em frente à tela e a uma distância de aproximadamente 58 $\mathrm{cm}$.

Os estímulos, letras "F" e "J" $\left(0,3^{\circ}\right.$ x $0,4^{\circ}$ de ângulo visual e espessura da linha de $\left.0,1^{\circ}\right)$ e uma dica (moldura quadrada), foram apresentados em preto $\left(0,9 \mathrm{~cd} / \mathrm{m}^{2}\right)$ sobre um fundo cinza $\left(41 \mathrm{~cd} / \mathrm{m}^{2}\right)$ da tela do monitor. A moldura foi apresentada em quatro tamanhos diferentes de $1,0^{\circ}, 1,5^{\circ}, 2,0^{\circ}$ e $2,5^{\circ}$ de ângulo visual de lado com espessura da borda de $0,1^{\circ}$ de ângulo visual. Para controle da excentricidade dos estímulos, o centro geométrico da moldura e as duas letras ("F" e "J") foram apresentados em volta do estímulo de fixação (losango com $0,3^{\circ} \times 0,3^{\circ}$ ) e com a mesma excentricidade de $5,8^{\circ}$ de ângulo visual. Em cada prova, a moldura e as duas letras poderiam aparecer em duas localizações fixas à esquerda ou à direita do ponto de fixação, mas nunca em lados opostos do campo visual como pode ser visualizado na Figura 2. A distância entre as letras "F" e "J" foi de 4,3․ 

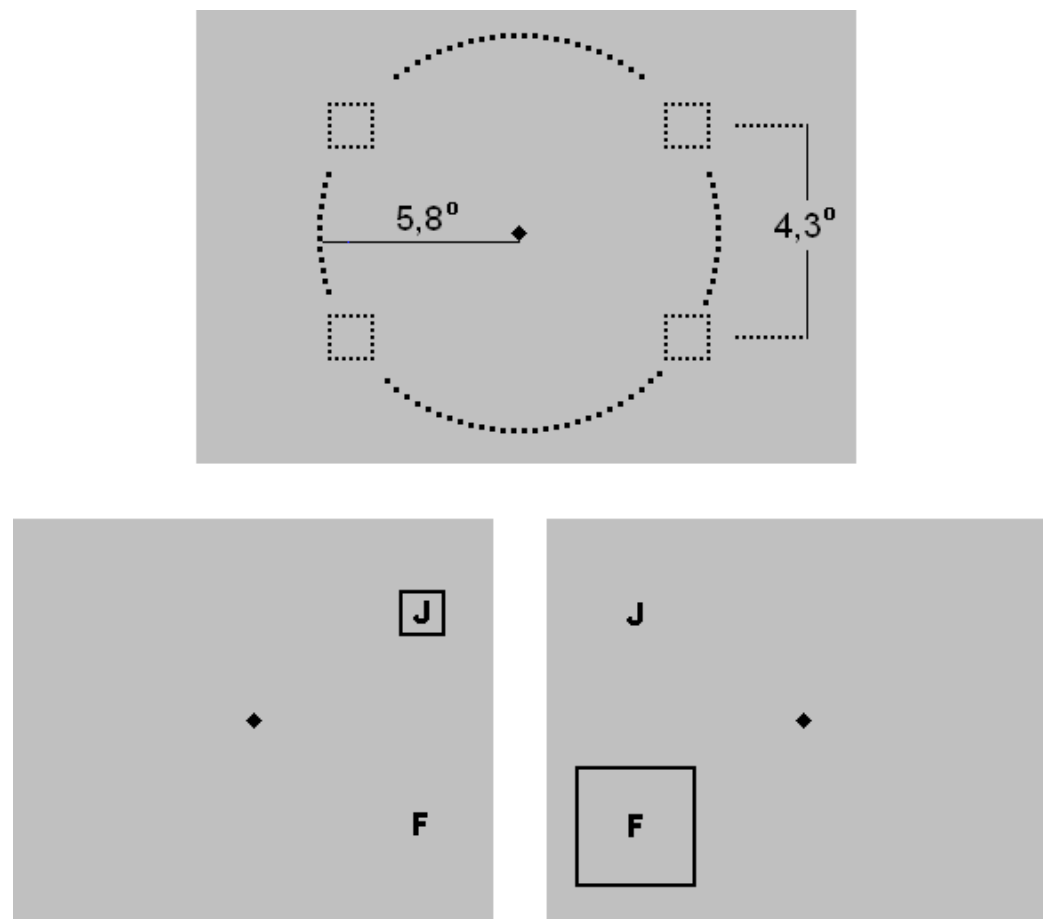

Figura 2. Distâncias e representação dos estímulos utilizados no Experimento 1a. Os quadrados pontilhados do primeiro quadrante representam as possíveis localizações em que a moldura e as duas letras poderiam aparecer. $O$ centro geométrico da moldura e as duas letras foram apresentados sempre a $5,8^{\circ}$ de ângulo visual do ponto de fixação e a distância entre as duas letras foi sempre de $4,3^{\circ}$ de ângulo visual. Os estímulos foram apresentados sempre do mesmo lado do campo visual (quadrantes inferiores). Os estímulos não estão em escala.

\section{Procedimento}

O participante foi instruído a realizar a tarefa o mais precisamente possível, não sendo necessário responder com rapidez mesmo quando incerto sobre a ordem em que os estímulos foram apresentados. Os movimentos oculares não foram monitorados e o participante recebeu instruções para manter o seu olhar sobre o ponto de fixação, pois isto facilitaria a sua tarefa.

A tarefa do participante foi julgar qual das duas letras "F" ou "J", apresentadas em seqüência, apareceu primeiro. As respostas foram dadas no teclado do computador com os dedos indicadores (julgamento da letra "F" com o indicador esquerdo na tecla $\mathrm{F}$ do teclado e julgamento da letra "J" com o indicador direito na tecla J). Cinco IEE, isto é, cinco intervalos entre o início da apresentação da primeira letra e o início da segunda de 20, 30, 60, 100 e 200 ms, foram usados. 
Cada prova começou com a apresentação da tela em cinza por 1 segundo. Em seqüência, o estímulo de fixação apareceu e após 300 ms a moldura foi apresentada. Tanto o estímulo de fixação quanto a moldura, permaneceram na tela até o final da prova. A primeira letra foi mostrada depois de um intervalo de exposição da moldura de 100 ms e a segunda letra foi apresentada após um dos cinco IEE. Depois da apresentação da segunda letra, todos os estímulos permaneceram na tela por mais $250 \mathrm{~ms}$ e, em seguida, desapareceram, permanecendo apenas o estímulo de fixação que mudou para a cor azul após 250 ms, sinalizando ao participante que sua reposta poderia ser realizada. Esse procedimento foi adotado para evitar respostas antecipadas. Após a resposta do participante, o estímulo de fixação mudou para a cor preta e permaneceu na tela por mais 200 ms. Em seqüência, uma nova prova começou. A seqüência e a duração dos eventos podem ser visualizadas na Figura 3.

A letra "F" foi apresentada primeiro em $50 \%$ das provas, sendo $25 \%$ dentro e $25 \%$ fora da moldura. Na outra metade, "J" foi apresentada primeiro, sendo $25 \%$ dentro e $25 \%$ fora da moldura. Cada letra e moldura apareceram em cada posição à esquerda e à direita do campo visual na mesma quantidade de provas. 


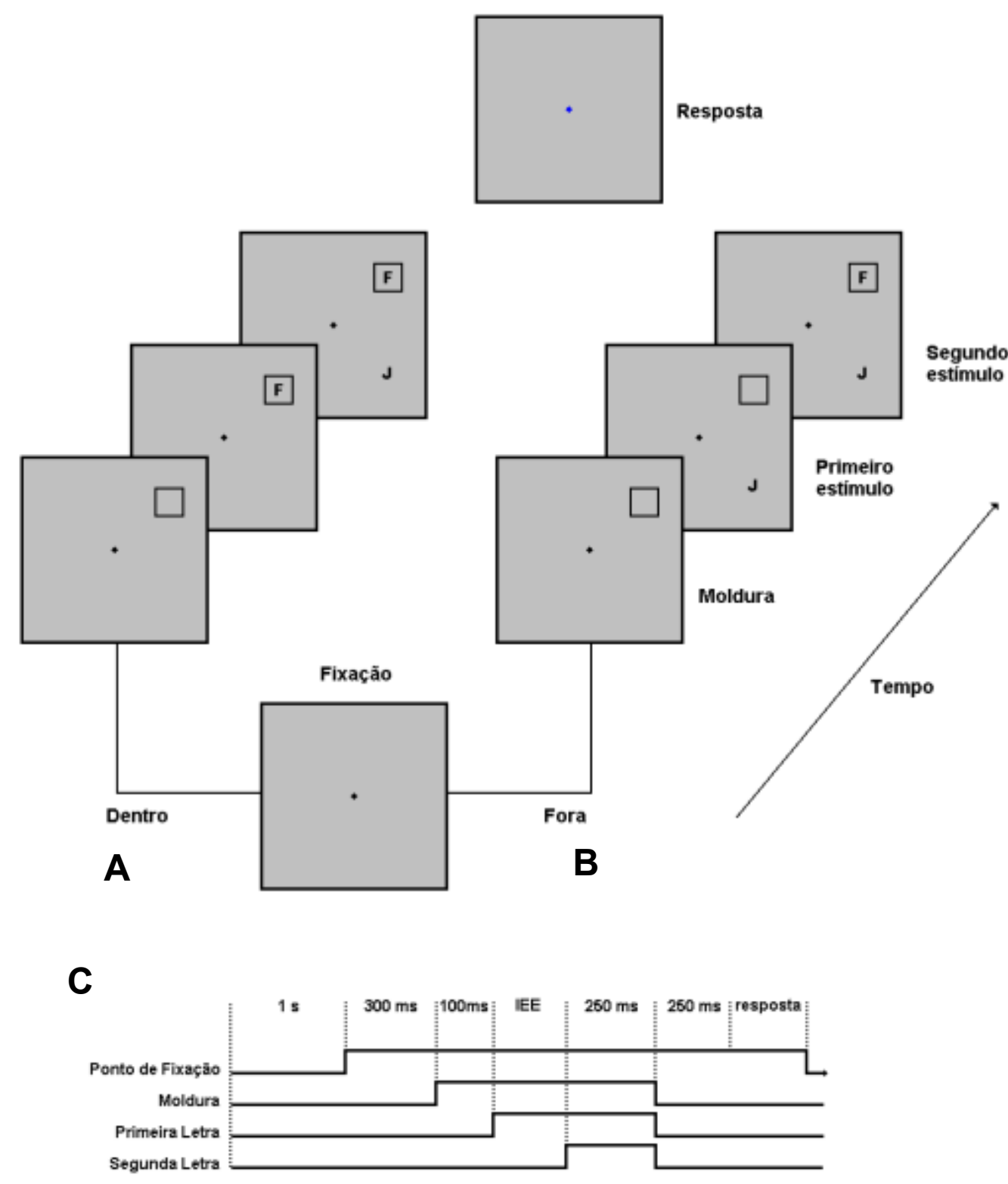

Figura 3. Seqüência de apresentação dos estímulos nas provas do Experimento $1 \mathrm{~A}$. Os participantes julgaram qual das duas letras " $F$ " ou "J" foi apresentada primeiro. (A) A letra poderia aparecer primeiro dentro da moldura ou (B) fora dela. (C) Intervalos de apresentação dos estímulos com um IEE variável de 20, 30, 60, 100 e 200ms entre provas. Os estímulos não estão em escala.

A primeira letra a ser apresentada ( $F$ ou $J)$, a localização da primeira letra (dentro ou fora da moldura), o tamanho da moldura $\left(1,0^{\circ}, 1,5^{\circ}, 2,0^{\circ}\right.$ e $\left.2,5^{\circ}\right)$ e o IEE $(20,30,60,100$ e $200 \mathrm{~ms})$, foram apresentados aleatoriamente em uma sessão experimental com 20 provas de treinamento e três blocos com 320 provas-teste cada. O participante poderia fazer um intervalo de até 10 minutos entre cada um dos três blocos de provas-teste. 


\section{$\underline{\text { Análises }}$}

As respostas dadas pelo participante para qual letra haviam percebido primeiro foram coletadas e analisadas. A FP foi calculada para cada tamanho de dica por meio da metade da diferença entre o PSS da condição em que a primeira letra apareceu dentro e o PSS da condição em que apareceu fora da moldura. Cada PSS foi obtido em duas etapas. Inicialmente a porcentagem de respostas " $F$ primeiro" dentro e fora foi calculada para cada IEE. Em seqüência, a distribuição dos valores empíricos foi ajustada à função sigmóide por meio da equação de Boltzmann, que permitiu a estimativa de cada PSS. A função de Boltzman é expressa por $Y=\left(\left(A_{1}-A_{2}\right) /\left(1+e^{(x-x 0) / d x}\right)\right)+A_{2}$, onde $Y$ é o valor a ser distribuído na curva relacionado ao SOA utilizado no experimento, $A_{1}$ são os valores de ajuste da parte inicial da curva (negativa), $A_{2}$ são os valores de ajuste da parte final da curva (positiva), e é uma constante (e=2,718282), $x$ é o SOA utilizado no experimento, $x 0$ é o PSS (valor da abscissa referente aos $50 \%$ de julgamento "qual a primeira letra apresentada?"), e $d x$, valor que corresponde a inclinação da curva.

O PSS médio calculado para a posição da primeira letra (dentro e fora) e tamanho da moldura $\left(1,0^{\circ}, 1,5^{\circ}, 2,0^{\circ}\right.$ e $\left.2,5^{\circ}\right)$ foi submetido a uma análise de variância (ANOVA, $p<0,05)$. Outra ANOVA $(p<0,05)$ para as médias da FP de cada tamanho da moldura de todos os participantes verificou se existiu diferença entre a FP encontrada para cada tamanho. Provas de treinamento foram excluídas das análises.

\section{Resultados}

Três participantes foram excluídos de análises posteriores por apresentarem PSS's muito fora da média (7 vezes o desvio padrão da média). 
O ajuste da função de Boltzmann à proporção média de respostas "letra $F$ primeiro" dos participantes para cada condição pode ser visualizado na Figura 4. Os intervalos entre estímulos negativos representam as provas em que a letra "J" foi apresentada primeiro e os valores positivos quando a letra "F" foi apresentada primeiro. Cada seta vertical indica o intervalo de tempo em que os participantes julgaram a letra "F" como apresentada primeiro em $50 \%$ das provas em cada condição, isto é, indica o PSS ou o intervalo que os participantes perceberam as duas letras simultaneamente em cada condição.

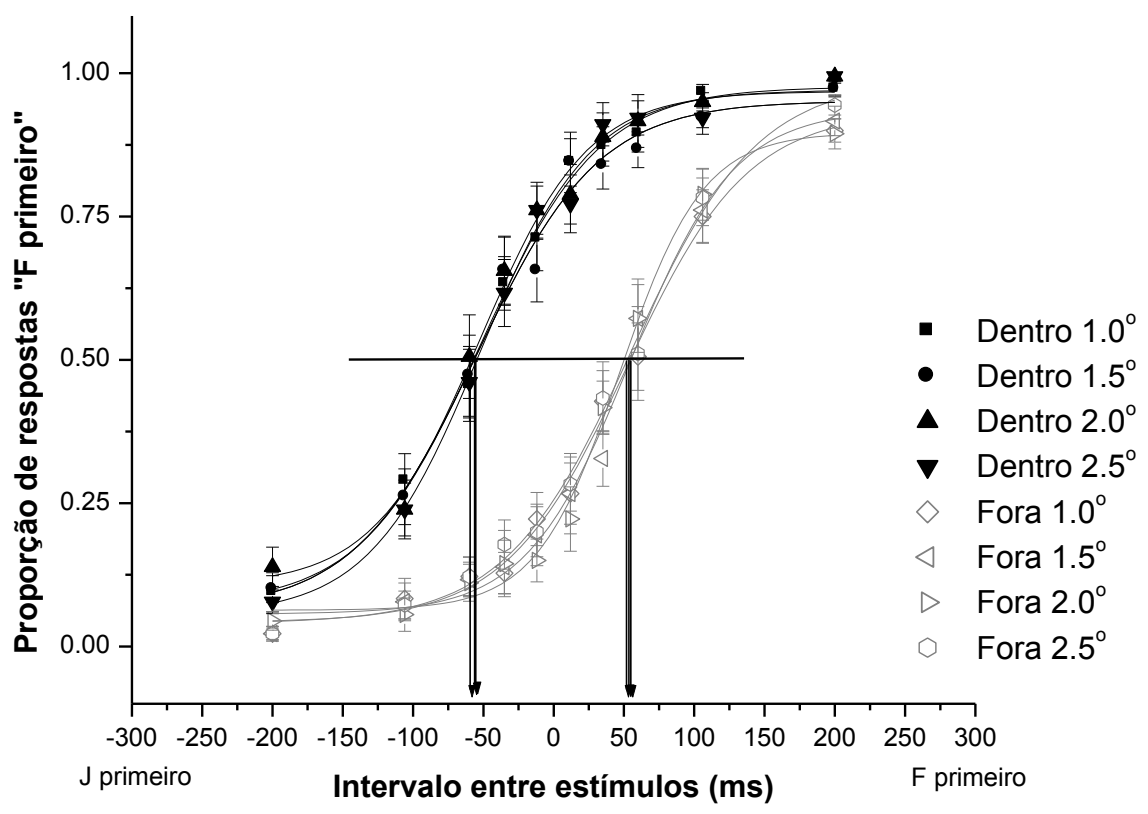

Figura 4. Média dos dados empíricos de todos os participantes do Experimento 1a e ajuste da função para as condições dentro e fora e os respectivos tamanhos de dica em cada condição. As setas verticais indicam os pontos de simultaneidade subjetiva (PSS) de cada condição.

O PSS das condições dentro e fora em relação a cada tamanho da moldura é mostrado na Figura 5A. Os valores negativos representam o PSS das condições em que a letra apareceu por primeiro dentro da moldura e podem ser interpretados como a vantagem ou o ganho em tempo proporcionado pela apresentação da letra 
dentro da moldura. Os valores positivos representam o PSS das condições em que a letra apareceu por primeiro fora da moldura e são interpretados como o custo em tempo para perceber a letra apresentada fora da moldura.

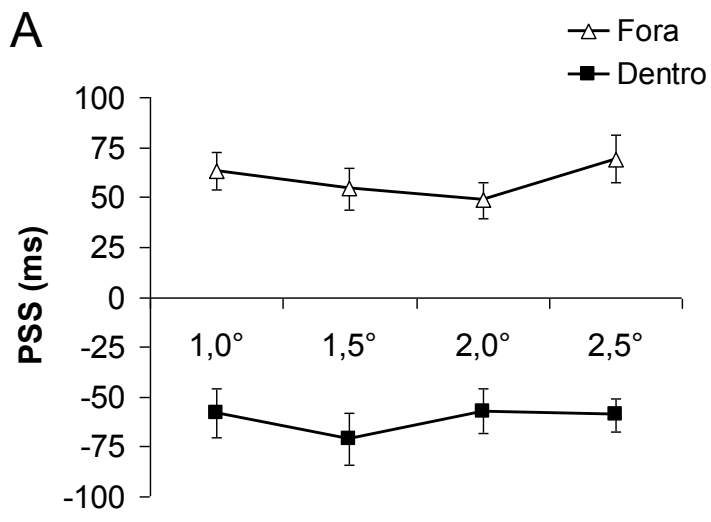

Tamanho da dica (graus)
$\mathrm{B}$

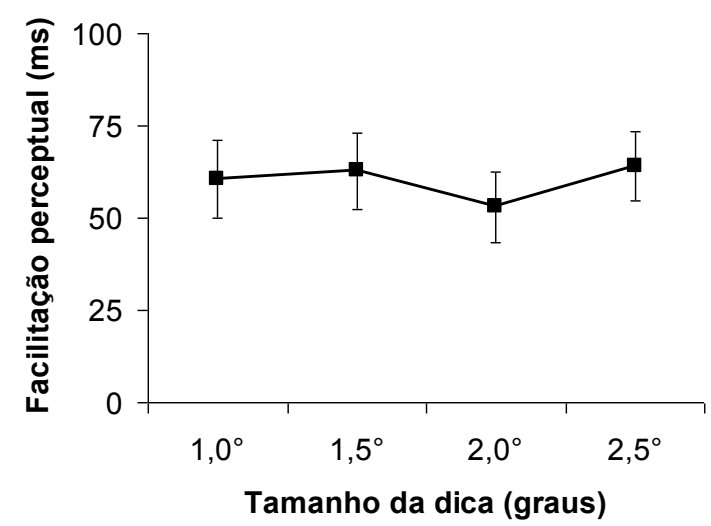

Figura 5. (A) Pontos de simultaneidade subjetiva (PSS) do local em que a primeira letra apareceu (dentro, fora), em função dos quatro tamanhos da moldura $\left(1,0^{\circ}, 1,5^{\circ}, 2,0^{\circ}, 2,5^{\circ}\right)$. (B) Facilitação perceptual (FP) calculada para cada tamanho de dica a partir do PSS da condição dentro e PSS da condição fora.

O teste ANOVA de duas vias para a média das medidas repetidas do PSS para os fatores, posição da primeira letra (dentro, fora) e tamanho da moldura $\left(1,0^{\circ}\right.$, $1,5^{\circ}, 2,0^{\circ}$ e $2,5^{\circ}$ ) revelou um efeito estatisticamente significativo para a posição (dentro $-61 \mathrm{~ms}$, fora $+59 \mathrm{~ms}, F(1,13)=41,45 ; p<0,001$, parcial $\eta^{2}=0,76$ ), nenhum efeito para o tamanho da moldura (respectivamente, $3 \mathrm{~ms},-8 \mathrm{~ms},-4 \mathrm{~ms}$ e $+5 \mathrm{~ms}$, $F(3,39)=1,90 ; p=0,15)$, e nenhuma interação estatisticamente significativa entre os dois fatores.

A ANOVA de uma via realizada para as medidas repetidas da FP obtidas para o fator tamanho da moldura demonstrou que não existiu diferença estatisticamente significativa entre a FP de cada tamanho da moldura $\left(1,0^{\circ}=61 \mathrm{~ms}, 1,5^{\circ}=63 \mathrm{~ms}\right.$, $2,0^{\circ}=53 \mathrm{~ms}$ e $\left.2,5^{\circ}=64 \mathrm{~ms}, \mathrm{~F}(3,39)=1,47 ; p=0,24\right)$. A FP encontrada para cada tamanho da dica pode ser visualizada na Figura 5B. A FP média geral foi de $60 \mathrm{~ms}$. 


\section{Discussão}

A diferença entre o PSS da condição dentro e o PSS da condição fora da moldura, indica que a apresentação abrupta da moldura na periferia do campo visual antes da apresentação das duas letras, alterou a percepção de ordem temporal dos participantes. A letra apresentada dentro da moldura teve a sua latência perceptual encurtada em 61 ms. Em outras palavras, o PSS da condição dentro indica que a letra apresentada dentro da moldura precisou ser apresentada $61 \mathrm{~ms}$ depois da letra apresentada fora para que o participante percebesse as duas letras como apresentadas simultaneamente. Já a letra apresentada fora teve a sua latência perceptual atrasada em 59 ms. Esses valores indicam que a FP ou efeito de entrada prioritária foi de 60 ms para a informação apresentada dentro da moldura.

De acordo com a hipótese de entrada prioritária, essa vantagem encontrada para a letra apresentada dentro da moldura deve ser atribuída ao deslocamento da atenção visual para a moldura, que encurtou a latência perceptual do estímulo que recebeu atenção em relação a o estímulo que não recebeu atenção (Scharlau, 2004a; Scharlau, 2004b; Shore et al., 2001; Stelmach \& Herdman, 1991; Vibell et al., 2007). Como a moldura foi um estímulo de início abrupto e exposta por $100 \mathrm{~ms}$ antes de a primeira letra aparecer, pode-se supor também que o efeito encontrado foi em grande parte causado pela orientação automática da atenção (Müller \& Findlay, 1988; Müller \& Rabbitt, 1989; Nakayama \& Mackeben, 1989; Remington et al., 1992; Von Grünau \& Faubert, 1994; Kröse \& Julesz, 1989).

No entanto, as análises do PSS e da FP de cada tamanho da dica mostraram que a manipulação do tamanho da moldura não interferiu na percepção de ordem temporal dos participantes. Supondo que a atenção tenha sido orientada para a moldura como sugere o PSS e a FP encontrados, uma explicação plausível para a 
ausência de variação gradual do PSS e da FP em função do aumento do tamanho da moldura, é a de que não tenha existido tempo suficiente para ocorrer o processo de focalização. Nos estudos de Castiello e Umiltá (1990), o efeito do tamanho da dica ocorreu apenas quando a moldura foi exposta por 500 ms antes da apresentação do alvo. Quando a moldura foi exposta na tela por 40 ms, o benefício em TR foi encontrado apenas para a comparação entre a dica válida e inválida, semelhante ao efeito entre dentro e fora deste experimento. Castiello e Umiltá (1990) interpretaram os seus resultados como indício de que 40 ms fosse suficiente apenas para a orientação da atenção visual para o local indicado, enquanto a focalização necessitaria de mais tempo. Evidências de que o ajuste possa ocorrer automaticamente com 100 ms de exposição da dica foram encontrados apenas quando a dica e os estímulos relevantes para a tarefa foram apresentados no centro do campo visual (Turatto et al. 2000). Isto é diferente do método usado neste Experimento 1a e do estudo de Castiello e Umiltá (1990), onde os estímulos foram apresentados na periferia do campo visual. Isto levanta a possibilidade de o intervalo de 100 ms usado nesse experimento ter sido curto para tentar obter o efeito do tamanho da dica com o JOT.

Outra possibilidade é a de que tenha ocorrido algum tipo de mascaramento entre a moldura e a letra apresentada dentro da moldura. O mascaramento pode ser entendido como a interferência entre dois ou mais estímulos apresentados em seqüência e em um intervalo espacial ou temporal muito curto. Essa interferência pode ser proativa, ou seja, quando uma informação prévia interfere em uma informação posterior (Humphreys \& Bruce, 1989). Portanto, é possível que a letra apresentada dentro da moldura tenha sofrido algum tipo de interferência das bordas da moldura que a contornavam. As bordas podem ter dificultado a identificação da 
letra apresentada dentro da moldura. Isso levaria ao aumento da incerteza sobre a ordem de apresentação dos estímulos, diminuindo o PSS. Assim, um controle foi realizado em dois experimentos não relatos aqui e os resultados sugeriram que um viés causado por esse tipo de interferência foi muito pequeno.

\subsection{Experimento $1 \mathrm{~b}-$ Mais tempo para o ajuste do foco}

Embora os resultados do Experimento 1a sugiram que os recursos de atenção tenham sido orientados para a moldura, não foram encontrados resultados que mostrassem o ajuste do foco ao tamanho da moldura. Portanto, o objetivo do Experimento $1 \mathrm{~b}$ foi investigar a possibilidade de o intervalo de $100 \mathrm{~ms}$ de exposição da dica, usado no Experimento 1a, ter sido muito curto para o processo de focalização. Assim, a quantidade de tempo de exposição da moldura antes do aparecimento da primeira letra foi manipulada por 100 e $400 \mathrm{~ms}$. O tempo de $400 \mathrm{~ms}$ foi escolhido por já ter sido usado em outro experimento com o mesmo método utilizado neste estudo (Cavallet et al., no prelo), revelando um efeito de entrada prioritária menor do que o obtido em 100 ms, porém com uma vantagem ainda significativa para a letra apresentada dentro da moldura. Intervalos maiores de exposição da moldura não foram usados porque em algumas situações esse aumento pode levar a uma inibição do local indicado (Lambert \& Hockey, 1991; Rafal et al., 1989; Posner \& Cohen 1984). Portanto, essa manipulação temporal deve mostrar uma vantagem para a informação apresentada dentro da moldura nos dois intervalos usados, mas o efeito do tamanho da dica deverá ser observado apenas quando o intervalo entre a moldura e a letra for de $400 \mathrm{~ms}$, assemelhando-se ao 
encontrado com 500 ms de exposição da dica em outros estudos que usaram tarefas de TR (Benso et al., 1998; Castiello \& Umiltà, 1990, 1992).

Os tamanhos da moldura também foram modificados em relação ao Experimento 1a com o objetivo de minimizar possíveis interações (mascaramento) entre as bordas da moldura e a letra apresentada dentro. As molduras foram aumentadas meio grau em relação às molduras do Experimento 1a. Apenas três tamanhos de dica foram usados para diminuir a quantidade de provas por sessão experimental e a diferença entre cada tamanho de dica também foi aumentada.

\section{Método}

\section{Participantes}

Dezoito voluntários (9 mulheres), estudantes do Campus da USP em Ribeirão Preto, com idade média de 26 anos, sem conhecimento prévio da proposta do estudo, participaram de uma sessão experimental de aproximadamente 1 hora. Todos os participantes relataram ter visão normal ou usavam lentes para correção.

\section{$\underline{\text { Material e estímulos }}$}

Foram utilizados os mesmos materiais e estímulos descritos no Experimento 1a com a exceção do tamanho da dica (moldura quadrada) que foi de $1,5^{\circ}, 2,5^{\circ} \mathrm{e}$ $3,5^{\circ}$.

\section{Procedimento}

Os detalhes do procedimento foram iguais aos do Experimento 1a com a exceção do tempo de exposição da moldura que foi de 100 e 400 ms e a inclusão da 
tecla de espaço que o participante pressionou para iniciar cada prova, permitindo a realização de pequenos intervalos para descanso durante a sessão experimental.

A primeira letra a ser apresentada ( $F$ ou J), a localização da primeira letra (dentro ou fora da moldura), o tamanho da moldura $\left(1,5^{\circ}, 2,5^{\circ}\right.$ e $\left.3,5^{\circ}\right)$, tempo de exposição da moldura (100 e 400 ms) e o IEE (20, 30, 60, 100 e 200ms), foram apresentados aleatoriamente em uma sessão experimental com 20 provas de treinamento e dois blocos com 480 provas-teste cada. O participante realizou um intervalo de até 10 minutos entre cada um dos dois blocos de provas-teste.

\section{Resultados}

Três participantes foram excluídos das análises finais. Um participante não completou todo o experimento, outro apresentou PSS muito fora do desvio padrão e outro não conseguiu discriminar a ordem temporal de apresentação dos estímulos.

O teste ANOVA de três vias para a média das medidas repetidas do PSS para os fatores, posição da primeira letra (dentro, fora), tempo de exposição da moldura $(100,400 \mathrm{~ms})$ e tamanho da moldura $\left(1,5^{\circ}, 2,5^{\circ}\right.$ e $\left.3,5^{\circ}\right)$, revelou um efeito estatisticamente significativo para a posição (dentro $=-53 \mathrm{~ms}$, fora $=+51 \mathrm{~ms}$, $F(1,14)=100,48 ; \quad p<0,001$, parcial $\left.\eta^{2}=0,88\right)$, nenhum efeito para o tempo de exposição da moldura $(100=+1 \mathrm{~ms}, 400=-5 \mathrm{~ms}, \mathrm{~F}(1,14)=0,85 ; \mathrm{p}=0,37)$ e nenhum efeito para o tamanho da moldura $\left(1,5^{\circ}=-4 \mathrm{~ms}, 2,5^{\circ}=-4 \mathrm{~ms}, 3,5^{\circ}=+6 \mathrm{~ms}\right.$, $F(2,28)=2,68 ; p=0,09)$. Embora a análise estatística não tenha revelado efeito principal para o intervalo de exposição da moldura e para o tamanho, ocorreram interações estatisticamente significativas entre posição e intervalo de exposição da moldura $\left(F(1,14)=12,51 ; p=0,01\right.$, parcial $\left.\eta^{2}=0,47\right)$, e entre posição e tamanho $\left(F(2,28)=4,03 ; p=0,03\right.$, parcial $\left.\eta^{2}=0,22\right)$. Comparações pareadas (teste post hoc de 
Newman-Keuls, $p<0,05)$ para os fatores posição e intervalo revelaram que quando a letra foi apresentada primeiro fora da moldura, o intervalo de 100 ms produziu PSS de magnitude maior (+63ms) do que o PSS encontrado para o intervalo de $400 \mathrm{~ms}$ (+38ms, Figura 6A). Quando a letra apareceu primeiro dentro da moldura, ocorreu uma tendência de os dois intervalos serem estatisticamente diferentes (PSS de -62 ms e $-44 \mathrm{~ms}$, respectivamente, $p=0,06)$. Comparações pareadas usando o mesmo teste para os fatores posição e tamanho revelaram que a moldura maior $\left(3,5^{\circ}\right)$ produziu PSS maior (+64 ms) para a posição fora em relação aos outros dois tamanhos $\left(1,5^{\circ}=+43 \mathrm{~ms}\right.$ e $\left.2,5^{\circ}=+45 \mathrm{~ms}\right)$, não existindo diferença estatisticamente significativa entre os três tamanhos para a posição dentro $(-52,-53$ e -53 ms, respectivamente, Figura $6 \mathrm{~B})$.
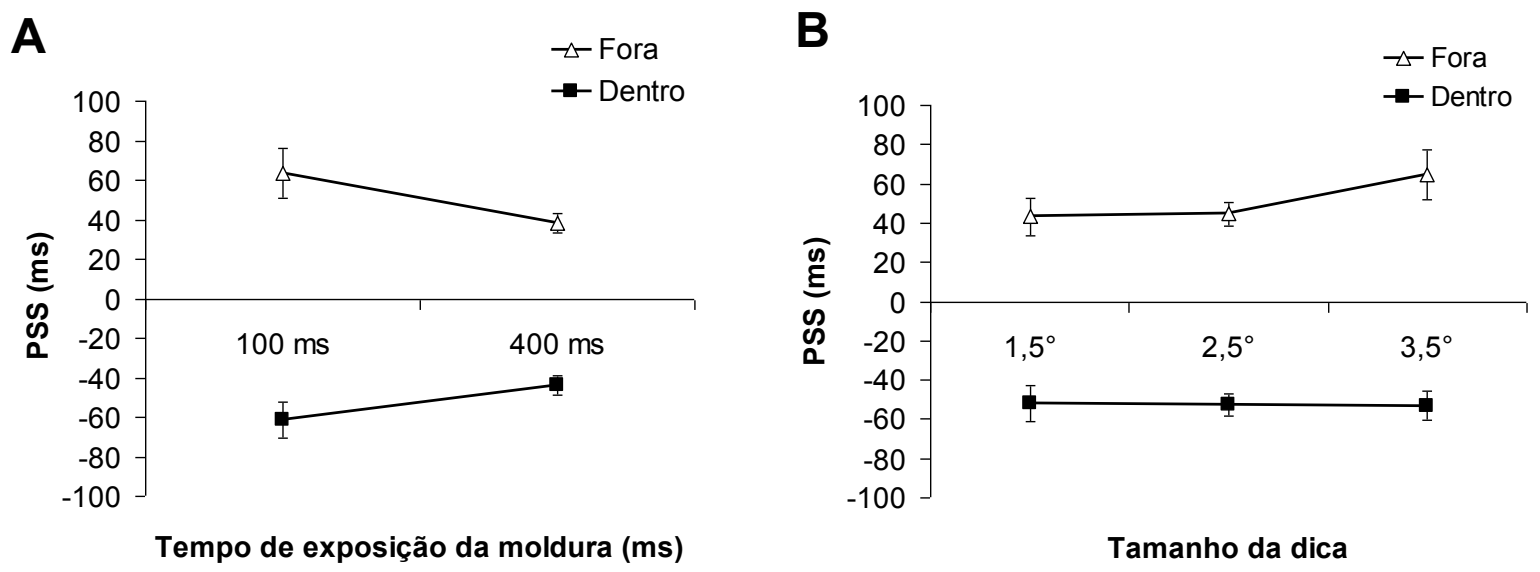

Figura 6. (A) Ponto de simultaneidade subjetiva (PSS) médio das condições posição da primeira letra (dentro, fora da moldura) em relação ao tempo de exposição da moldura (100 ou $400 \mathrm{~ms}$ ) e (B) em relação ao tamanho da moldura $\left(1,5^{\circ}, 2,5^{\circ}\right.$ ou $3,5^{\circ}$ de ângulo visual).

Outro teste ANOVA de duas vias para a média das medidas repetidas da FP para os fatores, tempo de exposição da moldura (100 e 400 ms) e do tamanho da moldura $\left(1,5^{\circ}, 2,5^{\circ}\right.$ e $\left.3,5^{\circ}\right)$, revelou um efeito estatisticamente significativo para o 
tempo de exposição da moldura (FP de 60 ms e 42 ms, respectivamente, $F(1,14)=12,51 ; p<0,01$, parcial $\eta^{2}=0,47$ ) e um efeito para o tamanho (FP de 48,49 e $59 \mathrm{~ms}$, respectivamente, $\mathrm{F}(2,28)=4,03 ; p=0,03$, parcial $\left.\eta^{2}=0,22\right)$, sem ocorrer interação entre estes fatores $(F(2,28)=1,98 ; p=0,16)$. O teste post hoc de NewmanKeuls $(p<0,05)$ revelou que a FP do tamanho da dica $3,5^{\circ}(59 \mathrm{~ms})$ foi maior do que a FP dos outros dois tamanhos $\left(1,5^{\circ}=48 \mathrm{~ms}, 2,5^{\circ}=49 \mathrm{~ms}\right)$. A FP geral encontrada foi de $52 \mathrm{~ms}$.

\section{Discussão}

A análise do PSS e da FP mostrou novamente uma vantagem geral para a letra apresentada dentro da moldura em relação à letra apresentada fora. Essa vantagem relativa foi estimada em 52 ms e é muito semelhante a FP encontrada no experimento anterior, que foi de $60 \mathrm{~ms}$.

As análises revelaram também que o tempo de exposição da moldura antes da apresentação da primeira letra, influenciou a vantagem para a letra apresentada dentro da moldura. O PSS e a FP tiveram maior magnitude durante o intervalo de $100 \mathrm{~ms}$ do que durante o intervalo de $400 \mathrm{~ms}$, mesmo assim produzindo uma vantagem grande no intervalo mais longo (FP $=42 \mathrm{~ms}$ ). Esses resultados são semelhantes ao padrão de resultados de estudos que utilizaram tarefas de TR (Cheal \& Lyon, 1991; Muller \& Findlay, 1988; Muller \& Rabbitt, 1989; Nakayama \& Mackeben, 1989) e tarefas de JOT (Schneider \& Bavelier, 2003; Cavallet et al., no prelo) para investigar a dinâmica temporal da orientação da atenção. Müller e colaboradores (Muller \& Findlay, 1988; Muller \& Rabbitt, 1989) verificaram um desempenho máximo, ou seja, número muito grande de acertos, durante curtos intervalos de tempo de exposição de dicas periféricas (de 50 a 150 ms) e um 
decaimento rápido no desempenho que se estabilizou depois, conforme o aumento do intervalo de exposição da dica, sugerindo uma ativação rápida e forte, mas transitória dos recursos de atenção. De acordo com Müller e colaboradores, esse padrão de resultados pode ser explicado pela ativação de um mecanismo inicial e rápido de orientação automática da atenção para a dica. Após, aproximadamente 150 ms de exposição da dica, um mecanismo mais lento e prolongado de orientação voluntária da atenção, manteria os recursos de atenção no local indicado, porém, não com o mesmo desempenho. Resultados semelhantes encontrados por estudos que usaram o JOT e manipularam o intervalo de tempo entre o estímulo de início abruto e o primeiro estímulo a ser julgado, também suportam essa interpretação (Schneider \& Bavelier, 2003; Cavallet et al. no prelo).

A análise do tempo de exposição da moldura revelou também que o valor do PSS da condição dentro e o valor do PSS da condição fora não inverteram no intervalo de 400 ms (i.e., não cruzaram o valor de PSS zero, Figura 6A). Isso sugere que os resultados não podem ser explicados pela inibição encontrada por Posner e Cohen (1984) para o local indicado quando o intervalo de exposição da dica periférica aumentou para 300 ms. Isso reforça a idéia de que os recursos de atenção permaneceram na moldura durante os $400 \mathrm{~ms}$ de sua exposição antes da primeira letra aparecer.

No entanto, a inexistência de interação entre o intervalo de exposição da moldura e o tamanho da moldura revelaram que o aumento do tempo para $400 \mathrm{~ms}$ não foi determinante para o ajuste do foco de atenção ao tamanho da moldura, não revelando o efeito do tamanho da dica. Esse resultado contrariou a hipótese de o ajuste ocorrer quando mais tempo fosse fornecido para a focalização ocorrer. 
O único resultado que sugere alguma influência do tamanho da moldura no ajuste do foco de atenção foi a FP maior para a moldura maior $\left(3.5^{\circ}\right)$ em relação aos outros dois tamanhos de moldura. Esse efeito foi causado pelo custo maior encontrado para o PSS da condição fora da dica de tamanho $3,5^{\circ}$ e não por uma vantagem maior para esta condição, como pode ser observado na Figura $6 \mathrm{~B}$. Embora o aumento tenha ocorrido apenas para a moldura maior, esse resultado revela um efeito oposto ao esperado. O esperado seria um custo proporcional ao ganho para o tamanho $3,5^{\circ}$, pois teoricamente, quanto maior a facilitação em processamento para a letra que recebeu atenção, maior inibição ou falta de recursos de atenção ocorreria para a letra apresentada fora da moldura (Posner, 1980, Posner et al., 1980). Portanto, a maior facilitação perceptual encontrada para a moldura de tamanho $3,5^{\circ}$ não nos permite afirmar que a vantagem foi produzida pela maior concentração de recursos nesta condição, mas sim, devido à falta de recursos para processar a letra apresentada fora da moldura maior.

Uma explicação para os resultados dos Experimentos 1a e 1b pode ser a de que o mecanismo de ajuste do foco de atenção ao tamanho de um estímulo não seja um mecanismo tão fácil de ser mensurado (Panagopoulos, von Grünau, Galera, Ivan \& Cavallet, 2006). Embora o tamanho dos objetos seja uma informação importante para o processamento da informação visual, o processo de focalização pode ocorrer em configurações temporais e espaciais muito específicas, variando conforme o tipo de tarefa utilizada e a configuração espacial, sendo mais suscetível a processos controlados de atenção (Greenwood \& Parasuraman, 2004; Yeshurun \& Carrasco, 2008).

Resultados encontrados por Greenwood e Parasuraman (2004) apontam nessa direção quando o participante não foi capaz de predizer o tamanho e a 
localização do alvo em seus experimentos. Os resultados mostraram desempenho superior com dicas periféricas grandes do que com dicas pequenas e indicam que o tamanho do foco de atenção pode ser ajustado para um tamanho grande quando alvos pequenos e de localizações incertas são usados. Esse ajuste pode ser definido de acordo com uma estratégia do indivíduo para obter o melhor desempenho possível, portanto, podendo ser, até certo nível, controlado. Além disso, outros estudos indicam que um foco grande de atenção pode ser mais eficiente quando as dicas são inválidas, ou seja, quando estão longe do local em que o alvo é apresentado, sugerindo que as características do alvo podem ser mais bem detectadas por um foco de atenção amplo e difuso (Greenwood \& Parasuraman, 1999; Greenwood, Parasuraman \& Alexander, 1997). No presente estudo, isto significaria que, os recursos de atenção podem ter sido distribuídos em forma de um gradiente de atenção amplo e difuso para abranger uma área grande em volta da moldura e ter detectado tanto a letra apresentada dentro quanto a letra apresentada fora da moldura, porém, com um gradiente maior de ativação dos recursos para a área de dentro da moldura. O gradiente maior de recursos dentro da moldura determinou a diferença entre as posições dentro e fora e a FP encontrada, mas ao mesmo tempo, a eficiência da moldura em concentrar os recursos de atenção pode ter sido voluntariamente diminuída por abranger essa área maior. Por isso, os resultados não mostraram vantagem maior para a letra apresentada dentro da moldura pequena. Além disso, Greenwood e Parasuraman (2004) sugerem que quando a escala de distribuição da atenção abrange áreas maiores do campo visual, o ajuste pode ser mais rápido a uma área grande do que a uma área pequena. Porém, no presente estudo, este efeito deveria ter provocado um ganho e um custo maior para a moldura de tamanho $3,5^{\circ}$, mas apenas um custo foi observado. 
Por outro lado, Yeshurun e Carrasco (2008) utilizaram uma tarefa de escolha forçada e duas dicas diferentes, uma moldura e uma barra, para investigar o processo de focalização e encontraram resolução espacial melhor para as dicas pequenas apresentadas a uma distância média entre o centro do campo visual e o local de apresentação do estímulo, mas não encontraram evidências de perda de resolução espacial com o aumento do tamanho das dicas.

O ajuste do foco também parece ser sensível à carga de atenção exigida pela tarefa. No estudo de Greenwood e Parasuraman (2004) o efeito do tamanho da dica sempre foi mais forte quando uma tarefa de busca visual exigia a integração de mais de uma característica dos estímulos relevantes, do que quando o estímulo relevante possuía uma característica única, não exigindo a integração de características.

Além disso, estudos têm mostrado que a modulação da atividade neuronal pela atenção é mais forte na presença do que na ausência de estímulos que competem pelos recursos de atenção (Motter, 1993; Noesselt et al. 2002). Isso chama a atenção porque entre os poucos estudos que têm investigado o ajuste do foco, um número considerável tem usado estímulos competidores em seus experimentos (Eriksen \& St. James, 1986; Greenwood \& Parasuraman, 1999; Greenwood \& Parasuraman, 2004; LaBerge et al. 1997), enquanto apenas o grupo de Umiltà demonstrou tal flexibilidade na ausência de tais estímulos (Benso et al. 1998; Castiello \& Umiltà, 1990, 1992; Maringelli \& Umiltà, 1998; Mizuno et al. 1998; Turatto et al. 2000).

Em resumo, estes estudos indicam que o processo de focalização ocorre em diferentes situações, mas que observá-lo por meio do efeito do tamanho da dica pode depender do tipo de tarefa usada e da relevância que a área indicada tem para a conclusão de uma tarefa. 
Outra possível explicação para a ausência de ajuste do foco ao tamanho da moldura nestes dois experimentos pode estar nas diferentes tarefas usadas. Vários estudos têm mostrado uma dissociação entre as tarefas de TR e JOT (Jaskowski, 1993; Tappe, et al. 1994). O principal resultado é o de que quando características físicas dos estímulos são manipuladas, o TR sofre maiores mudanças do que a latência relativa obtida pela tarefa de JOT. Isto foi verificado com variáveis diferentes, como, por exemplo, intensidade do estímulo (Jaskowski, 1992; Roufs, 1974), dicas espaciais (Neumann \& Esselmann, 1992, Neumann et al., 1993) e freqüência espacial (Jaskowski, 1993; Tappe et al. 1994). Com dicas espaciais, os resultados mostram que uma tarefa de detecção simples de um alvo apresentado em um lugar indicado pode produzir uma vantagem em TR significativa em relação ao desempenho das provas de dica inválida, enquanto que o PSS em determinadas situações não apresenta vantagem alguma (Neumann et al., 1993). Isso indica que o efeito do tamanho da dica pode não ocorrer com a tarefa de JOT, mesmo existindo indícios de que a atenção tenha sido deslocada para o local indicado como foi verificado no Experimento 1a e 1b.

No entanto, essas explicações são válidas apenas para entender porque o efeito do tamanho da dica não foi obtido nestes dois experimentos. Portanto, esses resultados são válidos para o objetivo secundário desse estudo, mostrando que o método usado neste experimento com a tarefa de JOT não parece adequado para investigar o ajuste do foco de atenção ao tamanho de uma área delimitada. Porém, para investigar a divisão do foco e o processo de focalização, é preciso verificar se o efeito do tamanho da dica ocorre quando tarefas de TR são realizadas como foi demonstrado nos estudos de Umiltà (Benso et al. 1998; Castiello \& Umiltà, 1990, 1992; Maringelli \& Umiltà, 1998; Mizuno et al. 1998; Turatto et al. 2000). Encontrar o 
efeito do tamanho da dica com tarefas de TR pode ajudar a entender a ausência desse efeito nos Experimento 1a e 1b, além de indicar se tarefas de TR podem ser usadas para estudar o processo de focalização em duas áreas indicadas.

\subsection{Experimentos $2 a, 2 b$ e $2 c$ - Tarefas de tempo de reação e o efeito do tamanho da dica}

Considerando as evidências de que o TR é mais afetado pela manipulação de características físicas de um estímulo do que o PSS obtido em tarefas de JOT (Jaskowski, 1992, 1993; Neumann \& Esselmann, 1992, Neumann et al., 1993; Roufs, 1974; Tappe et al. 1994) e devido aos resultados dos Experimentos 1a e 1b mostrarem que o efeito do tamanho da dica não ocorreu quando a tarefa de JOT foi solicitada, os Experimentos $2 \mathrm{a}$ e $2 \mathrm{~b}$ foram realizados para verificar se o efeito do tamanho da dica poderia ser replicado com tarefas de TR, permitindo usar este tipo de tarefa para estudar a divisão do foco ao manipular o tamanho das dicas. Portanto, o Experimento 2a foi designado para testar o efeito do tamanho da dica com uma tarefa de tempo de reação manual (TRM) e o Experimento $2 b$ para testar o mesmo efeito com uma tarefa de tempo de reação de sacada dos olhos (TRS) para o alvo. Além desses dois experimentos, o Experimento $2 \mathrm{c}$ foi realizado para testar novamente a tarefa de JOT, pois um monitoramento dos movimentos oculares foi realizado e os alvos usados nos Experimentos 1a e 1b foram trocados.

O monitoramento dos movimentos dos olhos permitiu verificar se os efeitos encontrados nas tarefas de TRM e JOT são atribuídos apenas a orientação implícita da atenção visual para os estímulos apresentados na periferia do campo visual e 
não confundidos com efeitos de excentricidade da retina, isto é, movimentos de sacada dos olhos para as localizações indicadas quando os estímulos são apresentados por mais de 150ms (Fischer, 1998). Além disso, essa técnica permitiu mensurar o TRS.

A tarefa de TRS foi realizada, pois seria uma boa oportunidade para verificar se a manipulação do tamanho da dica afetaria o TRS da mesma forma como afeta o TRM. Essa comparação pode ajudar a entender se existe uma dissociação entre tarefas de TR e JOT, ou se existe também uma dissociação entre tarefas de TRM e TRS, pois estudos mostram uma dissociação entre estes dois tipos de tarefas. Hughes e Kesley (1984), por exemplo, solicitaram que os seus participantes realizassem reações simples a estímulos de diferentes intensidades, apertando um botão ou realizando um movimento de sacada dos olhos para a posição em que o estímulo aparecia e verificaram que as diferentes intensidades dos estímulos tiveram maiores efeitos sobre o tempo de reação manual do que sobre o tempo de reação de sacada dos olhos. Jaskowski e Sobieralska (2004) obtiveram resultados semelhantes, comparando o desempenho em TR quando os participantes deveriam realizar uma resposta manual simples ou de escolha e quando realizaram movimentos de sacada para o estímulo apresentado na periferia do campo visual. No entanto, não encontraram dissociação quando setas apontaram a direção na qual os participantes deveriam realizar a sacada. Eles sugeriram que os resultados eram mais bem explicados pela existência de diferentes vias neurais pelas quais a informação deveria ser processada até a execução da resposta. Bompas e Sumner (2008) que compararam os três tipos de tarefas (i.e., JOT, TRM e TRS), encontraram uma dissociação tripla quando compararam o desempenho para detectar ou julgar uma mudança de contraste ou luminosidade de um quadrado 
apresentado do lado esquerdo ou direito do campo visual. O desempenho das tarefas de TR revelou que os participantes foram mais lentos para detectar o aumento do contraste, comparado ao aumento da luminosidade. No entanto, essa diferença foi maior quando as respostas foram realizadas com uma sacada dos olhos para o estímulo do que quando a resposta foi manual (i.e. pressionar um botão). Por outro lado, o JOT não revelou diferenças entre os dois tipos de mudanças. Bompas e Sumner concluíram que a dissociação era consistente com as diferenças entre a forma que as respostas motoras e de JOT são realizadas.

Assim, nesses três experimentos, os participantes realizaram tarefas de TR e JOT para verificar se as tarefas de TR revelavam o ajuste do foco ao tamanho da área indicada e se esse efeito continuaria ausente na tarefa de JOT. Portanto, se o efeito do tamanho da dica encontrado com tarefas de TR ocorrer, os resultados mostrarão um aumento no TR em tarefas de detecção simples realizadas manualmente ou com um movimento de sacada dos olhos, conforme o aumento do tamanho da dica. Por outro lado, o PSS e a FP obtidos na tarefa de JOT, não deve revelar alterações significativas conforme a variação do tamanho da dica. Encontrar o efeito do tamanho da dica com as respostas de TR manual e de sacada reforçariam a idéia de que existe uma dissociação entre tarefas de TR e JOT. Além disso, indicaria que a tarefa de TR pode ser usada para investigar a proposta principal desse estudo.

\section{Método}

\section{$\underline{\text { Participantes }}$}

Sete estudantes (4 mulheres) da Universidade Concórdia participaram do Experimento 2a. Os participantes tinham idade média de 24 anos e não possuíam 
conhecimento prévio da proposta do estudo com a exceção do autor (MC). Todos os participantes relataram ter visão normal ou usavam lentes para correção. Os mesmos estudantes também realizaram o Experimentos $2 \mathrm{~b}$ e apenas cinco participaram do Experimento 2c. Cinco participantes realizaram os três experimentos em seqüência diferente enquanto dois participantes repetiram uma das seqüências anteriores escolhidas ao acaso. Cada sessão experimental durou aproximadamente 1 hora e foram realizadas em dias diferentes. Todos assinaram um termo de consentimento livre e esclarecido (Apêndice B) antes de iniciar a sessão experimental. O estudo foi aprovado pelo Comitê de Ética da instituição (Anexo B).

\section{Material e estímulos}

Os experimentos foram montados e executados pelo programa SR Research Experiment Builder (disponível em http://sr-research.com/eb.html). O participante permaneceu sentado em frente à tela de um monitor (Viewsonic 19" CRT, resolução de 1024 x 768 pixels e taxa de atualização vertical de $100 \mathrm{~Hz}$ ) em uma sala escura com a cabeça posicionada sobre um apoiador de queixo à distância de $60 \mathrm{~cm}$ do monitor. As coordenadas espaciais dos olhos foram gravadas ao longo do tempo usando um monitoramento de vídeo binocular de alta velocidade (sistema EyeLink 2000, SR Research, Ontário, Canadá. Figura 7). O sistema EyeLink 2000 gravou a posição dos olhos com uma resolução temporal por olho de 1000 exemplos por segundo e com uma resolução espacial de $0.01^{\circ}$ de ângulo visual. 

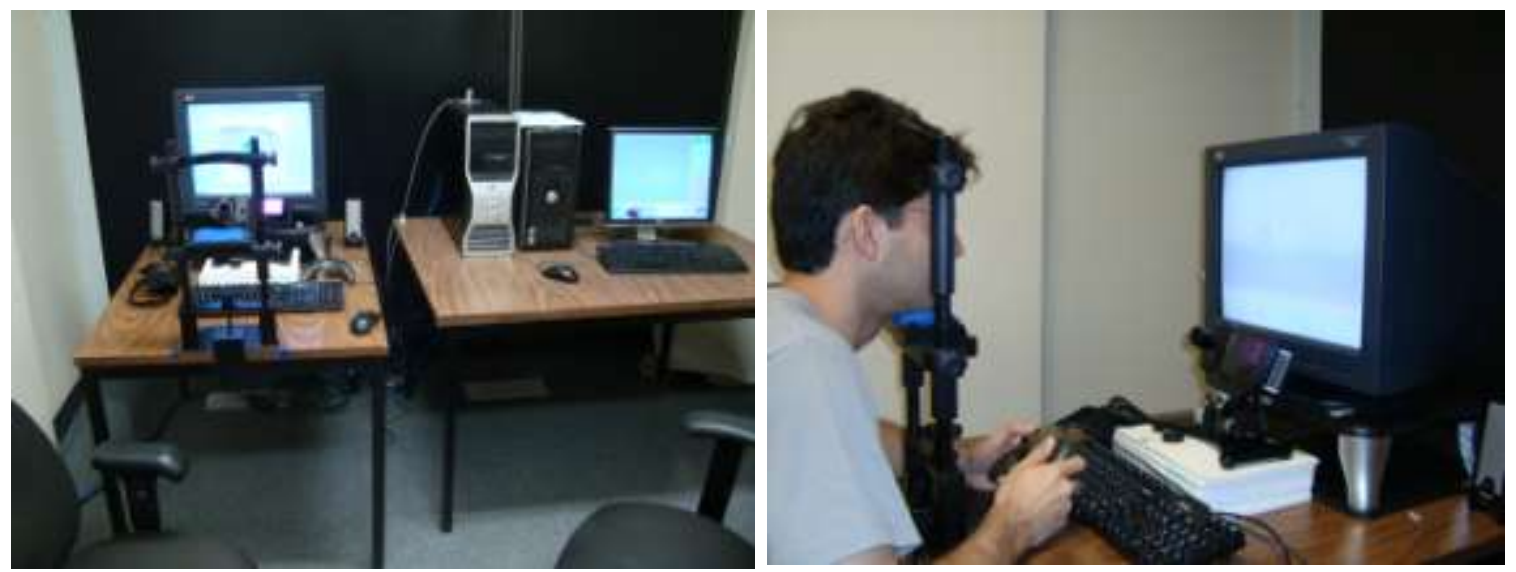

Figura 7. À esquerda é mostrado o Sistema EyeLink 2000 usado para gravar a posição dos olhos durante os experimentos e à direita um participante posicionado sobre o apoiador de queixo e usando um controle para realizar as respostas.

Os estímulos foram os mesmos usados no Experimento 1a com a exceção da onda senoidal multiplicada por uma função Gaussiana bidimensional conhecida como Gabor. Dois Gabors foram usados como alvo. Um Gabor teve as suas ondas orientadas a $0^{\circ}$ (vertical) e o outro a $90^{\circ}$ (horizontal) como pode ser visualizado na Figura 8. Os Gabors tiveram desvio padrão de $5^{\circ}$, freqüência espacial de 8 ciclos/grau, $100 \%$ de contraste, configurados dentro de uma área de $1,0^{\circ} \times 1,0^{\circ}$ de ângulo visual. Os Gabors foram escolhidos ao invés das letras por serem estímulos neutros e de um mesmo padrão. A moldura quadrada foi apresentada nos mesmos tamanhos usados no Experimento $1 \mathrm{~b}$, isto é, $1,5^{\circ}, 2,5^{\circ}$ e $3.5^{\circ}$ de ângulo visual de lado. As posições e distâncias dos estímulos foram as mesmas usadas no Experimento $1 \mathrm{~b}$. 


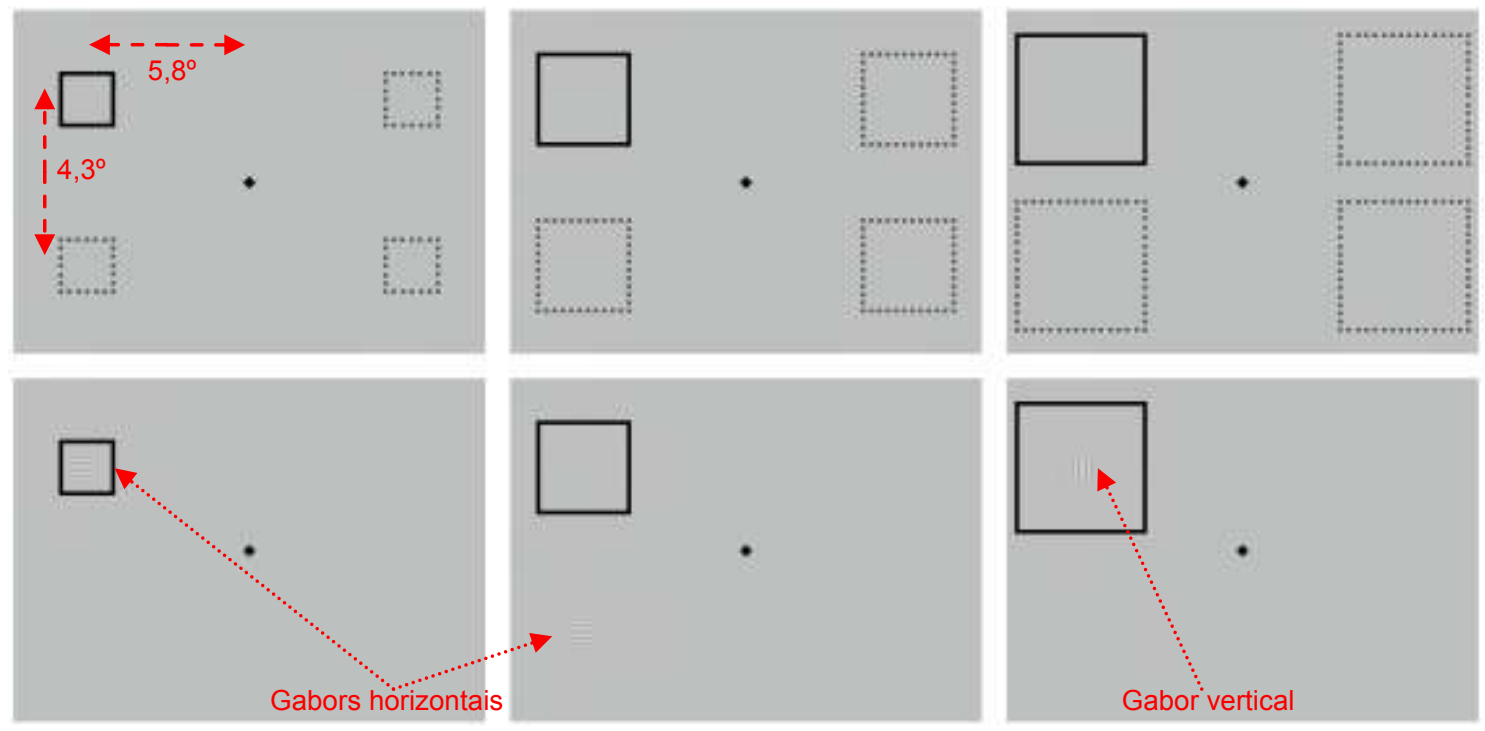

Figura 8. Distâncias e representações dos estímulos usados nos Experimentos 2a, 2b e 2c. As distâncias e localizações dos estímulos foram as mesmas usadas nos experimentos anteriores. Os quadrados pontilhados representam as possíveis localizações em que os estímulos foram apresentados (três quadrantes superiores). Dois Gabors (horizontal ou vertical) foram usados como alvos (três quadrantes inferiores). Nos três quadrantes inferiores é possível visualizar duas provas de dica válida (primeiro e terceiro exemplos da esquerda para a direita) e uma inválida (exemplo do meio). Os estímulos não estão em escala.

\section{$\underline{\text { Procedimento }}$}

Experimento 2a: Tarefa de tempo de reação manual

A TRM consistiu em pressionar com o dedo indicador o botão de um controle (Microsoft Sidewinder Game Pad), o mais rápido possível I, assim que o alvo fosse detectado. Em cada bloco de provas o alvo foi apresentado dentro da dica em $70 \%$ das provas (168 provas de dica válida) ou do mesmo lado da dica, mas fora dela, à distância de $4,1^{\circ}$ de ângulo visual do seu centro geométrico em $10 \%$ das provas (24 provas de dica inválida). Em 10\% das provas a dica não foi apresentada e o alvo foi mostrado em uma das quatro posições de apresentação dos estímulos (24 provas sem dica). Nestas provas o intervalo de tempo entre o começo da prova e a apresentação do alvo foi o mesmo usado com os outros tipos de provas. Nos outros $10 \%$ das provas o alvo não foi apresentado após a exposição da dica (24 provas sem alvo). O participante foi instruído a não realizar a resposta nas provas sem alvo, pois a sua resposta seria considera um erro. Também recebeu instruções 
para manter o seu olhar sobre o ponto de fixação durante cada prova. Caso o participante realizasse um movimento ocular de sacada de amplitude maior do que $1,5^{\circ}$ de ângulo visual em qualquer direção a partir do ponto de fixação, a prova era finalizada juntamente com um ruído informando que um erro havia sido cometido. Caso o alvo não fosse apresentado o participante deveria manter o olhar sobre o ponto de fixação e após 1500 ms a prova era encerrada e o participante podia mover ou fechar os olhos para descansar antes de iniciar a prova seguinte.

A sessão experimental foi composta por três blocos. O primeiro bloco foi composto por 30 provas de treinamento e os outros dois blocos por 240 provas-teste cada. O participante poderia fazer um breve intervalo para descanso entre os blocos. Cada bloco começou com a calibração do sistema de monitoramento dos olhos. Para calibrar o sistema, o participante foi solicitado a fixar um ponto padronizado, apresentado em uma grade de $3 \times 3$ posições. Após esse procedimento, 0 participante foi solicitado a fixar o olhar sobre um ponto padronizado, apresentado no centro da tela para a correção de pequenos movimentos da cabeça e dos olhos, antes de começar cada prova. Em seguida, ele/ela deveria pressionar um botão do controle. Caso a posição dos olhos não estivesse alinhada e centralizada sobre este estímulo apresentado no centro da tela, a prova não era iniciada. Além disso, uma nova calibração era realizada caso o sistema de monitoramento dos olhos não encontrasse a reflexão da pupila ou ocorresse qualquer problema de captura das coordenadas da posição dos olhos. Após pressionar o botão do controle, o ponto de fixação foi apresentado e em seguida, 1500 ms depois, a moldura foi apresentada. O alvo foi apresentado $100 \mathrm{~ms}$ depois da moldura e todos os estímulos permaneceram na tela até que o participante realizasse a resposta. 
A orientação do alvo (horizontal ou vertical), a localização do alvo e da moldura (4 posições), o tamanho da moldura $\left(1,5^{\circ}, 2,5^{\circ}\right.$ e $\left.3,5^{\circ}\right)$ e o tipo de prova (válida, inválida, sem dica, sem alvo), foram apresentados aleatoriamente dentro de cada bloco.

Experimento 2b: Tarefa de tempo de reação de sacada dos olhos

O procedimento foi igual ao procedimento do Experimento 2a com a exceção da tarefa do participante que foi realizar um movimento ocular de sacada sobre o alvo. O participante foi instruído o olhar para o estímulo de fixação e mover os olhos o mais rápido que pudesse sobre o alvo quando o alvo fosse detectado. Nas provas sem alvo o participante deveria manter o olhar sobre o ponto de fixação e após 1500 ms a prova foi encerrada.

Experimento 2c: Tarefa de julgamento de ordem temporal

A tarefa e os detalhes do procedimento foram os mesmos usados no Experimento 1a. As principais diferenças foram: (1) o controle de fixação dos olhos, que seguiu o mesmo procedimento de controle descrito no Experimento 2a; (2) a apresentação do Gabor horizontal e vertical como alvos ao invés das letras "F" e "J";

e (3) o uso de apenas quatro IEE para diminuir a quantidade de provas. Os valores do IEE foram 10, 30, 70 e $200 \mathrm{~ms}$, sendo semelhantes aos valores usados nos Experimentos $1 \mathrm{a}$ e $1 \mathrm{~b}$.

\section{Resultados}

Experimento 2a: Tarefa de tempo de reação manual

O TRM das respostas dos participantes foi calculado por meio da diferença entre o tempo que indicou o início da apresentação do alvo e o tempo em que o 
participante realizou a resposta manual. Os dados das provas de treinamento, os TRM's menores do que 150 ms (5\%) e TRM's maiores do que dois desvio padrão mais a média do TRM específico de cada condição experimental (1\%), foram excluídos de novas análises (Whelan, 2008). Os participantes cometeram erros em média em $28 \%$ das provas sem alvo. Erros de movimento ocular e piscadas durante a apresentação dos estímulos ocorreram em média em $7 \%$ do total de provas. Apenas o TRM de respostas consideradas corretas foi incluído nas análises principais.

A ANOVA $(p<0,05)$ de uma via do TRM médio para o fator tipo de prova (válida, inválida e sem dica) revelou um efeito estatisticamente significativo para estas condições $\left(F(2,12)=12,78 ; p<0,001\right.$, parcial $\left.\eta^{2}=0,68\right)$. Comparações pareadas (teste post hoc de Newman-Keuls, $\mathrm{p}<0,01)$ mostraram que o TRM médio (300 ms) das provas de dica válida foi 94 ms e 77 ms mais rápido, respectivamente, do que o TRM médio das provas sem dica (394 ms) e dica inválida (377 ms). Não existiu diferença entre o TRM das provas sem dica e dica inválida $(p=0,43)$. Os resultados podem ser vistos na Figura 9A.

Outra ANOVA $(p<0,05)$ de uma via do TRM médio das provas de dica válida para o fator tamanho da dica $\left(1,5^{\circ}, 2,5^{\circ}\right.$ e $\left.3,5^{\circ}\right)$ mostrou um efeito estatisticamente significativo para esse fator $\left(F(2,12)=10,26 ; p=0,003\right.$, parcial $\left.\eta^{2}=0,63\right)$. Comparações pareadas (teste post hoc de Newman-Keuls, $p<0,01$ ) revelaram que o TRM médio das provas de dica de tamanho $1,5^{\circ}(293 \mathrm{~ms})$ e $2,5^{\circ}(295 \mathrm{~ms})$ foi $18 \mathrm{~ms}$ e $16 \mathrm{~ms}$ mais rápido, respectivamente, do que o TRM médio das provas de dica de tamanho 3,5 (311 ms, Figura 9B). A Figura 9C mostra o TRM médio de cada participante em função do tamanho da dica válida, sendo possível verificar que o TRM dos participantes seguiu a mesma tendência de pequeno aumento para a dica maior, 
com a exceção do participante ASM, que apresentou um TRM mais lento em relação aos outros participantes e mais rápido para a dica maior do que em relação aos outros dois tamanhos de dica. Nós realizamos outra ANOVA $(p<0,05)$ para o TRM médio das provas de dica válida, porém, sem o TRM médio de ASM. O efeito estatisticamente significativo para o tamanho da dica foi maior $(F(2,10)=40,37$; $p<0,001$, parcial $\left.\eta^{2}=0,89\right)$ do que o encontrado na primeira análise e apresentou erros padrão da média bem menores (Figura 9D).

A

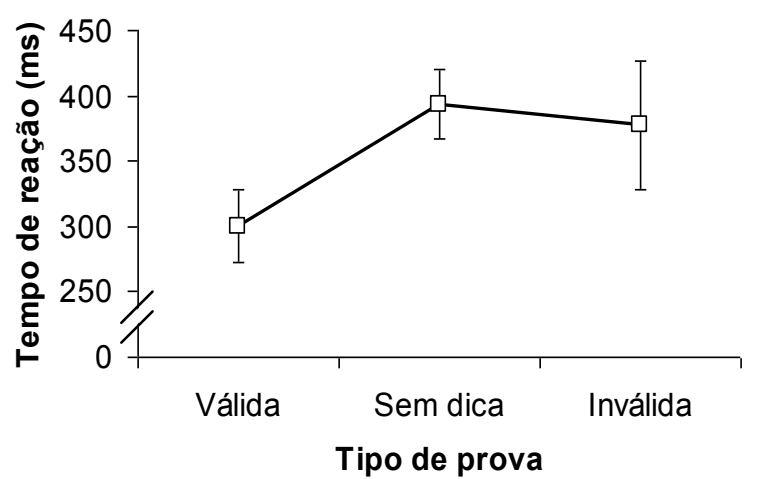

C

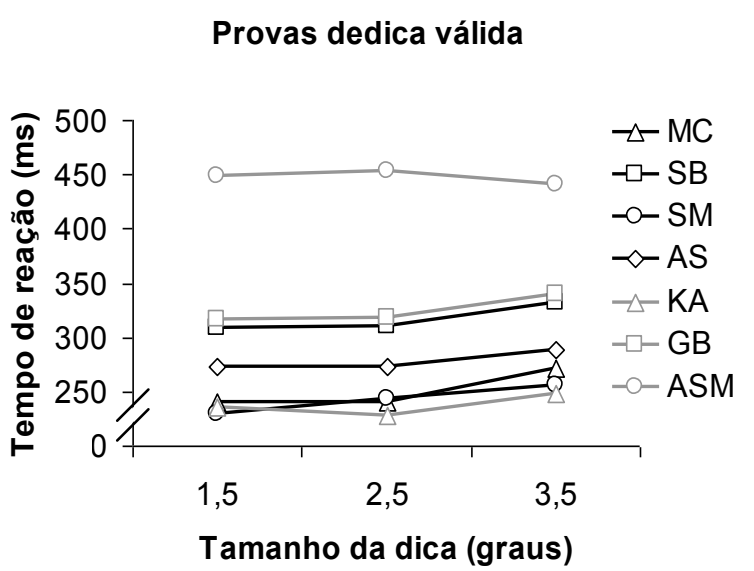

B

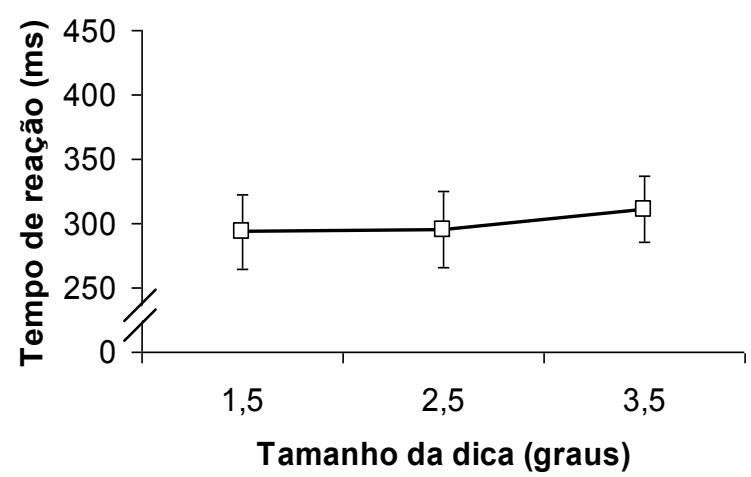

D

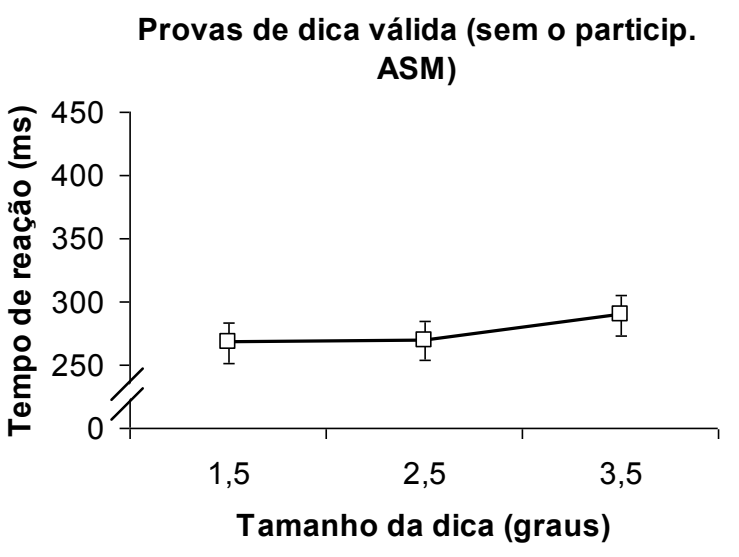

Figura 9. Tempo de reação (TR) de respostas manuais do Experimento 2a. (A) O TR médio é mostrado em função do tipo de prova (dica válida, sem dica e dica inválida); (B) em função do tamanho da dica das provas de dica válida para todos os participantes; (D) e sem o participante ASM. (C) O TR de cada participante também foi analisado individualmente em função do tamanho da dica válida. 
O TRM das respostas erradas das provas sem alvo também foi analisado devido à grande quantidade erros encontrado. A ANOVA $(p<0,05)$ de uma via para o fator tamanho da dica revelou uma diferença estatisticamente significativa entre o TRM das três condições $\left(F(2,12)=6,24 ; p=0,014\right.$, parcial $\left.\eta^{2}=0,51\right)$. Comparações pareadas (teste post hoc de Newman-Keuls, $p<0,05$ ) mostraram que o TRM médio da dica menor (244 ms) foi mais lento do que os outros dois tamanhos de dica (214 ms e $219 \mathrm{~ms}$, respectivamente).

Experimento 2b: Tarefa de tempo de reação de sacada dos olhos

O TRS foi calculado por meio da diferença entre o tempo de início da apresentação do alvo e o tempo em que o participante iniciou a sacada. Os dados das provas de treinamento, os TRS's menores do que $100 \mathrm{~ms}$ (10\%) e TRS's maiores do que dois desvios padrão mais a média do TRS específico de cada condição experimental (1\%), foram excluídos de novas análises. Os participantes cometeram erros em média em $14 \%$ das provas sem alvo. Erros de movimento ocular e piscadas durante a apresentação dos estímulos ocorreram em média em $8 \%$ do total de provas. Apenas os tempos de reação de respostas consideradas corretas foram incluídos nas análises principais.

A ANOVA $(p<0,05)$ de uma via do TRS médio para o fator tipo de prova (válida, inválida e sem dica) revelou um efeito estatisticamente significativo para esse fator $\left(F(2,12)=32,40 ; p<0,001\right.$, parcial $\left.\eta^{2}=0,84\right)$. Comparações pareadas (teste post hoc de Newman-Keuls, $p<0,001)$ mostraram que o TRS médio das provas de dica válida (228 ms) foi 110 e 88 ms mais rápido, do que o TRS médio das provas sem dica (338 ms) e dica inválida (316 ms), respectivamente. Não existiu diferença 
entre o TRS médio das provas de dica inválida e sem dica $(p=0,15)$. O TRS médio de cada tipo de prova pode ser visto na Figura $10 \mathrm{~A}$.

Outra ANOVA $(p<0,05)$ de uma via do TRS médio das provas de dica válida para o fator tamanho da dica $\left(1,5^{\circ}, 2,5^{\circ}\right.$ e $\left.3,5^{\circ}\right)$ mostrou um efeito estatisticamente significativo entre os três tamanhos de dica $\left(F(2,12)=8,79 ; p=0,005\right.$, parcial $\left.\eta^{2}=0,59\right)$. Comparações pareadas (teste post hoc de Newman-Keuls, $p<0,05$ ) revelaram que o TRS médio das provas de dica de tamanho $1,5^{\circ}(211 \mathrm{~ms})$ foi $19 \mathrm{~ms}$ e $32 \mathrm{~ms}$ mais rápido, do que o TRS médio das provas de dica de tamanho $2,5^{\circ}$ (230 ms) e $3,5^{\circ}$ (243 ms, Figura 10B), respectivamente. Na Figura 10C é possível visualizar o TRS médio de cada participante em função do tamanho da dica válida.

A

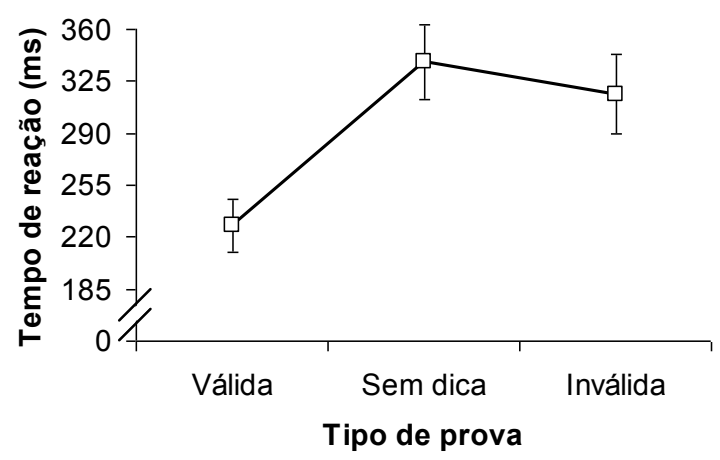

C

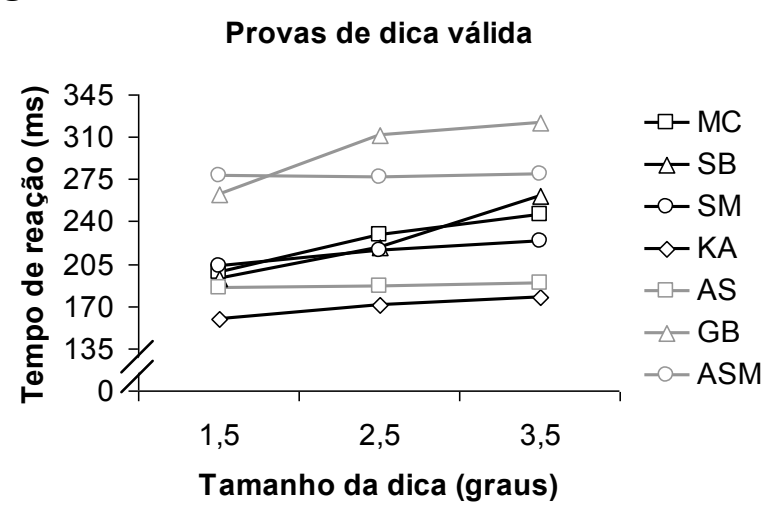

B

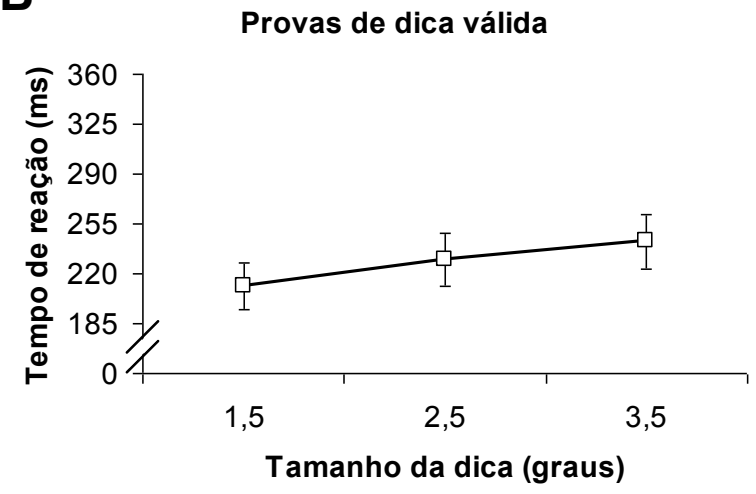

Figura 10. Tempo de reação (TR) de movimentos de sacada dos olhos do Experimento 2b. (A) TR médio em função do tipo de prova (dica válida, sem dica e dica inválida); (B) em função do tamanho da dica válida e (C) o TR médio de cada participante. 
Devido ao grande número de erros (14\%), o TRS das respostas erradas das provas sem alvo foi submetido a uma ANOVA $(p<0,05)$ de uma via para o fator tamanho da dica e mostrou que não existiu diferença estatisticamente significativa entre os três tamanhos de dica $(F(2,12)=2,71 ; p=0,12)$.

Experimento 2c: Tarefa de julgamento de ordem temporal

Apenas cinco dos sete participantes realizaram este experimento e destes cinco, apenas um participante, o autor MC, apresentou julgamentos de ordem temporal que fossem mais condizentes com a ordem real de apresentação dos estímulos em todas as condições. Devido a isto, o PSS destes participantes não foi calculado para as condições dentro e fora da dica de tamanhos diferentes, pois o ajustamento da função aos dados empíricos de cada condição não chegou a atingir os $50 \%$ de respostas na maioria das condições de cada participante. A única condição em que os participantes tiveram um desempenho melhor foi a condição sem dica. O PSS médio desta condição foi de $14 \mathrm{~ms}$ e pode ser visualizado com a distribuição média dos dados empíricos de todos os participantes e respectivos ajustamentos da função para cada condição na Figura 11. 


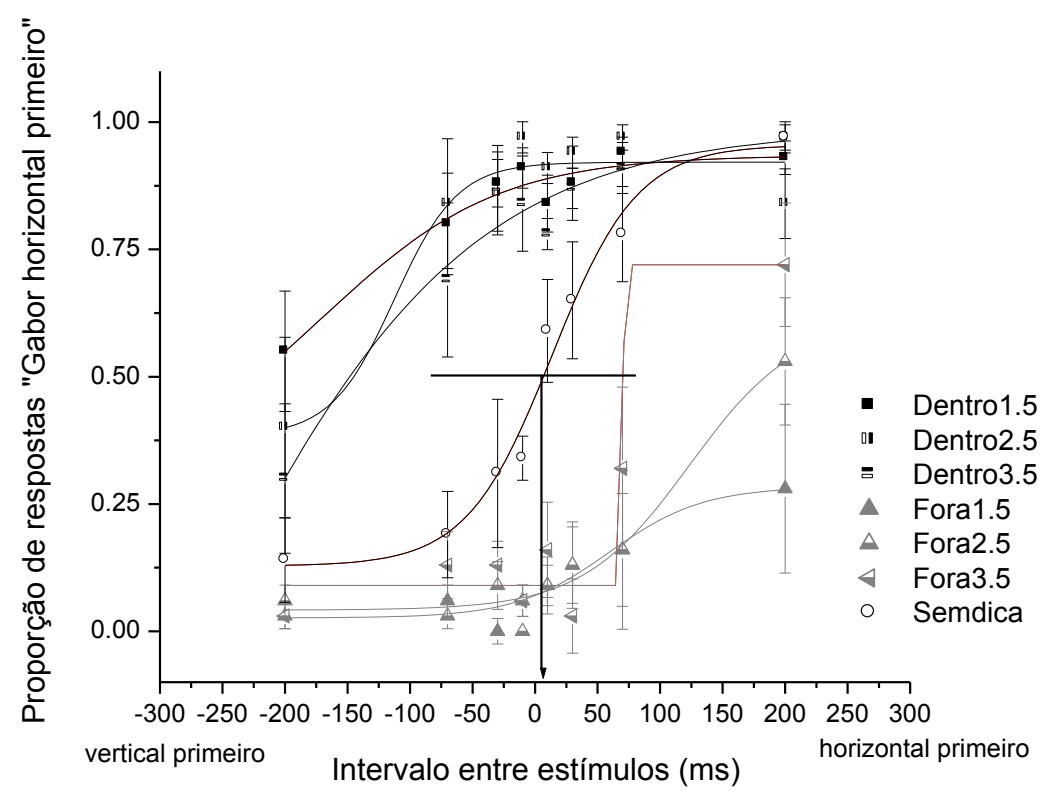

Figura 11. Dados empíricos de todos os participantes e ajustamento da função de Boltzmann para as condições: dentro (quadrados) e fora (triângulos) dos respectivos tamanhos de moldura. A condição sem dica (círculos) é a que apresentou melhor ajuste da função aos dados empíricos. A seta vertical indica o ponto de simultaneidade subjetiva da condição sem dica.

\section{Discussão}

Experimento 2a: Tarefa de tempo de reação manual

Os resultados mostraram que os participantes foram mais rápidos nas provas de dica válida do que nas provas sem dica e dica inválida. Este resultado já era esperado e corrobora com os resultados de estudos que utilizaram o paradigma de dicas espaciais associado ao monitoramento dos olhos para investigar a orientação encoberta da atenção visual (Jonides, 1981; Posner \& Cohen, 1984; Posner et al. 1980; Wright \& Ward, 1998). Esse efeito encontrado com um intervalo de exposição da dica de $100 \mathrm{~ms}$, sugere que o efeito foi causado pela orientação automática da atenção para o local indicado.

A análise das provas de dica válida mostrou que a manipulação do tamanho da dica afetou o desempenho dos participantes. Os participantes foram em média 17 
ms mais rápidos quando o alvo foi apresentado dentro da dica menor e média do que quando o alvo apareceu dentro da dica maior. Apesar de o aumento do TRM ter ocorrido apenas para o tamanho de dica maior, os resultados vão ao encontro de resultados que mostraram um aumento do TRM conforme o aumento do tamanho da dica em experimentos que não usaram estímulos que competem por recursos de atenção (Benso et al. 1998; Castiello \& Umiltà, 1990, 1992; Maringelli \& Umiltà, 1998; Mizuno et al. 1998; Turatto et al. 2000). É importante notar que este aumento ocorreu com um intervalo de exposição de dica de 100 ms, portanto, menor do que o intervalo usado por Castiello e Umiltà (1990). Isto sugere que mesmo em intervalos de tempo curtos já é possível obter certo ajustamento do foco de atenção ao tamanho de objetos apresentados na periferia do campo visual quando uma tarefa de TRM de detecção simples é solicitada.

No entanto, a porcentagem alta de erros encontradas nas provas sem dica põe em dúvida a confiabilidade desses resultados. Porém, a análise do TRM das respostas erradas sugere que a diferença entre os três tamanhos da moldura não foi causada por uma troca de precisão por velocidade, ou seja, os participantes não sacrificaram a precisão por respostas mais rápidas.

Experimento 2b: Tarefa de tempo de reação de movimento de sacada dos olhos

Assim como no Experimento 2a, os resultados do Experimento $2 \mathrm{~b}$ revelaram uma vantagem em desempenho para o alvo apresentado nos locais indicados em relação às provas em que o alvo apareceu fora da dica periférica.

Os resultados revelaram também que o TRS aumentou de maneira gradual conforme o aumento do tamanho da dica com um tempo de exposição da dica de 100 ms. Isso é interessante porque não existe relato na literatura de que a latência 
do movimento de sacada dos olhos possa ser alterada pela manipulação do tamanho de uma dica. Além disso, o aumento do TRS foi mais gradual do que o TRM obtido no Experimento 2a. Embora essa diferença seja pequena, ela pode ser verificada no tamanho dos efeitos das análises estatísticas encontrados em cada experimento para o tamanho da dica e quando as Figuras 9B e 10B são comparadas.

Os resultados também mostraram uma porcentagem alta de erros, sem existir diferenças estatisticamente significativas entre o TRS dessas respostas erradas em função do tamanho da dica, sugerindo que a diferença em desempenho entre os três tamanhos da dica não foi causada pela tentativa de responder mais rápido nas provas de dica menor.

\section{Experimento 2c: Tarefa de julgamento de ordem temporal}

Os resultados desse experimento mostraram que não foi possível calcular o PSS para cada tamanho da dica das condições dentro e fora. O IEE usado provavelmente foi a razão para isso ter ocorrido, pois a proporção de respostas em função do IEE das condições dentro e fora da moldura (Figura 11), mostraram que os participantes tiveram dificuldade em julgar qual estímulo foi apresentado primeiro quando a moldura foi apresentada. Embora em menor quantidade, isso também ocorreu para o intervalo maior (200 ms) entre o primeiro e o segundo Gabor, indicando que este intervalo não foi suficiente para reverter o efeito produzido pela moldura. Isso chama a atenção porque 200 ms foi também o tempo máximo entre as duas letras ("F" e "J") usadas nos Experimentos 1a e 1b, revelando-se suficiente para que os participantes percebessem a ordem temporal real entre as duas letras nas condições dentro e fora. 
Essa diferença pode estar relacionada ao tipo de alvo usado. As letras são estímulos de alta freqüência espacial, com bordas bem definidas, portanto, facilmente reconhecidas e levando menos tempo para serem comparadas. Por outro lado, Gabors são estímulos de freqüência espacial baixa, precisando, talvez, de mais tempo para serem comparados e julgados. Como resultado, nas provas em que a moldura foi apresentada, os participantes ficaram mais incertos sobre a ordem em que os estímulos foram apresentados, mesmo quando o IEE aumentou. Nas provas em que a moldura não foi apresentada (condição sem dica - Figura 11), os participantes julgaram a ordem em que os Gabors foram apresentados de forma mais condizente com a ordem real de apresentação dos estímulos, mesmo quando o intervalo temporal entre eles foi pequeno. A condição sem moldura indica que aumentar o IEE pode diminuir a incerteza dos participantes quando a moldura for apresentada.

\subsection{Experimentos $3 a, 3 b$ e $3 c-$ Ajuste do tamanho do foco}

Os resultados dos Experimentos $2 a$ e $2 b$ sugerem que os recursos de atenção foram orientados e focalizados na região indicada com um tempo curto de exposição da dica (100 ms), porém o efeito do tamanho da dica foi mais nítido e gradual quando as respostas foram realizadas com o movimento de sacada dos olhos para o alvo do que quando a resposta foi manual. Como os resultados de Castielo e Umiltà (1990) revelaram um efeito do tamanho da dica apenas quando o intervalo entre dica e alvo foi de 500 ms e a tarefa foi de TRM, acredita-se que aumentar o tempo de exposição da dica fornecerá mais tempo para o processo de focalização, aumentando o efeito do tamanho da dica. Portanto, os Experimentos 3a 
e $3 b$ foram idênticos ao Experimento $2 a$ e $2 b$, respectivamente, com a exceção do tempo de exposição da dica antes do alvo, que foi de $500 \mathrm{~ms}$.

Além disso, o efeito do tamanho da dica foi novamente investigado com a tarefa de JOT devido à impossibilidade de calcular o PSS das condições dentro e fora no Experimento 2c. Desse modo, o IEE foi manipulado no Experimento 3c para que a incerteza dos participantes diminuísse nas condições em que a moldura foi apresentada.

\section{Método}

\section{$\underline{\text { Participantes }}$}

Oito estudantes (4 mulheres) da Universidade Concórdia participaram do Experimento 3a. Os participantes tinham idade média de 23 anos e não possuíam conhecimento prévio da proposta do estudo. Todos os participantes relataram ter visão normal ou usavam lentes para correção. Os mesmos estudantes também realizaram os Experimentos $3 b$ e $3 c$. Seis participantes realizaram os três experimentos em seqüência diferente e dois participantes repetiram uma das seqüências anteriores, escolhidas aleatoriamente. Cada sessão experimental durou aproximadamente 1 hora.

\section{Material e estímulos}

Foram usados o mesmo material e estímulos dos Experimentos 2a, $2 \mathrm{~b}$ e $2 \mathrm{c}$. 


\section{Procedimento}

Experimento 3a: Tarefa de tempo de reação manual

O procedimento foi igual ao procedimento do Experimento 2a com a exceção do tempo de exposição da dica que foi de 500 ms.

Experimento 3b: Tarefa de tempo de reação de movimento de sacada dos olhos

O procedimento foi igual ao procedimento do Experimento 2b. A única diferença foi o tempo de exposição da dica que foi de $500 \mathrm{~ms}$.

Experimento 3c: Tarefa de julgamento de ordem temporal

O procedimento foi igual ao procedimento do Experimento 2c com a exceção do IEE, que foi de 20, 90, 160 e 260 ms. Este IEE foi defino a partir de testes realizados no laboratório.

\section{Resultados}

Experimento 3a: Tarefa de tempo de reação manual

Os critérios para exclusão dos tempos de reação e o calculo do TRM foram os mesmos usados no Experimento 2a. Os participantes cometeram erros em média em $3,1 \%$ das provas sem alvo e os erros de movimento ocular e piscadas durante a apresentação dos estímulos ocorreram em média em 3,3\% do total de provas. Nas provas com alvo $1 \%$ das provas foram excluídas por apresentar TRM menor do que 150 ms e 1\% por apresentar TRM maior do que dois desvio padrão mais a média do TRM específico de cada condição experimental.

O teste ANOVA $(p<0,05)$ de uma via do TRM médio para o fator tipo de prova (válida, inválida e sem dica) revelou em efeito significativo para este fator $\left(F(2,14)=93,49 ; p<0,001\right.$, parcial $\left.\eta^{2}=0,93\right)$. Comparações pareadas (teste post hoc 
de Newman-Keuls, $p<0,001$ ) mostraram que o TRM médio das provas de dica válida (309 ms) foi 121 ms e 61 ms mais rápido, respectivamente, do que o TRM médio das provas sem dica (430 ms) e dica inválida (370 ms), e que as provas de dica inválida foram 60 ms mais rápidas do que as provas sem dica. Os resultados podem ser vistos na Figura 12A, juntamente com o erro padrão da média de cada condição.

Outra ANOVA $(p<0,05)$ de uma via do TRM médio das provas de dica válida para o fator tamanho da dica $\left(1,5^{\circ}, 2,5^{\circ}\right.$ e $\left.3,5^{\circ}\right)$ mostrou um efeito estatisticamente significativo para os três tamanhos da dica $\left(F(2,14)=9,02 ; p=0,003\right.$, parcial $\left.\eta^{2}=0,56\right)$. Comparações pareadas (teste post hoc de Newman-Keuls, $p<0,05$ ) mostrou uma tendência de o TRM médio das provas de dica de tamanho 1,50 (300 ms) ser $9 \mathrm{~ms}$ mais rápido do que o TRM médio das provas de dica de tamanho 2,50 (309 ms, $\mathrm{p}=0,06$ ), sendo $19 \mathrm{~ms}$ mais rápido do que o TRM das provas de dica de tamanho $3,5^{\circ}$ (319 ms, $\left.p=0,002\right)$. Já o TRM das provas de dica de tamanho $2,5^{\circ}$ foi $10 \mathrm{~ms}$ mais rápido do que o TRM da dica de tamanho $3,5^{\circ}(p=0,043$, Figura 12B).

O TRM das respostas erradas foi analisado (ANOVA, $p<0,05$ ) e nenhuma diferença estatisticamente significativa foi encontrada entre os três tamanhos de dica das provas sem alvo.

Uma análise secundária também foi realizada para comparar o efeito do tamanho da dica entre os Experimentos 2a e 3a. Uma ANOVA $(p<0,05)$ para as medidas repetidas do TRM de cada tamanho de dica válida entre grupos revelou que não existiu diferença estatisticamente significativa entre os dois grupos $(F(1,12)=3,68 ; p<0,079)$, um efeito estatisticamente significativo para o tamanho da dica $\left(F(2,24)=28,47 ; p<0,001\right.$, parcial $\left.\eta^{2}=0,70\right)$ e nenhuma interação $(F(2,24)=2,02$; $p=0,15)$. O TR de cada grupo em função do tamanho da dica válida é mostrado na Figura 12C. 
A

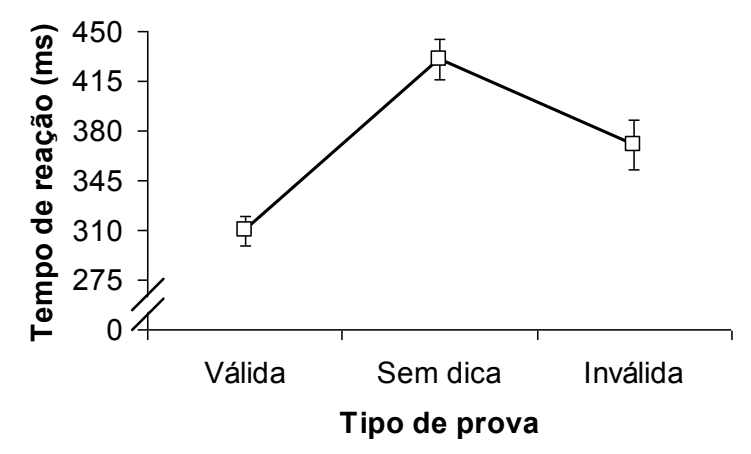

C

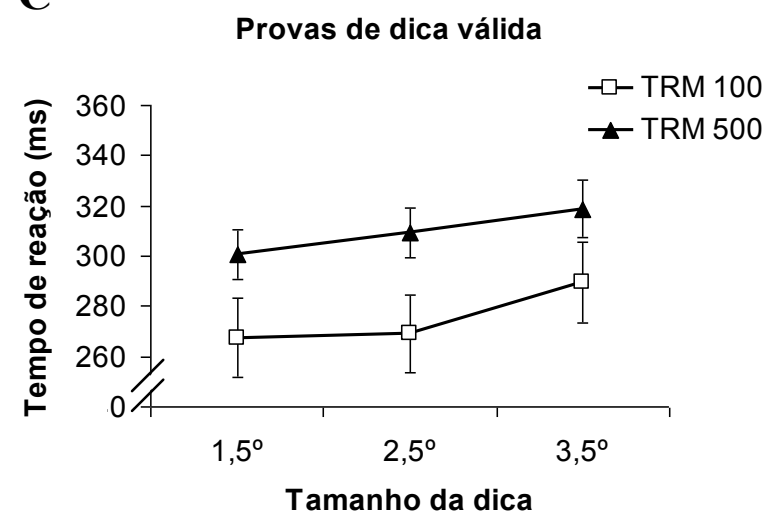

B

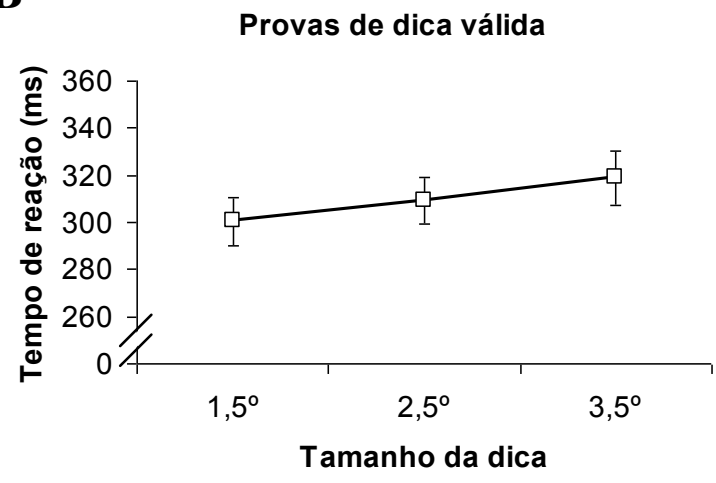

Figura 12. Tempo de reação de respostas manuais (TRM) do Experimento 3a. (A) O TRM médio das provas de dica válida, sem dica e inválida é mostrado com os seus respectivos erros padrão da estimativa. (B) O TRM médio das provas de dica válida foi reorganizado e analisado em função do tamanho da dica. (C) TRM médio da tarefa de tempo de reação manual com a dica exposta por 100 ms antes da apresentação do alvo obtido no Experimento 2a (TRM 100) e com a dica exposta por $500 \mathrm{~ms}$ obtido no Experimento 3a (TRM 500) em função do tamanho da dica.

Experimento 3b: Tarefa de tempo de reação de movimento de sacada dos olhos

Os critérios para exclusão dos tempos de reação e o calculo do TRS foram os mesmos usados no Experimento $2 \mathrm{~b}$. Os participantes cometeram erros em média em $4 \%$ das provas sem alvo e os erros de movimento ocular e piscadas durante a apresentação dos estímulos ocorreram em média em $17 \%$ das provas. Nas provas com alvo menos de $1 \%$ foram excluídas devido a TRM menor do que $150 \mathrm{~ms}$ e $1 \%$ por apresentar TRM maior do que dois desvio padrão mais a média do TRM específico de cada condição experimental. 
A ANOVA $(p<0,05)$ de uma via do TRS médio para o fator tipo de prova (válida, inválida e sem dica) revelou um efeito significativo para este fator $\left(F(2,14)=70,58 ; p<0,001\right.$, parcial $\left.\eta^{2}=0,91\right)$. Comparações pareadas (teste post hoc de Newman-Keuls, $p<0,001)$ mostraram que o TRS médio das provas de dica válida (254 ms) foi 137 e 70 ms mais rápido, do que o TRS médio das provas sem dica (392 ms) e dica inválida (324 ms), respectivamente, e que o TRS das provas de dica inválida foi 68 ms mais rápido do que o TRS das provas sem dica. Os resultados podem ser vistos na Figura $13 \mathrm{~A}$.

A

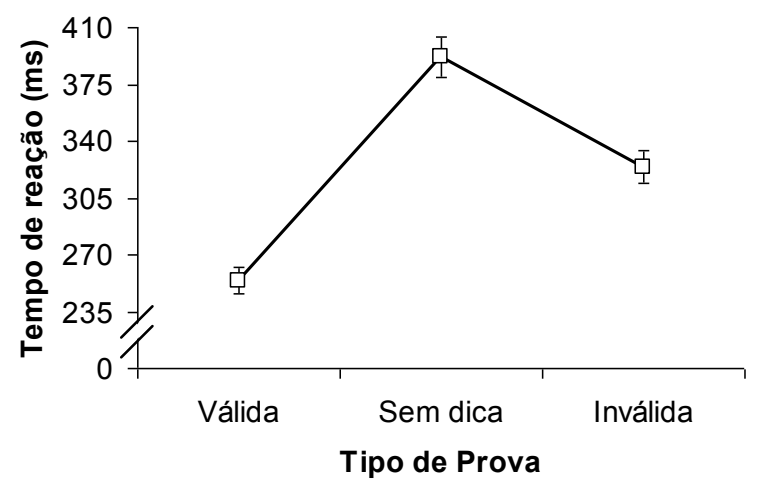

C

Provas de dica válida

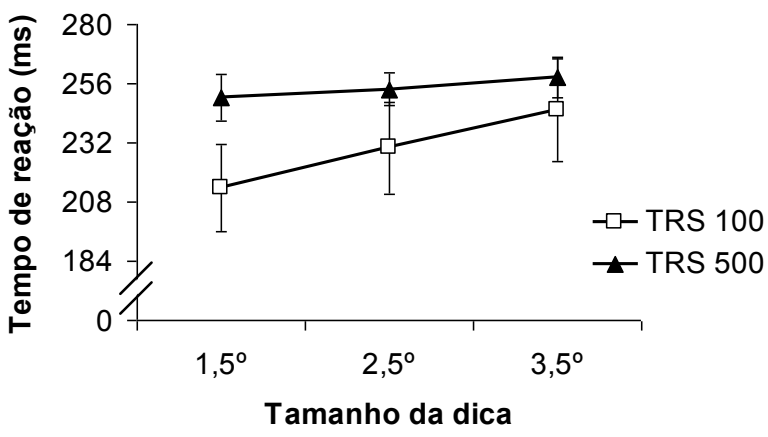

B Provas de dica válida

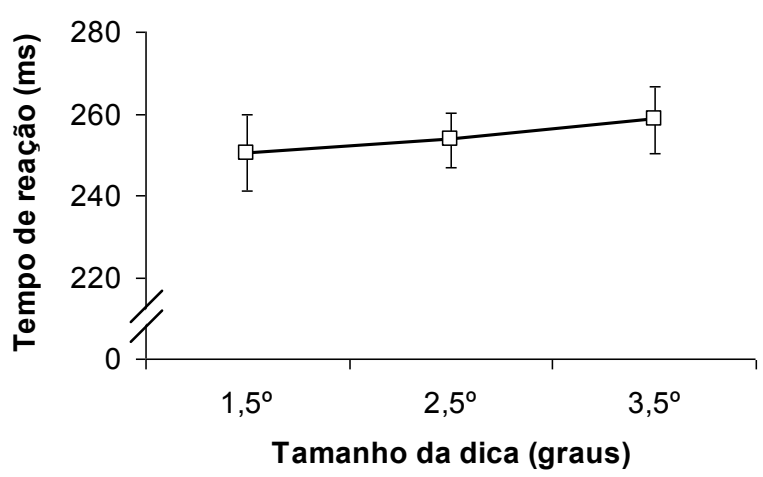

Figura 13. Tempo de reação (TR) de movimentos de sacada dos olhos do Experimento 3b. (A) TR médio em função do tipo de prova (dica válida, sem dica e dica inválida) e (B) em função dos três tamanhos de dica válida. (C) TR da tarefa de sacada dos olhos com a dica exposta por $100 \mathrm{~ms}$ antes da apresentação do alvo obtido no Experimento 2b (TRS 100) e com a dica exposta por $500 \mathrm{~ms}$ obtido no Experimento 3b (TRS 500) em função do tamanho da dica. 
Outra ANOVA $(p<0,05)$ de uma via do TRS médio das provas de dica válida para o fator tamanho da dica $\left(1,5^{\circ}, 2,5^{\circ}\right.$ e $\left.3,5^{\circ}\right)$ revelou que nenhum efeito estatisticamente significativo foi encontrado para o tamanho da dica $(F(2,14)=2,32$; $p=0,134)$. A Figura 13B mostra os TRS das provas de dica válida em relação aos tamanhos da dica $\left(1,5^{\circ}=250 \mathrm{~ms} ; 2,5^{\circ}=254 \mathrm{~ms}\right.$ e $\left.3,5^{\circ}=258 \mathrm{~ms}\right)$.

Outra análise comparou o efeito do tamanho da dica entre os Experimentos $2 b$ e $3 b$. Uma ANOVA $(p<0,05)$ para as medidas repetidas do TRS das provas de dica válida de cada tamanho de dica, considerando cada experimento como grupos independentes revelou que não existiu diferença estatisticamente significativa entre os dois grupos (Experimento $2 b=230 \mathrm{~ms}$, Experimento $3 b=254 \mathrm{~ms}, \mathrm{~F}(1,13)=1,63$; $p=0,23)$, um efeito estatisticamente significativo para o tamanho da dica $\left(F(2,26)=12,68 ; \quad p<0,001\right.$, parcial $\left.\eta^{2}=0,49\right)$ e uma interação estatisticamente significativa entre os dois fatores $\left(F(2,26)=4,47 ; p=0,021\right.$, parcial $\left.\eta^{2}=0,26\right)$. Comparações pareadas (teste post hoc de Newman-Keuls, $p<0,05$ ) mostraram que o aumento do tamanho da dica exposta por $100 \mathrm{~ms}$ no Experimento 2b produziu um aumento gradual do TRS médio de cada tamanho da dica $\left(1,5^{\circ}=214 \mathrm{~ms}, 2,5^{\circ}=230\right.$ $\mathrm{ms}$ e $3,5^{\circ}=245 \mathrm{~ms}$ ) enquanto que a mesma diferença não foi encontrada quando a dica foi exposta por 500 ms no Experimento 3b $(250$ ms, 254 ms e 258 ms, respectivamente). O TRS de cada grupo em função do tamanho da dica válida é mostrado na Figura 12C.

\section{Experimento 3c: Tarefa de julgamento de ordem temporal}

Provas de treinamento não foram analisadas e os erros de movimento ocular e piscadas durante a apresentação dos estímulos ocorreram em média em 3\% das provas.

O ajuste da função de Boltzmann aos dados empíricos de cada participante para cada condição pode ser visualizado na Figura 14A. Os intervalos entre estímulos negativos mostram quando o Gabor vertical foi apresentado primeiro e os 
valores positivos quando o Gabor horizontal foi apresentado primeiro. As setas verticais indicam o intervalo de tempo corresponde aos $50 \%$ de respostas "Gabor horizontal primeiro", isto é, indicam o ponto de maior incerteza do participante sobre a ordem temporal de apresentação dos estímulos. O PSS de cada condição experimental foi submetido a um teste ANOVA $(p<0,05)$ para medidas repetidas.

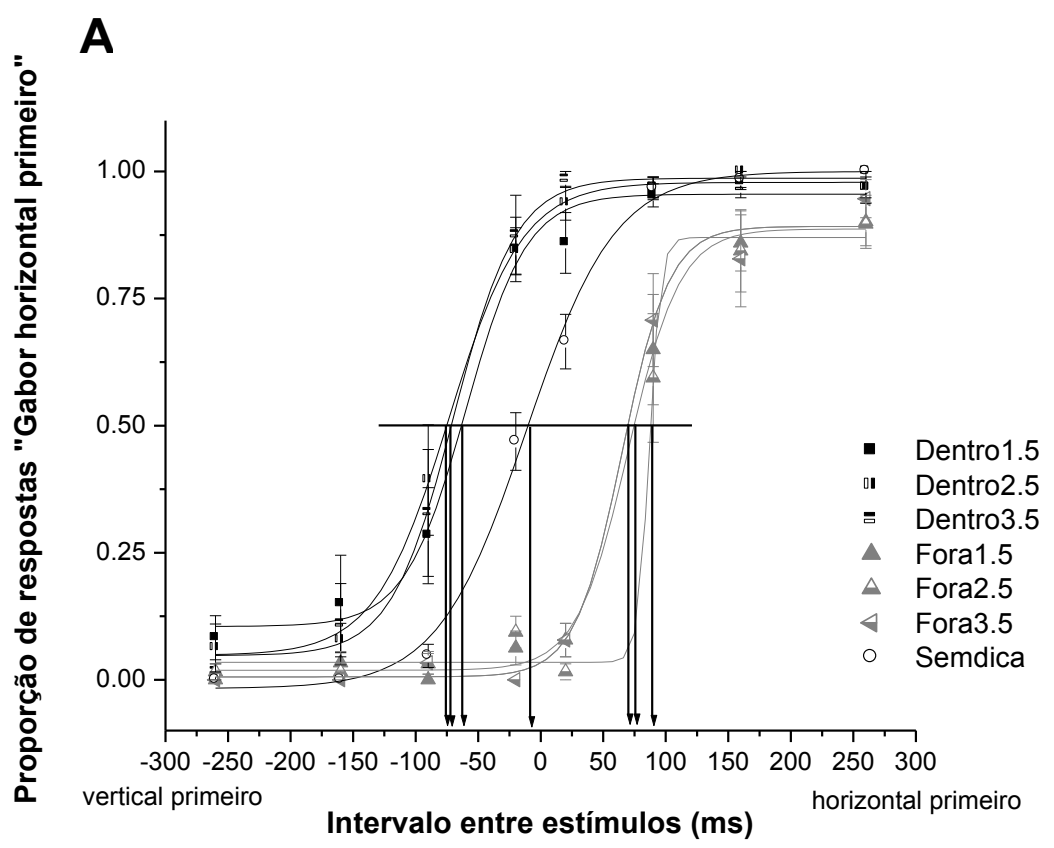

B

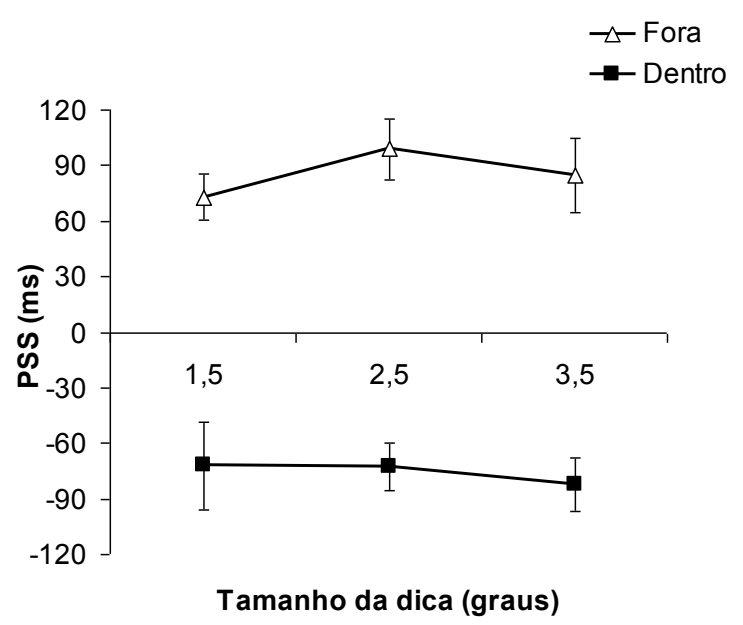

Figura 14. (A) Média dos dados empíricos de todos os participantes e ajustamento da função de Boltzmann para as condições dentro (quadrados) e fora (triângulos) e respectivos tamanhos de dica, assim como para a condição sem dica (círculos). As setas verticais indicam os pontos de simultaneidade subjetiva (PSS) de cada condição. (B) O PSS médio é mostrado em função do tamanho da dica usada para as condições fora e dentro da moldura. As barras verticais representam os respectivos erros padrão da estimativa. 
A ANOVA do PSS para os dois fatores, posição da primeira letra (dentro, fora) e tamanho da moldura $\left(1,5^{\circ}, 2,5^{\circ}\right.$ e $\left.5,5^{\circ}\right)$ revelou um efeito estatisticamente significativo para a posição (dentro $-76 m s$, fora $+86 m s, F(1,7)=32,37$; $p<0,001$, parcial $\eta^{2}=0,82$ ), nenhum efeito para o tamanho da moldura (respectivamente, $0 \mathrm{~ms}$, +13ms e $+1 \mathrm{~ms}, F(2,14)=1,09 ; p=0,363)$, e nenhuma interação. O PSS médio de todos os participantes das condições dentro e fora da moldura em função do tamanho da dica pode ser visualizado na Figura 14B.

Outra análise de variância para a FP mostrou que não existiu diferença entre a vantagem temporal dos três tamanhos de moldura $\left(1,5^{\circ}=72 \mathrm{~ms}, 2,5^{\circ}=86 \mathrm{~ms}\right.$ e $\left.3,5^{\circ}=84 \mathrm{~ms}, \mathrm{~F}(2,14)=0,85 ; \mathrm{p}<0,449\right)$. A FP média encontrada foi de $81 \mathrm{~ms}$.

\section{Discussão}

Experimento 3a: Tarefa de tempo de reação manual

As análises mostraram que o aumento do tempo de exposição da dica produziu um aumento gradual do TRM conforme o aumento do tamanho da dica. Embora a análise comparando os resultados do Experimento 2a e 3a não tenha relevado um efeito estatisticamente significativo entre os dois grupos, o aumento gradual do TRM em função do aumento do tamanho da dica foi mais gradual e evidente no Experimento 3a. Essa diferença pode ser observada nas análises estatísticas realizadas em cada experimento para o tamanho da dica das provas válidas e na Figura 12C.

A diferença entre o TRM de dica válida, sem dica e inválida também ocorreu indicando que os recursos de atenção foram orientados para a dica, produzindo uma vantagem para o processamento da informação indicada. Além disso, as respostas 
erradas das provas sem alvo foram menores, sugerindo que o aumento do intervalo de tempo ajudou a obter um desempenho melhor.

Os resultados desse experimento reforçam a idéia de que o foco de atenção pode ser orientado para a área indicada e que o seu ajuste ao tamanho dessa área pode ocorrer quando a dica é exposta por mais tempo no campo visual. Apesar de os resultados não poderem ser considerados evidência de que existam dois processos, um de orientação e outro de focalização dos recursos de atenção (Turatto et al. 2000), os resultados sugerem que a manipulação temporal é importante para o ajuste do tamanho do foco quando a orientação é encoberta e a tarefa solicitada é uma tarefa de TRM de detecção simples de um alvo. Além disso, a porcentagem pequena de erros sugere que o intervalo maior de tempo entre dica e alvo ajudou a evitar respostas antecipadas.

Experimento 3b: Tarefa de tempo de reação de movimento de sacada dos olhos

O aumento do tempo de exposição da dica para 500 ms não produziu o efeito do tamanho da dica para este tipo de resposta, mas a diferença entre dica válida, inválida e sem dica, foi mantida. Esses resultados indicam que recursos de atenção foram orientados de maneira explícita para o local indicado, mas não reproduzem o efeito do tamanho da dica encontrado no Experimento 2b, quando a dica foi exposta por 100 ms. Embora tenha ocorrido um número grande de erros no Experimento 2b e não neste, o que torna esses resultados mais confiáveis, os resultados são intrigantes, porque ao contrário dos resultados obtidos com a tarefa de TRM, estes resultados revelam um efeito do tamanho da dica nítido em um intervalo curto de tempo entre a dica e o alvo e ausência de tal efeito quando o intervalo aumentou para 500 ms. Esses resultados sugerem que os efeitos obtidos com a orientação e a focalização da atenção podem ocorrer mais cedo quando a resposta de detecção do 
alvo é realizada com uma sacada dos olhos para o alvo do que com uma resposta manual. No entanto, novos experimentos com um número maior de participantes e uma quantidade de erro menor podem ajudar a responder essa questão.

Experimento 3c: Tarefa de julgamento de ordem temporal

Os resultados mostraram que o aumento do intervalo de tempo entre a apresentação dos dois alvos diminuiu a incerteza dos participantes. O ajustamento da função à média dos dados empíricos dos participantes, mostrado na Figura 14A, revela essa mudança quando comparado aos dados da Figura 11 obtidos no Experimento 2c. Isso parece confirma a hipótese inicial de que mais tempo seria necessário para o julgamento dos dois Gabors em comparação ao tempo necessário para o julgamento das duas letras quando a moldura foi apresentada.

Além disso, os resultados mostraram que a ausência do efeito do tamanho da dica para a tarefa de JOT não parece ser devido a um tipo específico de estímulo usado como alvo ou a algum movimento dos olhos para os estímulos enquanto a moldura e os alvos foram apresentados. As possíveis explicações para esses resultados, discutidas no Experimento $1 \mathrm{~b}$, pode ser tanto um reajuste do tamanho do foco para englobar uma área maior do campo visual, visto que um dos dois alvos foi apresentado dentro e o ouro fora da moldura, quanto uma dissociação entre tarefas de JOT e TR para o efeito do tamanho da dica. A primeira possibilidade pode ter ocorrido, embora não seja possível confirmá-la apenas com os resultados deste estudo, além de exigir um delineamento experimental muito bem planejado para testá-la, devido às características da tarefa de JOT. A segunda explicação também é possível, mas infelizmente, também não pode ser confirmada devido à maneira como os estímulos foram apresentados nos dois tipos de tarefas. Nas tarefas de TR ocorreu a apresentação de apenas um alvo após a dica, mas na tarefa de JOT dois 
alvos foram apresentados em seqüência após a dica. Isso pode ter interferido no ajuste do foco de atenção ao tamanho da moldura como alguns estudos têm revelado, usando diferentes tarefas (Greenwood et al., 1997; Greenwood \& Parasuraman, 1999; 2004; Yeshurun \& Carrasco, 2008). Mas a possibilidade de existir uma dissociação parece ser mais facilmente testada caso a tarefa de TR e a de JOT sejam solicitadas na mesma prova ou a configuração sensorial seja igual nas duas tarefas.

\subsection{Experimento 4 - Distribuição da atenção visual sobre regiões não adjacentes localizadas em lados opostos do campo visual}

Os Experimentos 1, 2 e 3 deste estudo mostraram que o TR foi sensível a manipulação do tamanho da dica enquanto o JOT não. Portanto, embora a tarefa de JOT tenha sido inicialmente escolhida para investigar a divisão do foco de atenção, as tarefas de TR parecem mais adequadas para explorar o ajuste do foco a duas áreas não adjacentes do campo visual. Assim, a tarefa de TRM foi usada no Experimento 4 e o tamanho de uma ou duas áreas indicadas foi manipulado. $\mathrm{A}$ tarefa de TRM foi escolhida ao invés da tarefa de TRS, por ser a mesma tarefa usada em outros experimentos que investigaram a divisão da atenção e o efeito do tamanho da dica (Castiello e Umiltà, 1992; McCormick et al., 1998). Além disso, os resultados são semelhantes aos encontrados com o mesmo intervalo de tempo de 500 ms entre a dica e o alvo nestes estudos.

Duas abordagens diferentes de distribuição espacial da atenção visual foram consideradas para explicar os resultados: Àquelas que prevêem um foco único de atenção e a proposta de divisão da atenção. De acordo com os modelos de foco 
único da atenção, quando duas dicas periféricas (e.g. molduras quadradas) são apresentadas ao mesmo tempo e de cada lado do campo visual, o foco de atenção seria capaz de se expandir como o zum de uma lente (Eriksen \& St. James, 1986), abrangendo as duas dicas e toda a área entre as duas dicas. Alvos apresentados dentro das dicas ou na área entre as duas dicas receberiam a mesma vantagem em desempenho por estarem dentro do mesmo foco (Heinze et al., 1994; McCormick et al., 1998; Pan \& Eriksen, 1993). A outra proposta sugere que o foco de atenção é capaz de se dividir e se ajustar a duas áreas separadas no campo visual (Awh \& Pashler, 2000; Bichot et al., 1999; Castiello \& Umiltà, 1992; Hahn \& Kramer, 1995, 1998; Kramer \& Hahn, 1995; Kraft et al. 2005; Müller \& Findlay, 1987; Müller et al., 2003; McMains \& Somers, 2004, 2005; Silva \& Ribeiro-do-Valle, 2008). O desempenho seria melhor apenas quando o alvo é apresentado dentro de uma das áreas indicadas, não existindo vantagem em desempenho quando o alvo é apresentado entre as localizações indicadas.

O presente estudo usou o mesmo paradigma de dicas usado nos estudos de Castiello e Umiltà (1992) e McCormick et al., (1998), apresentando uma ou duas dicas periféricas (molduras quadradas) simultaneamente, uma de cada lado do campo visual. O tamanho da(s) dica(s) foi manipulado para verificarmos se o TRM revelaria um ajuste do foco de atenção sobre a área indicada. Assim como em McCormick et al., (1998), o alvo foi apresentado dentro da dica (provas de dica válida) ou fora da dica (provas de dica inválida) e existiram provas com uma ou duas dicas. O TRM entre estas condições foi comparado e se a hipótese de um foco único estivesse correta, o TRM seria igual entre as provas válidas e inválidas com duas dicas e diferente entre as provas válidas e inválidas com apenas uma dica, mas se a hipótese de divisão do foco estivesse correta, o TRM seria diferente entre provas de 
dica válida e inválida com uma ou duas dicas, revelando um desempenho melhor (TRM menor) quando o alvo foi apresentado dentro de uma das duas regiões indicadas e um desempenho pior (TRM maior) quando apresentado entre as duas dicas.

A diferença entre esse experimento e os experimentos realizados por Castiello e Umiltà (1992) e McCormick et al., (1998) foram as localizações em que os estímulos foram expostos. Em Castiello e Umiltà (1992) os estímulos foram apresentados à direita ou à esquerda do centro do campo visual, a uma mesma excentricidade e alinhados com o meridiano horizontal, mas o alvo não foi apresentado entre as duas localizações indicadas e os resultados sugeriram a divisão do foco de atenção. McCormick et al., (1998) apresentaram o alvo entre as localizações indicadas, mas com uma excentricidade menor do que as localizações indicada e os resultados indicaram a existência de um foco único de atenção. Embora a menor excentricidade do alvo apresentado entre as dicas não pareça ser um problema no estudo de McCormick et al., pois eles comparam o desempenho entre provas com uma dica e duas dicas, mostrando que o TRM para detectar o alvo foi significativamente mais rápido quando o alvo apareceu entre duas dicas do que quando apareceu na mesma localização, mas entre uma dica e o estímulo de fixação, essa disposição dos estímulos foi evitada no presente estudo. Os estímulos foram apresentados sempre com a mesma excentricidade, incluindo a localização entre as duas áreas indicadas, mas não foram alinhados ao meridiano horizontal. Essa configuração foi usada para evitar qualquer benefício em TR para estímulos apresentados mais próximos ao centro do campo visual quando comparado com o TR para detectar os estímulos apresentados mais distantes (Masland, 2001; Palmer, 1999). 


\section{Método}

\section{$\underline{\text { Participantes }}$}

Onze estudantes (7 mulheres) da Universidade de Concórdia participaram de uma sessão experimental que durou aproximadamente 45 minutos. Os participantes tinham idade média de 23 anos e não possuíam conhecimento prévio da proposta do estudo. Todos os participantes relataram ter visão normal ou usavam lentes para correção.

\section{Material, estímulos}

O material e os estímulos foram os mesmos usados no Experimento 2a, mas foram realizadas mudanças quanto à localização dos estímulos e número de dicas apresentadas. As dicas poderiam aparecer em quatro localizações diferentes, duas acima e duas abaixo do estímulo de fixação e todas com a mesma excentricidade usada nos outros experimentos desse estudo ( $5,8^{\circ}$ de ângulo visual). No entanto, as localizações foram deslocadas $2,4^{\circ}$ de ângulo visual do meridiano horizontal (Figura 15, quadrante do meio superior). As duas molduras poderiam ser apresentadas simultaneamente e sempre em lados opostos do campo visual com distância entre elas de $5,7^{\circ}$ de ângulo visual. Os tamanhos das molduras foram os mesmos usados nos Experimentos 2 e 3. Apenas o Gabor de $90^{\circ}$ (horizontal) foi usado como alvo na tarefa de TRM. 

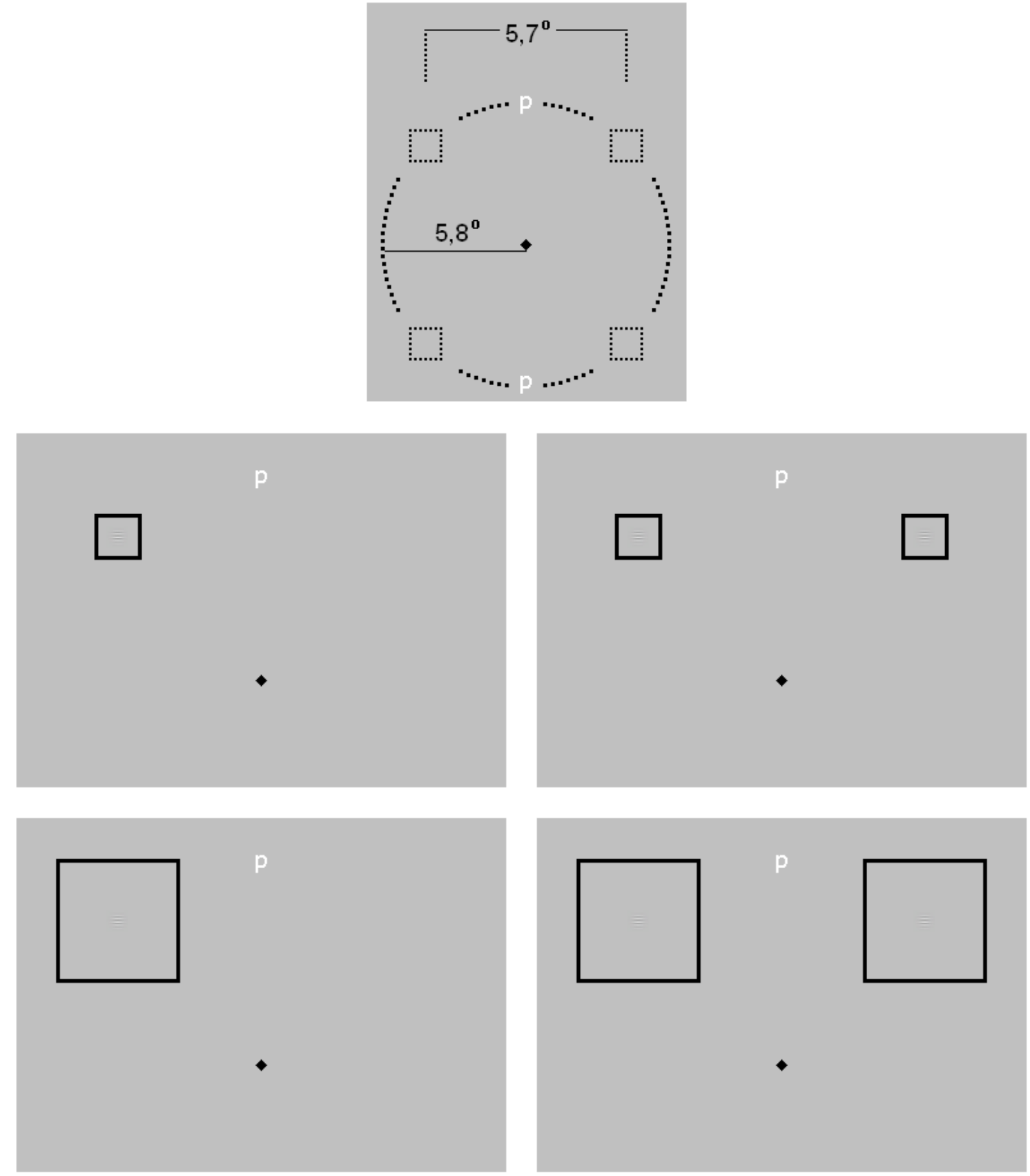

Figura 15. Distâncias e representações dos estímulos usados no Experimento 4. No centro e acima, os quadrados pontilhados representam as possíveis localizações onde a(s) dica(s) (moldura) e o alvo (Gabor) foram apresentados. Nas provas de dica inválida o alvo foi apresentado em uma localização fora da(s) dica(s) (letra "p" branca) acima ou abaixo do estímulo de fixação. Nas provas de dica válida o alvo foi apresentado dentro de uma dica (quadrantes da esquerda) ou dentro de uma de duas dicas apresentadas simultaneamente sempre em lados opostos do campo visual (quadrantes da direita). Os estímulos não estão em escala.

\section{Procedimento}

Em cada prova, a seqüência de apresentação dos estímulos e a tarefa solicitada foram as mesmas usadas no Experimento $3 a$, onde a resposta de 
detecção simples do alvo foi realizada pressionando com o dedo indicador da mão dominante um botão do controle usado nos Experimentos 2 e 3. A única diferença foi a quantidade de dicas usadas. Em metade das provas apenas uma dica foi apresentada enquanto que na outra metade duas dicas de tamanhos iguais foram expostas simultaneamente, acima ou abaixo do estímulo de fixação e sempre em lados opostos do campo visual. A Figura 15 revela as possíveis localizações em que os estímulos foram apresentados (primeiro quadrante) e mostra quatro exemplos com possíveis localizações de apresentação dos estímulos (quadrantes da esquerda e da direita). Em cada prova, o alvo (Gabor) poderia aparecer dentro de uma dica (Figura 15, esquerda) ou dentro de uma das duas dicas apresentadas (Figura 15 direita), ambas, provas de dicas válidas. As localizações em que o Gabor foi apresentado dentro da dica foram: canto superior esquerdo, direito, inferior esquerdo ou direito. O alvo poderia aparecer também em uma localização fora da dica, acima ou abaixo do estímulo de fixação, sendo consideradas provas de dica inválida. $\mathrm{Na}$ Figura 15 essa localização é representada pela letra "p", sendo a mesma nas provas com uma ou duas dicas.

A sessão experimental foi composta por seis blocos de provas e cada bloco começou com a calibração do sistema de monitoramento do olho, descrito anteriormente (procedimento do Experimento 2a). O primeiro bloco foi realizado para treinamento e continha 30 provas. Os outros cinco blocos foram compostos por 72 provas-teste cada, sendo 48 provas de dica válida, 12 provas de dica inválida e 12 provas sem alvo. Das 48 provas de dica válida, 24 provas foram apresentadas com uma dica e 24 com duas dicas. Cada tamanho de dica foi apresentado em 8 provas. As provas de dica inválida e falsa seguiram a mesma divisão de proporção de provas. Todas as condições experimentais foram aleatoriamente distribuídas dentro de cada bloco de provas. 


\section{Resultados}

Os critérios para calcular e excluir o TRM foram os mesmos descritos no Experimento 2a. Um participante foi excluído das análises principais por apresentar TRM 4 vezes o desvio padrão da média. Os participantes cometeram erros em média em $4 \%$ das provas sem alvo. $1 \%$ das provas com alvo foi excluído por apresentar TRM menor do que 150 ms e $2 \%$ por apresentar TRM maior do que dois desvio padrão mais a média do TRM específico de cada condição experimental. Erros de movimento ocular e piscadas durante a apresentação dos estímulos ocorreram em média em $5 \%$ do total de provas.

A ANOVA $(p<0,05)$ de duas vias do TRM médio das respostas corretas para os fatores tipo de prova (dica válida ou inválida) e número de dicas (uma ou duas), revelou um efeito estatisticamente significativo para o tipo de prova (válida $319 \mathrm{ms,}$ inválida $360 \mathrm{~ms}, \mathrm{~F}(1,9)=26,22 ; \mathrm{p}<0,001$, parcial $\left.\eta^{2}=0,74\right)$, nenhum efeito para o número (uma dica $337 \mathrm{~ms}$, duas dicas $342 \mathrm{~ms}, F(1,9)=1,60 ; p=0,24$ ) e nenhuma interação estatisticamente significativa entre os dois fatores $(F(1,9)=1,21 ; p=0,3)$. 0 TRM médio de cada condição pode ser visualizado na Figura 16A.

Outra ANOVA $(p<0,05)$ de duas vias para o TRM médio das provas de dica válida para os fatores número de dicas (uma ou duas) e tamanho da dica $\left(1,5^{\circ}, 2,5^{\circ}\right.$ e $\left.3,5^{\circ}\right)$ mostrou um efeito estatisticamente significativo para o número $(F(1,9)=9,57$; $p=0,013$, parcial $\left.\eta^{2}=0,52\right)$, revelando que o TRM das provas de dica válida com uma dica (313 ms) foram $11 \mathrm{~ms}$ mais rápido do que o TRM das provas de dica válida com duas dicas (325 ms), e uma tendência a ser estatisticamente significativo para o tamanho (323 ms, $316 \mathrm{~ms}, 318 \mathrm{~ms}$, respectivamente, $F(2,18)=3,16 ; p=0,067$ ), sem nenhuma interação entre os dois fatores $(F(2,18)=0,26 ; p=0,77)$. O teste post hoc de Newman-Keuls $(p<0,05)$ mostrou que existiu uma tendência de o TRM médio da dica 
menor ser 8 ms mais lento do que o TRM da dica média. O TRM médio das provas em que uma ou duas dicas foram apresentadas em função do seu tamanho pode ser visualizado na Figura 16B.

A

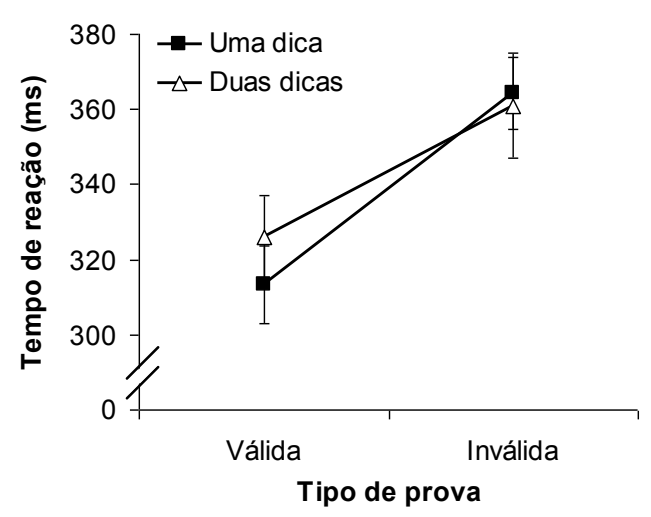

B

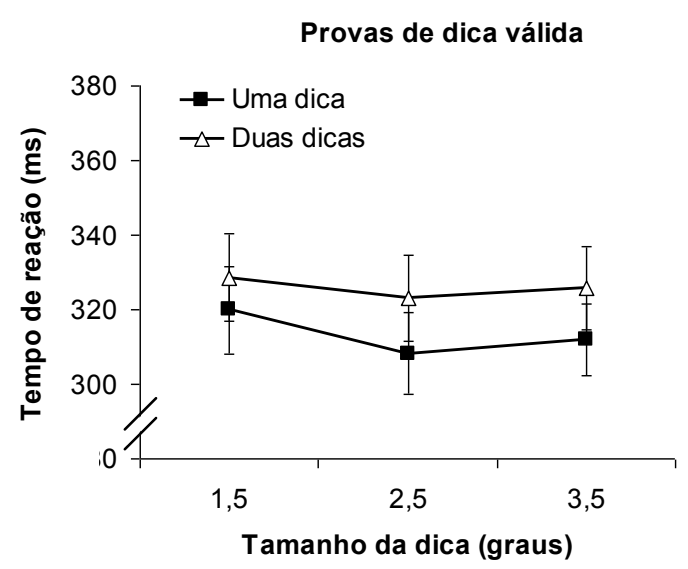

Figura 16. (A) Tempo de reação médio das provas de dica válida e inválida em função da quantidade de dicas apresentadas. (B) Tempo de reação médio das provas com uma ou duas dicas válidas em relação ao tamanho da dica.

Assim como em Castiello e Umiltà (1992), uma inspeção visual das doze distribuições do TRM das provas válidas com duas dicas, produzidas pela combinação da localização em que o alvo foi apresentado e o tamanho da dica, foi realizada para verificar a interpretação de que um foco único de atenção se deslocou para cada uma das localizações indicadas entre provas (Posner et al., 1980). Caso isso tenha ocorrido, Castiello e Umiltà (1992) argumentam que metade das provas válidas teriam tornado-se provas inválidas e a outra metade, provas válidas. Se isso ocorreu, verificaremos dois picos na distribuição do TRM, ou seja, um pico para as provas válidas e um pico para as provas inválidas. A inspeção visual das doze distribuições do TRM dessas condições sugere muito pouca evidência de que tenham existido duas modas nas provas de dicas válidas com duas dicas apresentadas acima (Figura 17) ou abaixo do centro do campo visual (Figura 18). 
Esquerda acima
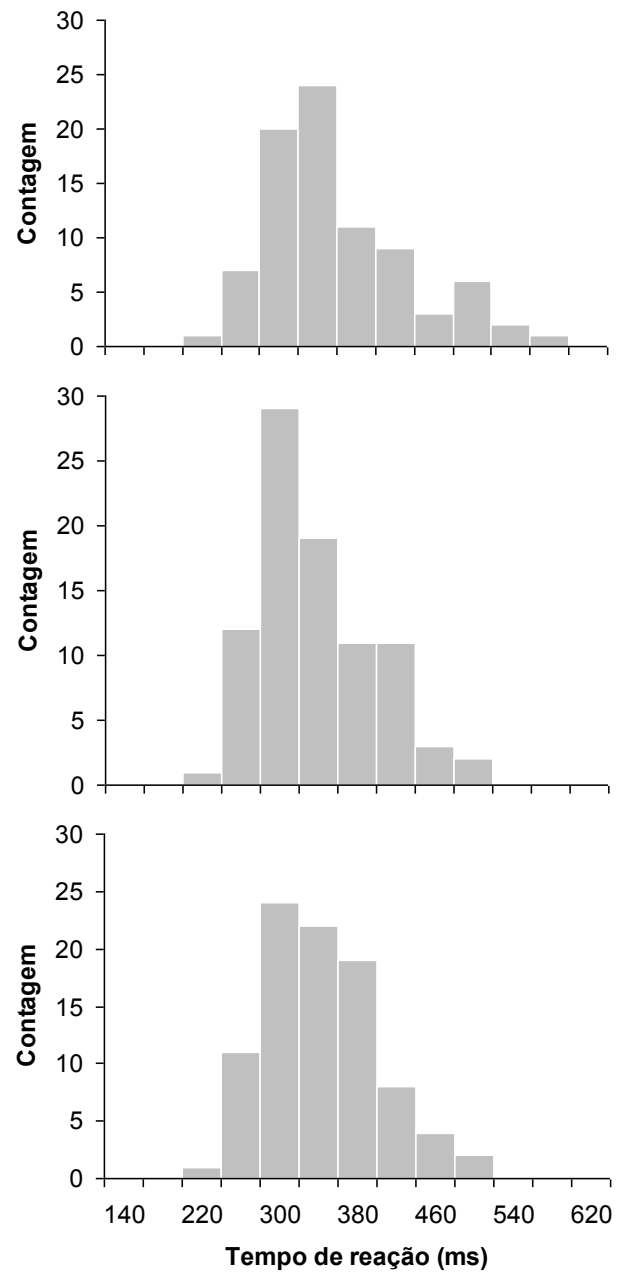

Direita acima
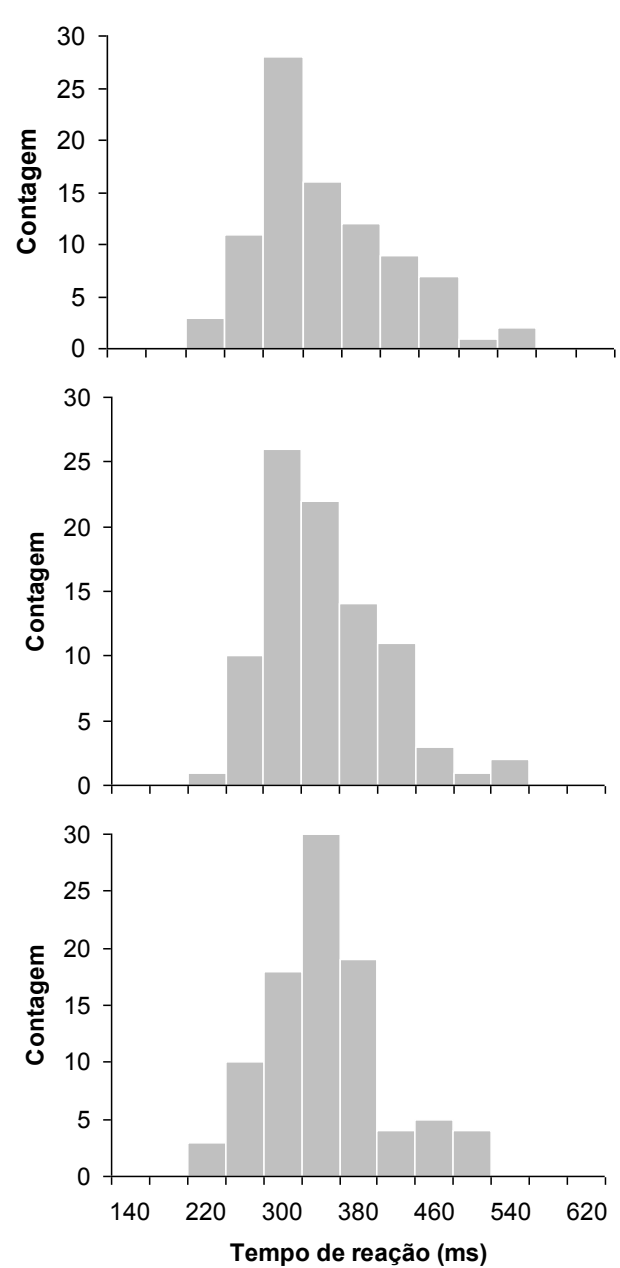

Figura 17. Seis distribuições de tempo de reação produzidas pela combinação do lado do campo visual em que o alvo foi apresentado acima do estímulo de fixação (esquerda acima ou direita acima) e o tamanho da dica das provas válidas $\left(1,5^{\circ}, 2,5^{\circ}\right.$ e $3,5^{\circ}$ de ângulo visual). Essas distribuições comportam o tempo de reação das respostas corretas e os valores brutos dos tempos de reação, ou seja, sem o corte de dois desvios padrão mais a média do TRM específico de cada condição experimental. 
Esquerda abaixo
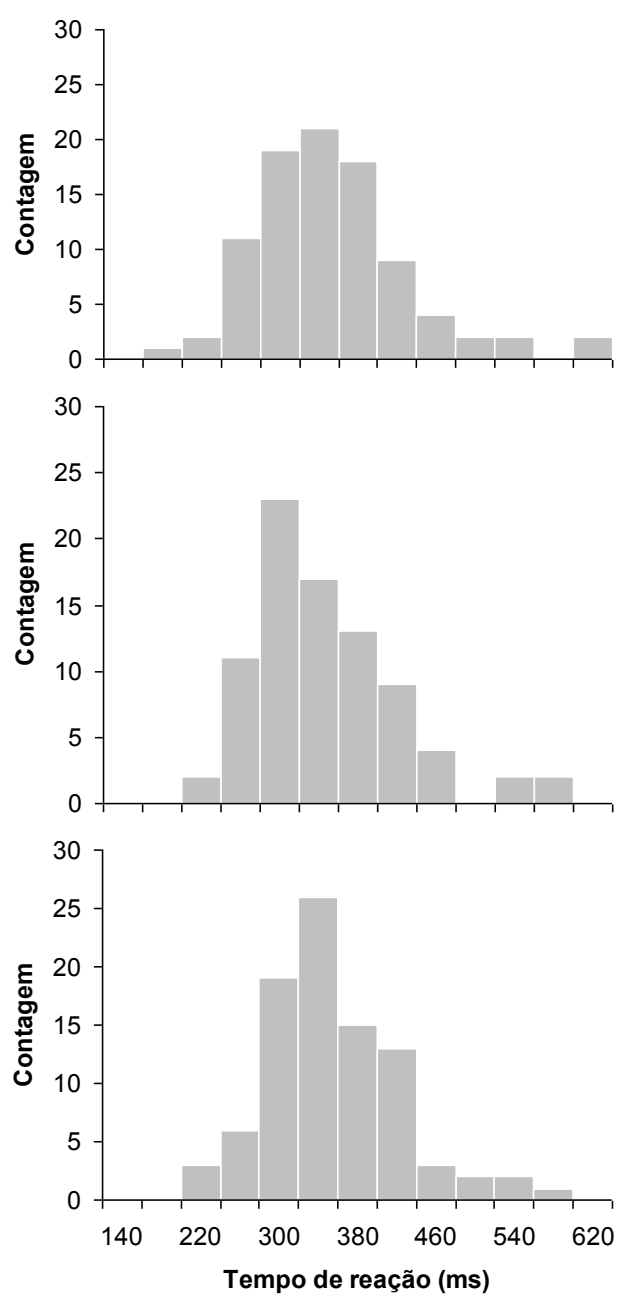

Direita abaixo

$1,5^{\circ}$

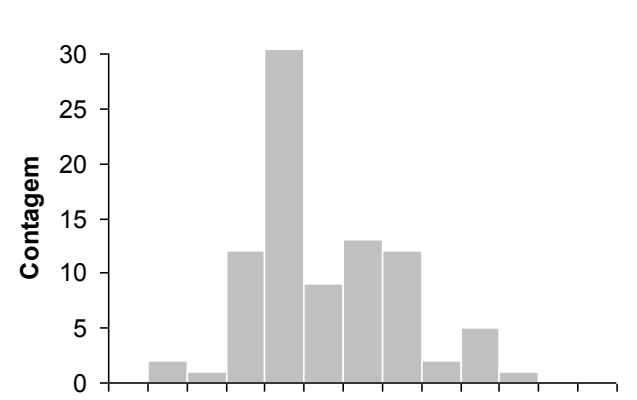

$2,5^{\circ}$

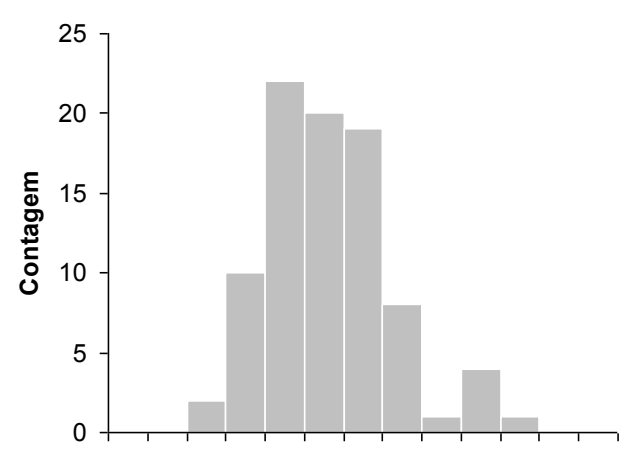

$3,5^{\circ}$

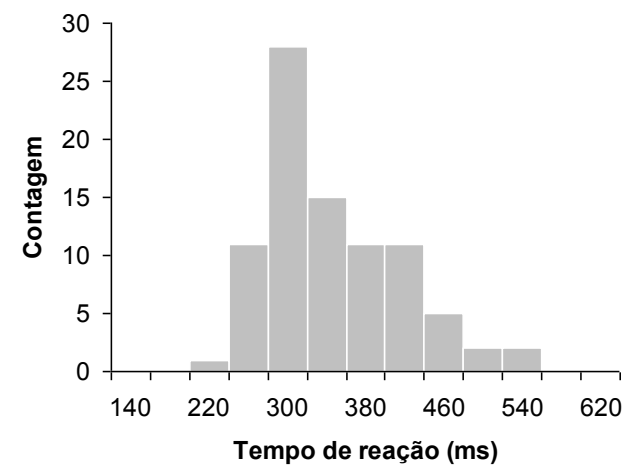

Figura 18. Seis distribuições de tempo de reação bruto produzidas pela combinação do lado do campo visual em que o alvo foi apresentado abaixo do estímulo de fixação (esquerda abaixo ou direita abaixo) e o tamanho da dica das provas válidas $\left(1,5^{\circ}, 2,5^{\circ}\right.$ e $3,5^{\circ}$ de ângulo visual).

\section{Discussão}

Os resultados das condições de dica válida e inválida mostraram uma clara vantagem em TRM para a detecção do alvo apresentado dentro da região indicada em relação às provas em que o alvo apareceu fora da dica. Além disso, o TRM foi igualmente mais lento quando o alvo foi apresentado fora de uma dica ou entre as duas dicas. Estes resultados são difíceis de serem explicados pelos modelos de foco único de atenção, que prevêem um TRM rápido para a localização entre as duas 
dicas ou pelo menos igual ao TRM encontrado nas provas com duas dicas válidas e não um TRM mais lento como foi encontrado neste experimento. Assim, esses resultados não indicam que um foco único de atenção, como o zum de uma lente, se expandiu e abarcou as duas dicas e a área entre elas onde o alvo foi apresentado.

Os resultados parecem ser mais bem explicados pela proposta de divisão do foco de atenção para as áreas indicadas, que prevê um desempenho melhor nestas áreas e pior fora ou entre as dicas, sugerindo a divisão da atenção em duas localizações não adjacentes. Além disso, a interpretação de que a atenção tenha sido deslocada entre provas para uma das áreas indicadas (Posner et al., 1980), não parece ser suportada pela inspeção visual da distribuição do TRM produzida quando o alvo foi apresentado em cada uma dessas localizações. Mas existe ainda o argumento de que os resultados podem ter sido causados pelo deslocamento rápido da atenção entre as localizações na mesma prova, pois estudos mostram que o tempo necessário para identificar um estímulo em uma localização indicada e deslocar para uma segunda localização indicada pode ser de 150 ms a 250 ms (Weichselgartner \& Sperling, 1987) ou de 100 a 400 ms (Eriksen \& Collins, 1969). Como o alvo ficou exposto até que os participantes realizassem a resposta, um deslocamento rápido da atenção de uma localização indicada para outra pode ter ocorrido. Embora essa possibilidade não possa ser descartada, parece pouco provável que tenha ocorrido, pois esse deslocamento rápido também teria provocado TRM's rápidos quando o alvo foi apresentado entre as duas dicas, uma vez que a distância entre essa localização intermediária e um dos locais indicados foi a metade da distância entre as duas dicas. Além disso, essa idéia é contrária a evidências de que estímulos apresentados abruptamente no campo visual e usados como dicas periféricas, capturam a atenção de maneira automática, inibindo momentaneamente 
a focalização em novos estímulos apresentados subseqüentemente a dica (Folk, Remington \& Johnston, 1992; Yantis \& Jonides, 1990).

No entanto, os resultados das provas de dica válida revelaram que não ocorreu o aumento do TRM conforme o aumento do tamanho de uma ou duas dicas. Uma tendência geral foi encontrada para o tamanho da dica, mas a diferença foi muito pequena (8ms) e oposta à esperada, ocorrendo apenas entre a dica menor e a dica de tamanho médio. Uma explicação para a ausência do efeito do tamanho da dica nas provas de dica válida com duas dicas pode estar na própria divisão da atenção, ou seja, a divisão do foco de atenção pode ter levado à divisão dos recursos de atenção disponíveis. Devido a esses recursos não serem infinitos (Eriksen \& Yeh, 1985; Eriksen \& St. James, 1986), a sua distribuição por áreas não adjacentes pode ter diminuído a quantidade de recursos disponíveis para serem distribuídos em cada uma dessas áreas indicadas. Bichot et al. (1999) argumentam que a divisão da atenção pode produzir custos extras e Kraft et al. (2005) encontraram pequenos aumentos no TRM quando a atenção foi distribuída sobre duas localizações não adjacentes. No presente experimento, a análise do TRM das provas de dica válida revelou que os participantes foram 11 ms mais rápidos para detectar o alvo apresentado dentro de apenas uma localização indicada do que quando o alvo apareceu dentro de uma de duas localizações indicadas. Embora essa diferença não tenha sido estatisticamente significativa, esse resultado e os resultados de Kraft et al. parecem corroborar com o argumento de que pode ocorrer um custo em desempenho quando dois locais precisaram receber atenção simultaneamente. Isso pode ser interpretado como uma diminuição na concentração dos recursos de atenção em duas áreas indicadas, comparado a situações onde 
apenas uma área é indicada, que, provavelmente, deve afetar a focalização da atenção ao tamanho das dicas.

Esses resultados são contrários aos encontrados em outros estudos que investigaram a divisão da atenção e manipularam o tamanho das dicas (Castiello \& Umiltà, 1992; McCormick et al., 1998). Castiello e Umiltà (1992) encontraram o efeito do tamanho da dica quando duas dicas foram apresentadas simultaneamente de cada lado do campo visual, sugerindo que o foco de atenção havia sido dividido. McCormick et al. (1998), que investigaram a divisão do foco usando um procedimento muito semelhante ao de Castiello e Umiltà, relatam um aumento no TRM conforme o aumento do tamanho das dicas, apenas em uma análise geral, que incluiu tanto provas com uma dica quanto provas com duas dicas. No entanto, seus resultados apontaram no sentido oposto ao de Castiello e Umiltà, ou seja, para a existência de um foco único de atenção. Isso pode indicar que o efeito do tamanho da dica pode ser observado apenas quando existe um foco único de atenção.

Mas, como explicar então, a ausência desse efeito quando apenas uma dica foi apresentada neste experimento? Uma possível explicação pode ser a mudança na estratégia de distribuição dos recursos de atenção visual ao longo da sessão experimental. O aumento da quantidade de dicas e condições experimentais dentro do bloco, comparado aos Experimentos 2a, 2b e 3a deste estudo, onde foi obtido o efeito do tamanho da dica com uma dica, pode ter modificado a maneira como o participante deu prioridade às áreas relevantes para a detecção do alvo. A apresentação da dica pode ter sido forte o bastante para desencadear apenas a orientação da atenção, mas não a focalização dos recursos no local indicado. Greewood et al., (Greenwood \& Parasuraman, 1999; Greenwood et al., 1997) já revelaram que o ajuste da atenção ao tamanho de uma área indicada pode ser 
susceptível ao controle do indivíduo, pelo menos parcialmente, e pode não ocorrer ou ocorrer de maneira contrária se isso levar a um desempenho melhor para o indivíduo. Assim, o sistema de atenção pode ter evitado ajustar o foco de atenção ao tamanho da dica nas provas com apenas uma dica, porque ao longo da sessão experimental metade das provas foi apresentada com duas dicas. A possibilidade de o alvo aparecer igualmente (50\%) em uma das duas localizações indicadas pode ter inibido a focalização da atenção ao tamanho da dica, mas permitido um ajuste mais amplo e difuso ao redor da área em que a dica foi apresentada, como argumentado por Greewood et al. (Greenwood \& Parasuraman, 1999; Greenwood et al., 1997).

Em resumo, os resultados indicam que os recursos de atenção não foram focalizados simultaneamente nas duas dicas apresentadas de cada lado do campo visual, mas sugerem que a atenção visual foi orientada ao mesmo tempo para essas áreas, sem incluir a zona entre as duas dicas.

Porém, um argumento que ainda pode questionar a hipótese de divisão do foco de atenção nesse experimento é o de que o alvo tenha sido apresentado fora de um possível foco único de atenção quando apareceu fora das duas dicas, isto é, nas provas inválidas com duas molduras. Nessas provas o alvo foi apresentado com a mesma excentricidade da dica para evitar qualquer benefício em TRM por estar mais próximo do estímulo de fixação e conseqüentemente mais próximo da área coberta pela fóvea (Masland, 2001; Palmer, 1999). Devido a isso, essa localização não estava exatamente entre as dicas, mas um pouco além dessa área. Isso foi mais evidente quando o alvo apareceu entre as dicas menores do que entre as dicas maiores (Figura 15) e em alguns casos não seria considerado fora de um suposto foco único de atenção (Silva \& Ribeiro-do-Valle, 2008), mas o TRM mais lento nessa condição pode ter sido causado por esse posicionamento do alvo. 
Uma tentativa indireta de verificar se a detecção do alvo foi prejudicada pelo seu posicionamento fora da área entre as duas dicas foi realizada ao analisar o TRM das provas inválidas com duas molduras em função do tamanho da dica. A idéia era verificar se nas provas com dicas menores o TRM seria mais lento do que nas provas com dicas maiores. Isso sugeriria que nas provas inválidas com duas dicas grandes o alvo estaria dentro da área abrangida por um foco único, mas o teste ANOVA $(p<0,05)$ de uma via para as medidas repetidas do TRM das provas inválidas com duas molduras para o fator tamanho da dica, não revelou diferença estatisticamente significativa entre o TRM obtido em cada tamanho de dica. Em outras palavras, tanto nas provas com duas dicas inválidas grandes quanto pequenas, o desempenho foi igualmente prejudicado, sugerindo que não tenha existido um foco único, pelo menos indiretamente.

Uma maneira mais direta de verificar se a localização do alvo fora das duas dicas o colocou fora de um possível foco único de atenção seria apresentá-lo com uma excentricidade menor na localização entre as duas dicas. Isso o colocaria mais próximo da zona entre as duas dicas. Essa possibilidade foi investigada no Experimento 6.

\subsection{Experimento 5 - Distribuição da atenção visual sobre regiões não- adjacentes e não apresentadas do mesmo lado do campo visual}

De acordo com o modelo proposto por Kraft et al. (2005) estímulos apresentados em lados opostos do campo visual tem mais recursos de atenção para serem processados do que estímulos apresentados em apenas um lado do campo visual. Isso permitiria maior facilidade para dividir a atenção quando eventos ocorrem simultaneamente de cada lado do campo visual. O modelo prevê ainda que 
estímulos apresentados no mesmo lado sejam processados por um foco único de atenção. Os resultados do Experimento 4 sugerem que a atenção possa ser dividida quando duas localizações foram indicadas de cada lado do campo visual, por um período relativamente longo de exposição entre a dica e o alvo (500 ms). Portanto, o objetivo deste experimento foi verificar se os indícios de divisão do foco encontrados no Experimento 4 também são observados quando os mesmos estímulos e distâncias usados foram deslocados para o lado esquerdo ou direito do campo visual. O TRM coletado permitiu verificar se os participantes foram igualmente rápidos quando o alvo apareceu entre ou dentro das dicas ou se foram mais rápidos apenas quando o alvo apareceu dentro de uma das duas dicas.

\section{Método}

\section{Participantes}

Doze estudantes (7 mulheres) da Universidade de Concórdia participaram de uma sessão experimental que durou aproximadamente 45 minutos. Os participantes tinham idade média de 25 anos e não possuíam conhecimento prévio da proposta do estudo com a exceção do autor MC. Todos os participantes relataram ter visão normal ou usavam lentes para correção.

\section{Material e estímulos}

O material e os estímulos foram os mesmos usados no Experimento 4, mas foram realizadas mudanças quanto à localização dos estímulos apresentados. Nas provas com apenas uma área indicada, a dica poderia ser apresentada acima, abaixo, à esquerda ou a direita do campo visual. Nas provas com duas áreas indicadas, duas dicas foram apresentadas simultaneamente na periferia do campo visual, acima e a esquerda, acima e a direita, abaixo e a esquerda ou abaixo e a direita do estímulo de fixação. Nas provas de dica válida o alvo foi apresentado 
dentro da dica e nas provas de dica inválida, o alvo foi apresentado fora da(s) dica(s) no canto superior esquerdo, canto superior direito, canto inferior esquerdo ou canto inferior direito como é indicado pela letra "p" na Figura 17 (quadrante superior). A distância entre os estímulos foi a mesma usada no experimento anterior.
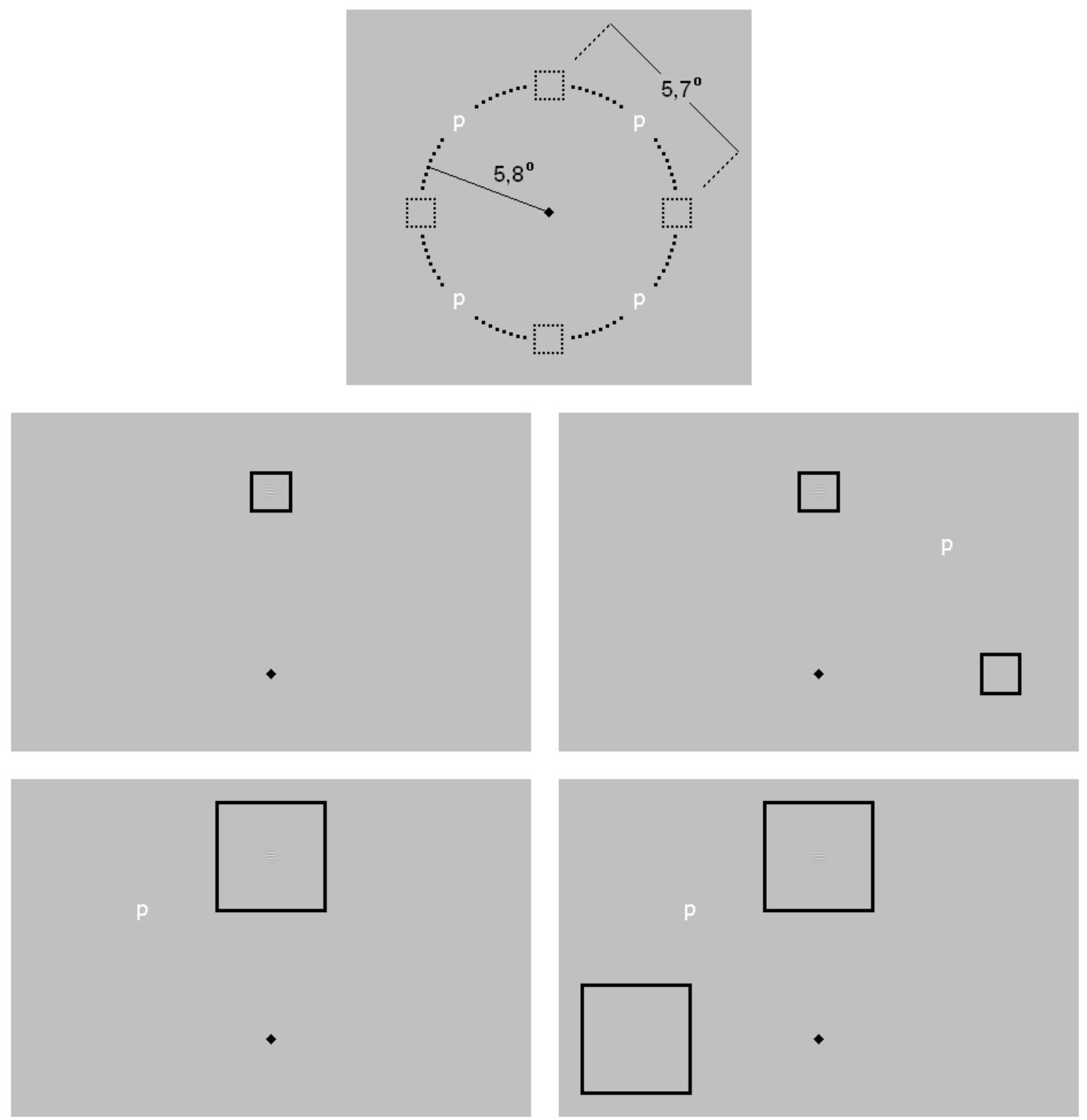

Figura 17. Distâncias e representações dos estímulos usados no Experimento 5. No centro e acima, os quadrados pontilhados representam as possíveis localizações onde a(s) dica(s) (moldura) e o alvo (Gabor) foram apresentados. Nas provas de dica inválida o alvo foi apresentado em uma localização fora da(s) dica(s) (letra "p" branca) à esquerda acima ou abaixo do estímulo de fixação ou à direita acima ou abaixo do estímulo de fixação. Nas provas de dica válida o alvo foi apresentado dentro de uma dica (quadrantes da esquerda) ou dentro de uma de duas dicas apresentadas simultaneamente sempre do mesmo lado do campo visual (quadrantes da direita). Os estímulos não estão em escala. 


\section{Procedimento}

O procedimento foi igual ao procedimento do Experimento 4.

A sessão experimental foi composta por seis blocos de provas e cada bloco começou com a calibração do sistema de monitoramento dos olhos, descrito anteriormente (procedimento do Experimento 2a). O primeiro bloco foi realizado para treinamento e continha 30 provas. Os outros cinco blocos foram compostos por 72 provas-teste cada, sendo 48 provas de dica válida, 12 provas de dica inválida e 12 provas sem alvo. Das 48 provas de dica válida, 24 provas foram apresentadas com uma dica e 24 com duas dicas. Cada tamanho de dica foi apresentado em 8 provas. As provas de dica inválida e falsa seguiram a mesma divisão de proporção de provas. Todas as condições experimentais foram aleatoriamente distribuídas dentro de cada bloco de provas. Apesar de existirem duas localizações a mais onde o alvo poderia aparecer fora da dica, isso não representou um aumento no número de provas porque essas localizações foram igualmente distribuídas ao longo dos blocos de provas realizados durante a sessão experimental.

\section{Resultados}

Os critérios para calcular e excluir o TRM foram os mesmos descritos no Experimento 2a. Os participantes cometeram erros em média em $4 \%$ das provas sem alvo. Erros de movimento ocular e piscadas durante a apresentação dos estímulos ocorreram em média em $5 \%$ do total de provas. $1 \%$ das provas com alvo foram excluídas devido a TRM menor do que $150 \mathrm{~ms}$ e $2 \%$ foram excluídas por apresentarem TRM maior do que dois desvio padrão mais a média do TRM específico de cada condição experimental.

Uma ANOVA $(p<0,05)$ de duas vias para o TR médio das medidas repetidas das respostas corretas para os fatores validade da dica (válida ou inválida) e número 
de dicas (uma ou duas), revelou um efeito estatisticamente significativo para a validade da dica (válida 309 ms, inválida 339 ms, $F(1,11)=31,54 ; p<0,001$, parcial $\eta^{2}=0,74$ ), um efeito para o número de dicas (uma dica $332 \mathrm{~ms}$, duas dicas $316 \mathrm{~ms}$, $F(1,11)=22,21 ; p<0,001$, parcial $\left.\eta^{2}=0,67\right)$ e uma interação entre os dois fatores $\left(F(1,11)=31,95 ; p<0,001\right.$, parcial $\left.\eta^{2}=0,74\right)$. Comparações pareadas (teste post hoc de Newman-Keuls, $p<0,001)$ mostraram que o TRM (362 ms) das provas com apenas uma dica inválida foi mais lento do que o TRM de todas as outras condições, ou seja, provas com uma dica válida, com duas dicas válidas e duas dicas inválidas (302, 315 e 317 ms, respectivamente). O TRM médio das provas com uma ou duas dicas válidas e inválidas é mostrado na Figura 18.

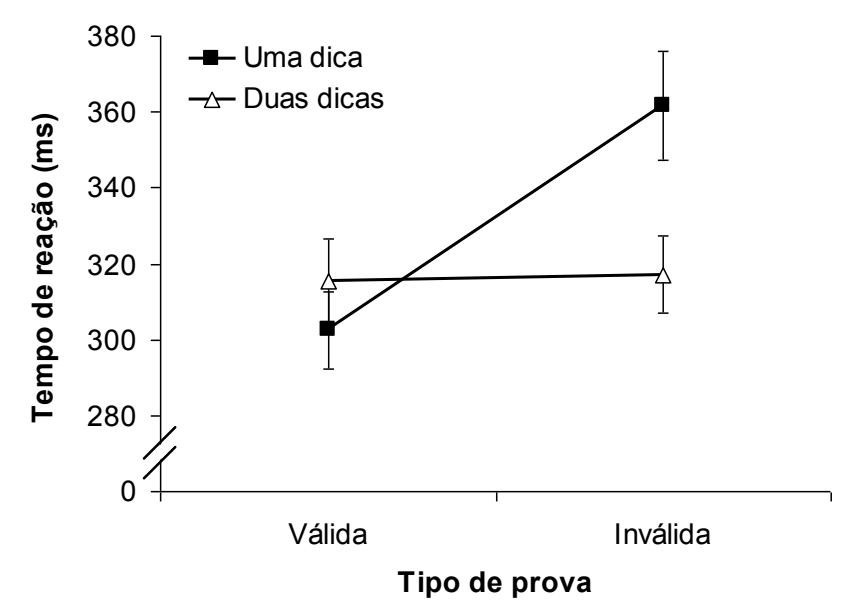

Figura 18. Tempo de reação das provas de dica válida e inválida em função do número de dicas apresentadas por prova.

Outra ANOVA $(p<0,05)$ de duas vias para o TRM médio das medidas repetidas das provas de dica válida para os fatores número de dicas (uma ou duas) e tamanho da dica $\left(1,5^{\circ}, 2,5^{\circ}\right.$ e $\left.3,5^{\circ}\right)$ mostrou um efeito estatisticamente significativo para o número (uma dica $302 \mathrm{~ms}$, duas dicas $315 \mathrm{~ms}, \mathrm{~F}(1,11)=14,01 ; \mathrm{p}=0,003$, parcial $\left.\eta^{2}=0,56\right)$, nenhum efeito para o tamanho $\left(1,5^{\circ}=309 \mathrm{~ms}, 2,5^{\circ}=307 \mathrm{~ms}, 3,5^{\circ}\right.$ $=310 \mathrm{~ms}, F(2,22)=0,26 ; p=0,77)$ e nenhuma interação estatisticamente significativa entre os dois fatores $(F(2,22)=2,22 ; p=0,13)$. 


\section{Discussão}

Os resultados das provas com apenas uma dica mostraram uma clara vantagem em TRM para detectar o alvo apresentado dentro da dica do que fora dela. Já os resultados das provas com duas dicas mostraram que não existiu diferença em desempenho entre apresentar o alvo dentro ou fora (entre) das duas dicas. Além disso, o TRM destas duas condições foi igual ao TRM das provas em que o alvo foi apresentado dentro de apenas uma dica, mostrando que o alvo apresentado entre as duas dicas recebeu um benefício semelhante ao benefício obtido quando foi apresentado dentro da dica. Esses resultados sugerem que as duas dicas e a área entre as duas dicas receberam atenção ao mesmo tempo e são mais bem explicados por modelos que propõem um foco único de atenção, como o modelo do zum de uma lente, que se expandiu e abrangeu as duas dicas e a área entre as dicas. Os resultados deste experimento e do Experimento 4 parecem apontar na mesma direção da proposta de Kraft et al. (2005). Eles sugeriram que a atenção pode ser mais facilmente dividida quando eventos ocorrem em lados opostos do campo visual, mas quando os eventos ocorrem em apenas um lado, um foco único de atenção é formado. É importante apontar também, que nas provas em que uma das dicas foi apresentada acima ou abaixo do centro da tela, cada metade da dica estava em um lado do campo visual, mesmo assim, não foi observado indícios de que o foco de atenção tenha sido dividido.

No entanto, devido à moldura quadrada possuir cantos, existiu uma pequena diferença na distância entre as bordas das duas molduras apresentadas neste experimento e a distância entre as bordas das duas molduras apresentadas no experimento anterior. Isso pode levar a interpretação de que a formação de um foco único de atenção neste experimento foi causada pela maior proximidade dos cantos 
das molduras com a região interveniente e não pela distribuição diferente da atenção entre os lados do campo visual. Embora isso possa ter ocorrido, parece pouco provável, pois a distância entre os dois cantos das duas molduras ainda foi grande, mesmo nas provas com duas molduras grandes. Mesmo assim, uma análise comparando os TRM's das provas de dica inválida com duas molduras para cada tamanho de dica foi realizada, não revelando qualquer influência do tamanho das duas dicas sobre o desempenho dos participantes. Portanto, os resultados deste experimento sugerem que não ocorreu a divisão da atenção quando boa parte dos estímulos foi apresentada do mesmo lado do campo visual.

Os resultados são diferentes dos resultados de Silva e Ribeiro-do-Valle (2008), que encontraram indícios de que a atenção possa ser orientada de maneira automática para duas localizações não adjacentes e posicionas do mesmo lado do campo visual. Resultados de outros estudos que investigaram a dinâmica temporal da atenção (Cheal \& Lyon, 1991; Müller \& Findlay, 1988; Müller \& Rabbitt, 1989; Nakayama \& Mackeben, 1989), sugerem que o motivo para esses distintos resultados pode ter sido os diferentes intervalos de tempo usados para a exposição das dicas periféricas. De acordo com esses estudos, dicas periféricas podem ativar tanto um mecanismo de orientação automático da atenção nos primeiros 50 a 150 ms de exposição da dica periférica, quanto um mecanismo voluntário de orientação após os 150 ms para sustentar a atenção no local indicado. O tempo de exposição das dicas periféricas usado por Silva e Ribeiro-do-Valle (2008) foi curto (50 ms) com um intervalo entre o início da apresentação da dica e o início do alvo de 100 ms, enquanto que neste experimento a dica ficou exposta por $500 \mathrm{~ms}$ antes da apresentação do alvo, permanecendo no campo visual até o final da prova. Assim, a divisão da atenção encontrada por Silva e Ribeiro-do-Valle parece ter sido produzida pela orientação automática da atenção, verificada por um pico em desempenho nos 
100 ms iniciais. Já a ausência de divisão verificada neste experimento pode estar relacionada ao início de um processo voluntário de orientação da atenção, que produz um desempenho satisfatório, mas menor do que o observado nos 100 a 150 ms iniciais. Essa manutenção voluntária da atenção nos locais indicados pode exigir ainda mais do sistema quando os estímulos ocorrem em sua maioria, dentro do mesmo lado do campo visual, pois menos recursos de atenção estariam disponíveis de acordo com o modelo proposto por Kraft et al. (2005). Essa explicação pode ser aplicada também aos resultados de Hahn e Kramer (1998), que verificaram a divisão da atenção quando dicas periféricas foram expostas por $150 \mathrm{~ms}$ e os alvos foram expostos de maneira não abrupta do mesmo lado do campo visual. No entanto, Awh e Pashler (2000) também mostraram que a atenção pode ser dividida do mesmo lado do campo visual quando duas dicas informaram por $750 \mathrm{~ms}$ as prováveis localizações de dois alvos. Porém, o desempenho foi estatisticamente pior quando as localizações estavam do mesmo lado do campo visual do que quando em lados opostos. Eles realizaram um controle no Experimento 3 do seu estudo e os resultados foram favoráveis a interpretação da hipótese de uma vantagem bilateral de campo. Os resultados de Awh e Pashler (2000), assim como os resultados deste experimento sugerem que essa diferença entre dividir ou não a atenção no mesmo lado do campo visual deve ser relativa e não absoluta.

\subsection{Experimento 6 - A localização do alvo entre as duas dicas e a distribuição da atenção visual}

Apesar de os resultados do Experimento 4 sugerirem que a atenção visual foi dividida, ainda existe a interpretação de que o alvo apresentado entre as duas dicas periféricas poderia estar fora de um possível foco único de atenção. O Experimento 
6 foi realizado para investigar essa hipótese, mantendo todas as características do Experimento 4 e modificando apenas a excentricidade da localização do alvo apresentado fora das dicas. Essa excentricidade foi um pouco menor ( $1^{\circ}$ de ângulo visual) do que a usada no Experimento 4. A alteração permitiu que o alvo ficasse mais próximo da área entre as duas dicas e conseqüentemente estivesse dentro de um suposto foco único de atenção, que abarcaria toda essa região. Também existiu um cuidado para que essa diminuição da excentricidade fosse pequena para que qualquer alteração no TRM não fosse explicada pela maior proximidade do alvo com a região abrangida pela fóvea (Masland, 2001; Palmer, 1999).

\section{Método}

\section{Participantes}

Seis estudantes (4 mulheres) da Universidade de Concórdia realizaram uma sessão experimental que durou aproximadamente 45 minutos. Os participantes tinham idade média de 22 anos (dp 2,6 anos) e não possuíam conhecimento prévio da proposta do estudo. Todos os participantes relataram ter visão normal ou usavam lentes para correção.

\section{Material e estímulos}

O material e os estímulos foram os mesmos usados no Experimento 4. A única diferença foi a excentricidade do alvo apresentado fora das dicas, que foi de $4.8^{\circ}$ de ângulo visual.

\section{Procedimento}

Idêntico ao procedimento usado no Experimento 4. 


\section{Resultados}

Os critérios para calcular e excluir o TRM foram os mesmos descritos no Experimento 2a. Os participantes cometeram erros em média em 3,4\% das provas sem alvo. Erros de movimento ocular e piscadas durante a apresentação dos estímulos ocorreram em média em $9,5 \%$ do total de provas. $1 \%$ das provas com alvo foi excluído por apresentar TRM menor do que 150 ms e $2 \%$ por apresentar TRM maior do que dois desvio padrão mais a média do TRM específico de cada condição experimental. Erros de movimento ocular e piscadas durante a apresentação dos estímulos ocorreram em média em $5 \%$ do total de provas.

A ANOVA $(p<0,05)$ de duas vias para as medidas repetidas do TRM médio das respostas corretas de cada participante para os fatores validade da dica (válida ou inválida) e número de dicas (uma ou duas), revelou um efeito estatisticamente significativo para a validade da dica $\left(F(1,5)=18,54 ; p<0,01\right.$, parcial $\left.\eta^{2}=0,79\right)$, nenhum efeito para o número $(F(1,5)=1,02 ; p=0,36)$ e uma interação estatisticamente significativa entre os dois fatores $\left(F(1,5)=11,11 ; p=0,02\right.$, parcial $\left.\eta^{2}=0,69\right)$. Comparações pareadas (teste post hoc de Newman-Keuls, $p<0,05$ ) entre os dois fatores mostraram que o TRM (379 ms) para detectar o alvo apresentado fora das provas com apenas uma dica foi mais lento do que o TRM das provas com uma dica válida, com duas dicas válidas e duas dicas inválidas (332, 344 e 352 ms, respectivamente). O TRM médio de cada condição é mostrado na Figura 19A.

A ANOVA $(p<0,05)$ de duas vias do TRM médio das provas de dica válida para os fatores número de dicas (uma ou duas) e tamanho da dica $\left(1,5^{\circ}, 2,5^{\circ}\right.$ e $\left.3,5^{\circ}\right)$ mostrou um efeito estatisticamente significativo para o número $(F(1,5)=9,29 ; p=0,028$, parcial $\left.\eta^{2}=0,65\right)$, nenhum efeito para o tamanho $(F(2,10)=1,06 ; p=0,38)$, e uma interação estatisticamente significativa entre os dois fatores $(F(2,10)=4,89 ; p=0,033$, parcial 
$\left.\eta^{2}=0,49\right)$. O teste post hoc de Newman-Keuls $(p<0,05)$ mostrou que o TRM médio (330 ms) das provas com duas dicas de tamanho $1,5^{\circ}$ foi mais rápido do que o TRM médio (356 ms) das provas com duas dicas de tamanho 3,5 (Figura 19B).

A

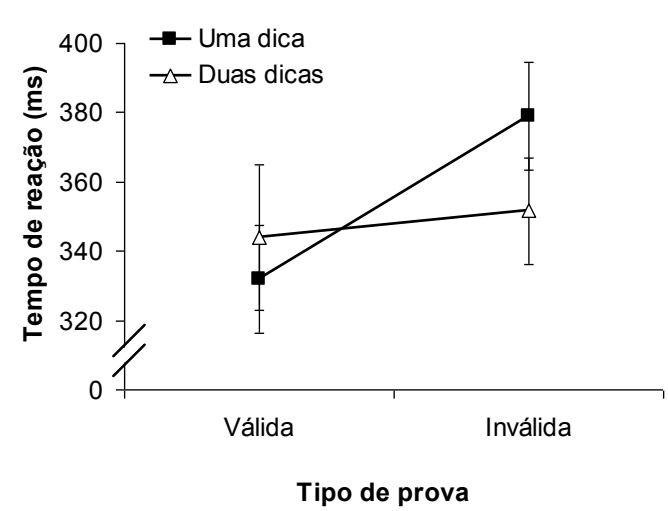

B

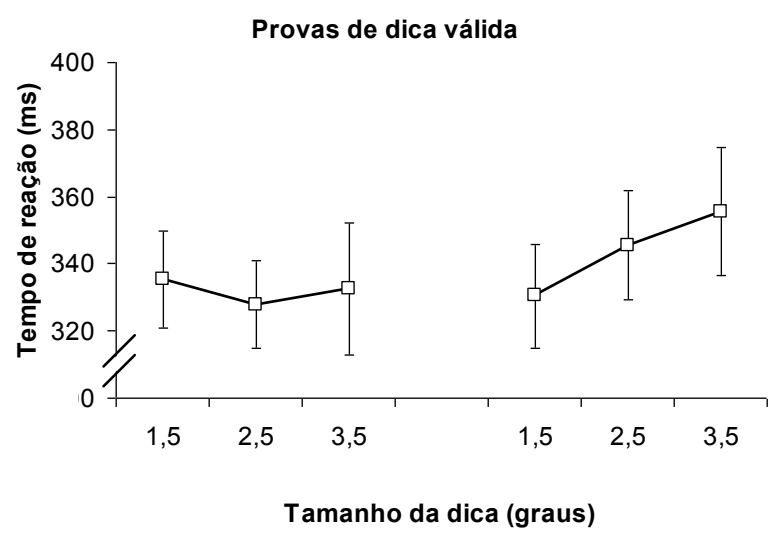

Figura 19. (A) Tempo de reação médio das provas de dica válida e inválida em função da quantidade de dicas apresentadas. (B) Tempo de reação médio das provas com uma ou duas dicas válidas em relação ao tamanho da dica.

\section{Discussão}

Os resultados mostraram que diminuir em um grau a excentricidade do alvo apresentado fora da dica, não interferiu no TRM para o participante detectar o alvo apresentado dentro e fora de uma dica, produzindo vantagem e custo semelhantes aos encontrados no Experimento 4. No entanto, interferiu no TRM para detectar o alvo apresentado entre as duas dicas, que foi igualmente rápido ao TRM para detectar o alvo apresentado dentro da dica, sugerindo um foco único de atenção capaz de se expandir e abarcar as duas dicas e a área entre elas. $\mathrm{O}$ aumento gradual do TRM conforme o aumento do tamanho das duas dicas válidas também parece apontar nesse sentido, sugerindo que o aumento do tamanho das dicas influenciou a concentração dos recursos de atenção dentro de um foco único que se expandiu em tamanho. De acordo com o modelo do zum de uma lente, ajustar o foco 
a uma área maior diminuiu a concentração dos recursos de atenção dentro do foco, aumentando o TRM para detectar o alvo.

Os resultados desse experimento não confirmam a hipótese de divisão do foco suportada pelos resultados do Experimento 4. O reposicionamento do alvo em uma localização mais próxima à zona entre as duas dicas sugere que a sua localização no Experimento 4 estava fora de um foco único que abarcou as duas dicas e a área entre elas.

Para confirmar se os resultados desse experimento estão corretos, o Experimento 7 foi realizado com as mesmas distâncias e excentricidades usadas neste experimento, mas com a possibilidade de apresentar o alvo em outras duas localizações próximas às dicas.

\subsection{Experimento 7 - Alvo apresentado em diferentes excentricidades: tempo de reação para detectá-lo em provas com ou sem dicas}

O Experimento 4 mostrou que apresentar um alvo entre duas dicas expostas em lados opostos do campo visual produziu resultados que indicaram a divisão do foco de atenção, mas os resultados do Experimento 6 sugerem que isso foi obtido devido a apresentação do alvo fora da área abrangida por um foco único de atenção. Assim, para confirmar se esta interpretação está correta, no Experimento 7 o alvo foi apresentado na mesma localização entre as duas dicas usada no Experimento 6 e em outras duas localizações nos flancos das dicas, mas fora da área entre as dicas. O objetivo foi comparar o desempenho em TRM para detectar o alvo entre as duas dicas e nos flancos das dicas, assim como, para comparar essas duas condições com a condição em que o alvo foi apresentado dentro das dicas. Se os resultados do 
Experimento 6 forem confirmados, o TRM para detectar o alvo entre as duas dicas deve ser tão rápido quanto o TRM para detectá-lo dentro da dica. Além disso, o TRM para detectar o alvo apresentado fora dessa área deve ser igual ao TRM para detectá-lo fora das provas com apenas uma dica. Resultados diferentes a esses indicariam a possibilidade de a atenção ter sido dividida.

Além de comparar essas condições, o Experimento 7 comparou o TRM para detectar o alvo nas diferentes excentricidades usadas. Esse controle foi realizado em uma sessão experimental separada, onde apenas o alvo foi apresentado. Se as diferentes excentricidades entre as localizações em que o alvo foi apresentado dentro das dicas e fora das dicas influenciarem o TRM, a detecção do alvo nas localizações menos excêntricas deve ser mais rápida do que a detecção do alvo nas localizações mais excêntricas (Masland, 2001; Palmer, 1999). Esse controle permitirá verificar se o TRM das provas em que o alvo foi apresentado fora da dica se deve às diferentes excentricidades ou a um efeito da atenção.

\section{Método}

\section{Participantes}

Dezessete estudantes (7 mulheres) do Campus da USP em Ribeirão Preto, com idade média de 24 anos, sem conhecimento prévio da proposta do estudo, participaram de três sessões experimentais de aproximadamente 45 minutos cada e realizadas em dias diferentes. Todos os participantes relataram ter visão normal ou usavam lentes para correção. 
Material, estímulos e delineamento experimental

O experimento foi montado e executado pelo pacote de programas E`Prime ${ }^{\circledR}$ 1.0 Psychology Software Tools, Inc. (disponível em http://www.pstnet.com) processado em um microcomputador. Os estímulos foram apresentados em um monitor Flatron ez T930B, com resolução de 1024 x 768 pixels e taxa de atualização vertical de $100 \mathrm{~Hz}$. As respostas corretas e erradas, assim como o TRM em cada prova foram coletados com a caixa de respostas SR Box produzida pela Psychology Software Tools, Inc.

Os estímulos foram os mesmos usados no Experimento 6 com a exceção do tamanho da dica e a localização do alvo apresentado fora das dicas. Foram usados apenas dois tamanhos de dica de $1,5^{\circ}$ e $3,5^{\circ}$ de ângulo visual para não aumentar muito a quantidade de provas por sessão experimental e o alvo, além de ser apresentado acima ou abaixo do estímulo de fixação, foi apresentado também à esquerda ou à direita do centro do campo visual. Portanto, nas provas em que as duas dicas foram apresentadas simultaneamente acima ou abaixo do centro do campo visual, o Gabor poderia aparecer dentro de uma das dicas (provas de dica válida) nas mesmas localizações usadas nos Experimentos 4 e 6 ou em uma de quatro possíveis localizações fora das dicas (provas de dica inválida), conforme a localização das dicas: se as dicas foram apresentadas acima do estímulo de fixação, o alvo poderia aparecer (1) entre as duas dicas, acima do centro do campo visual ou no flanco de uma das duas dicas (2) à esquerda ou (3) à direita do campo visual; se as duas dicas foram apresentadas abaixo do estímulo de fixação, o alvo poderia aparecer (1) entre as duas dicas, abaixo do centro do campo visual ou nos flanco de uma das duas dicas (2) à esquerda ou (3) à direita do campo visual. Da mesma forma, nas provas com apenas uma dica, o alvo poderia aparecer dentro da dica 
(provas de dica válida) ou em uma das quatro localizações fora da dica (provas de dica inválida), dependendo da localização da dica: se a dica fosse apresentada no canto superior esquerdo do campo visual, o alvo poderia aparecer (1) acima do centro do campo visual (na mesma localização entre as duas dicas) ou (2) à esquerda do centro do campo visual (flanco da dica); se a dica fosse apresentada no canto superior direito, (1) o alvo poderia aparecer acima do centro do campo visual (localização entre) ou (2) à direita do centro do campo visual (flanco da dica); se a dica fosse apresentada no canto inferior esquerdo ou inferior direito, o alvo poderia aparecer (1) abaixo do centro do campo visual (localização entre) ou, respectivamente, (2) à esquerda ou (3) à direita do centro do campo visual (flanco da dica). Assim, o alvo poderia aparecer em quatro localizações fora da(s) dica(s) e em quatro localizações dentro da dica. Todas as localizações fora da dica tiveram a mesma excentricidade $\left(4,8^{\circ}\right.$ de ângulo visual) e distância das dicas, como pode ser visualizado na Figura 20, onde as letras "p" representam as equiprováveis localizações de apresentação do Gabor fora da dica. As localizações em que o alvo poderia aparecer dentro da dica são representadas por um quadrado pontilhado e foram mais excêntricas (5,8 de ângulo visual) do que as localizações fora da dica.

Na sessão experimental em que as dicas não foram apresentadas, os alvos foram expostos nas mesmas localizações das sessões com dicas. 

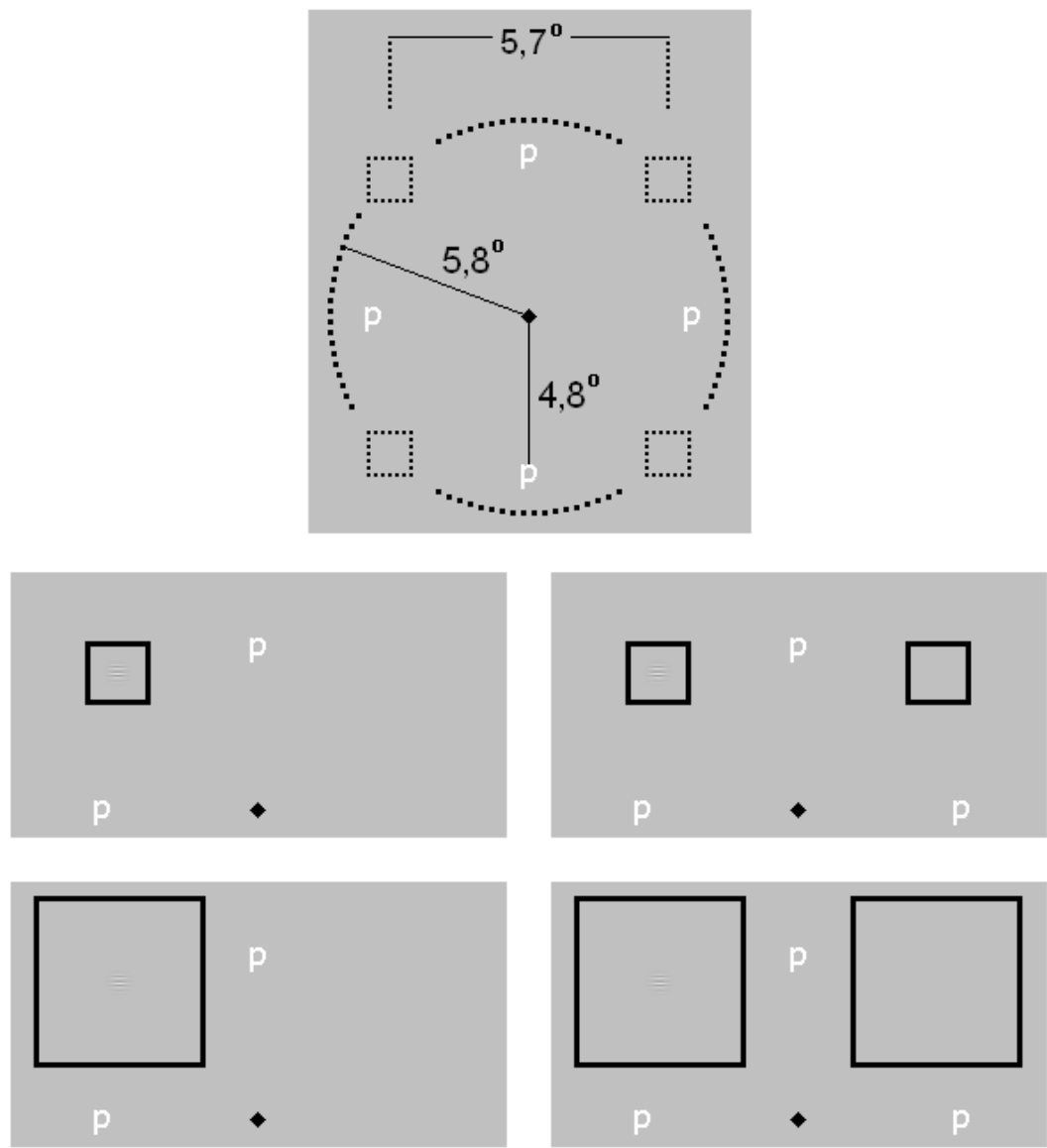

Figura 20. Distâncias e representações dos estímulos usados no Experimento 7. No centro e acima, os quadrados pontilhados representam as possíveis localizações onde a(s) dica(s) (moldura) e o alvo (Gabor) foram apresentados. Nas provas de dica inválida o alvo foi apresentado em uma localização fora da(s) dica(s) (letra "p" branca) acima ou abaixo do estímulo de fixação. Nas provas de dica válida o alvo foi apresentado dentro de uma dica (quadrantes da esquerda) ou dentro de uma de duas dicas apresentadas simultaneamente sempre em lados opostos do campo visual (quadrantes da direita). Os estímulos não estão em escala.

\section{Procedimento}

A tarefa solicitada aos participantes nas três sessões experimentais foi a mesma usada nos Experimentos 4, 5 e 6, ou seja, detectar o mais rapidamente possível o aparecimento do alvo (Gabor), pressionando um botão de uma caixa de respostas. A resposta foi dada com o dedo indicador da mão preferida pelo participante.

Em duas das três sessões realizadas, a seqüência de apresentação dos estímulos foi a mesma usada no Experimento 4, mas sem o procedimento de monitoramento de movimento dos olhos, ou seja, após pressionar a tecla de espaço 
do teclado do computador para começar cada prova, o estímulo de fixação apareceu no centro da tela e permaneceu até o final da prova. Após 1500 ms de exposição do estímulo de fixação, a dica foi apresentada e depois de 500 ms o Gabor foi apresentado dentro ou fora da dica. Todos os estímulos permaneceram na tela até que o participante realizasse a resposta. $O$ participante foi informado sobre o seu desempenho após cada resposta: Respostas corretas foram seguidas pela apresentação da palavra "certo!" na cor azul; respostas erradas foram seguidas pela apresentação de um som grave e a palavra "errado!" na cor vermelha; caso o participante não realizasse a resposta até 1700 ms, as palavras "resposta não detectada!" na cor amarela foram apresentadas. Essas informações foram apresentadas no centro da tela por $800 \mathrm{~ms}$.

Na sessão designada para investigar a influência da excentricidade no TRM, a única diferença foi a não apresentação da dica. Assim, após pressionar a tecla de espaço do teclado do computador para começar cada prova, o estímulo de fixação aparecia no centro da tela e permanecia até o final da prova. Após $2000 \mathrm{~ms}$ de exposição do estímulo de fixação, o alvo era apresentado e os dois estímulos permaneceram na tela até que o participante realizasse a resposta. Nas provas sem o alvo o participante foi instruído a manter o olhar sobre o estímulo de fixação até o final da prova sem realizar qualquer resposta manual. As informações sobre o desempenho foram transmitidas ao participante da mesma forma realizada nas outras duas sessões experimentais.

Cada uma das duas sessões com dicas foi composta por sete blocos de provas. O primeiro bloco foi um treinamento e continha 30 provas. Os outros seis blocos foram compostos por 80 provas-teste cada. Cada bloco continha 48 provas de dica válida (60\%), 16 provas de dica inválida (20\%) e 16 provas sem alvo (20\%). 
Das 48 provas de dica válida, 24 provas foram apresentadas com uma dica e 24 com duas dicas. Cada tamanho de dica $\left(1,5^{\circ}\right.$ ou $\left.3,5^{\circ}\right)$ foi apresentado em 12 provas. As provas de dica inválida e sem alvo foram subdivididas da mesma maneira. Nas provas de dica inválida, o alvo foi apresentado em cada uma das localizações fora (acima, abaixo, à direita ou à esquerda do estímulo de fixação) da(s) dica(s) na mesma quantidade de vezes em cada bloco e as combinações entre o número de dicas e localizações fora foram divididos de maneira semi-aleatória entre os blocos. Todos os tratamentos experimentais foram aleatoriamente distribuídos dentro de cada bloco de provas.

A sessão experimental sem dicas foi composta por sete blocos de provas. $O$ primeiro bloco foi um treinamento e continha 20 provas. Os outros seis blocos foram compostos por 80 provas-teste cada, sendo que em 64 provas (80\%) o alvo foi apresentado e em 16 provas (20\%) o alvo não foi apresentado. O alvo foi apresentado de maneira aleatória 8 vezes em cada uma das oito possíveis localizações por bloco, que foram classificadas como localizações menos excêntricas (quatro localizações = acima, abaixo, esquerda ou direita do estímulo de fixação), sendo as mesmas localizações das provas em que o alvo foi apresentado fora da(s) dica(s) e localizações mais excêntricas (quatro = canto inferior esquerdo, inferior direito, superior esquerdo ou superior direito), sendo as mesmas localizações em que o alvo foi apresentado dentro da(s) dica(s). Assim, o alvo apareceu em cada localização 48 vezes no final dos seis blocos.

Seis participantes realizaram a sessão sem dica no primeiro dia de testes, cinco participantes no segundo dia e seis participantes no terceiro dia. 


\section{Resultados}

Tempo de reação manual das sessões experimentais com dicas

Os critérios para calcular e excluir o TRM nas duas sessões experimentais com as dicas foram os mesmos descritos no Experimento 2a. Os participantes cometeram erros em $3 \%$ das provas sem alvo. Apenas uma prova foi excluída por apresentar TRM menor do que $150 \mathrm{~ms}$ e $5 \%$ das provas por apresentar TRM maior do que dois desvio padrão mais a média do TRM específico de cada condição experimental.

A ANOVA $(p<0,05)$ de duas vias para as medidas repetidas do TRM médio das respostas corretas para os fatores número de dicas (uma ou duas) e validade da dica (válida, inválida acima/abaixo, inválida esquerda/direita), revelou nenhum efeito estatisticamente significativo para o número de dicas (provas com uma dica $=384$ $\mathrm{ms}$, provas com duas dicas $=386 \mathrm{~ms}, \mathrm{~F}(1,16)=0,12 ; p=0,73)$, um efeito significativo para a validade (válidas $=342 \mathrm{~ms}$, inválida acima/abaixo $=398 \mathrm{~ms}$, inválida esquerda/direita $=416 \mathrm{~ms}, F(2,32)=19,61 ; p<0,001$, parcial $\left.\eta^{2}=0,55\right)$, e uma interação estatisticamente significativa entre os dois fatores $(F(2,32)=7,43 ; p=0,002$, parcial $\left.\eta^{2}=0,32\right)$. Comparações pareadas (teste post hoc de Newman-Keuls, $p<0,01$ ) para o fator validade da dica mostrou que o TRM médio das provas de dica válida foram $56 \mathrm{~ms}$ e $75 \mathrm{~ms}$ mais rápido do que o TRM das provas de dica inválida acima/abaixo e inválida esquerda/direita, respectivamente. Comparações pareadas (teste post hoc de Newman-Keuls, $\mathrm{p}<0,01$ ) para os fatores validade e número de dicas revelaram que nas provas com apenas uma dica, o TRM médio das provas de dica válida (332 ms) foi mais rápido do que o TRM médio das provas de dica inválida e que não existiu diferença entre o TRM médio das localizações de dica inválida (acima/abaixo $=407 \mathrm{~ms}$, esquerda/direita $=414 \mathrm{~ms})$. Nas provas com duas dicas, o 
TRM médio foi mais rápido nas provas de dica válida (351 ms) do que nas provas de dica inválida, existindo uma diferença de 29 ms entre as localizações das provas de dica inválida (acima/abaixo $=389 \mathrm{~ms}$, esquerda/direita $=418 \mathrm{~ms})$. A análise mostrou também que apresentar o alvo nas localizações acima/abaixo das provas com duas dicas inválidas foi $17 \mathrm{~ms}$ mais rápido do que apresentar o alvo nas mesmas localizações com apenas uma dica inválida. O TRM médio das provas com uma ou duas dicas em função da validade da dica pode ser visualizado na Figura 21.

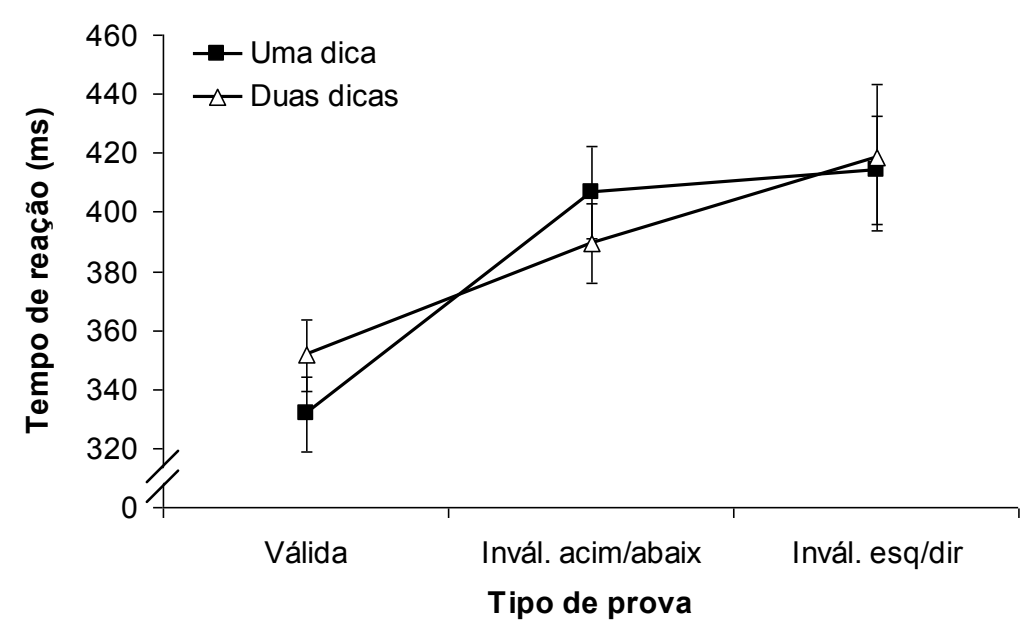

Figura 21. Tempo de reação médio das provas com uma ou duas dicas em função da validade da dica (provas de dica válida, inválida acima/abaixo e inválida esquerda/direita).

Outra ANOVA $(p<0,05)$ de duas vias para as medidas repetidas do TRM médio das provas de dica válida para os fatores número de dicas (uma ou duas) e tamanho da dica $\left(1,5^{\circ}\right.$ ou $\left.3,5^{\circ}\right)$ mostrou um efeito estatisticamente significativo apenas para o número $\left(F(1,16)=22,98 ; p<0,001\right.$, parcial $\left.\eta^{2}=0,59\right)$, indicando que 0 TRM médio das provas de dica válida com apenas uma dica (332 ms) foi $20 \mathrm{~ms}$ mais rápido do que o TRM médio obtido nas provas com duas dicas (354 ms).

Devido à diferença entre o desempenho das condições de dica válida e inválida das provas com duas dicas ter ocorrido, foi realizada uma inspeção visual das oito distribuições do TRM das provas válidas com duas dicas, produzidas pela 
combinação da localização em que o alvo foi apresentado e o tamanho da dica. Essa inspeção foi uma tentativa de verificar se a vantagem em desempenho para as dicas válidas foi provocada pelo deslocamento de um foco único para as localizações indicadas entre provas. A existência de duas modas ou picos na distribuição do TRM indicaria se metade das provas válidas tornaram-se provas inválidas por deslocar a atenção para uma das localizações. A inspeção visual das doze distribuições do TRM dessas condições parece revelar apenas uma moda nas provas de dicas válidas com duas dicas apresentadas acima (Figura 22) ou abaixo do centro do campo visual (Figura 23).
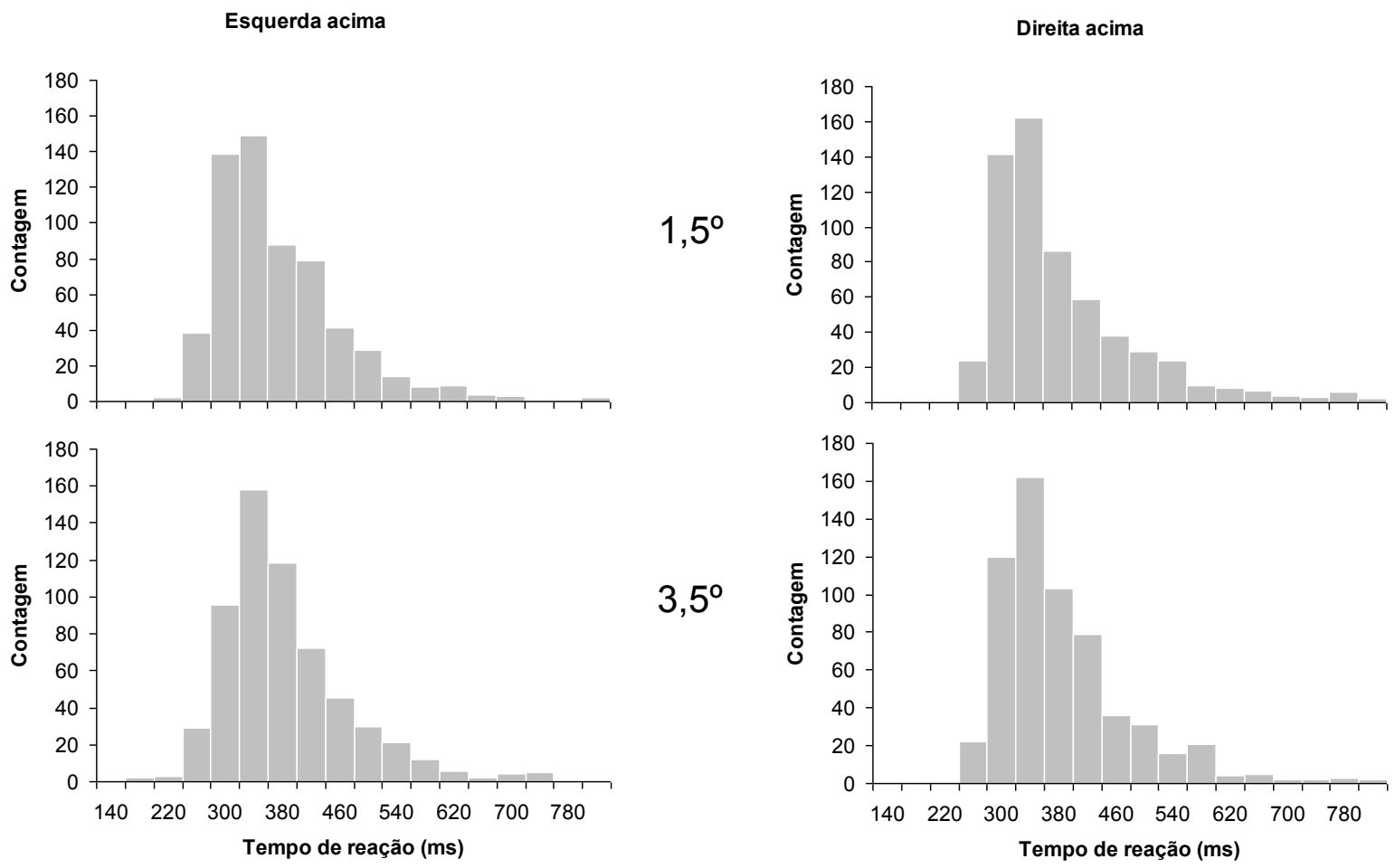

Figura 22. Quatro distribuições de tempo de reação produzidas pela combinação do lado do campo visual em que o alvo foi apresentado acima do estímulo de fixação (esquerda acima ou direita acima) e o tamanho da dica das provas válidas $\left(1,5^{\circ}\right.$ e $3,5^{\circ}$ de ângulo visual). Essas distribuições comportam o tempo de reação das respostas corretas e os valores brutos dos tempos de reação, ou seja, sem o corte de dois desvios padrão mais a média do TRM específico de cada condição experimental. 
Esquerda abaixo
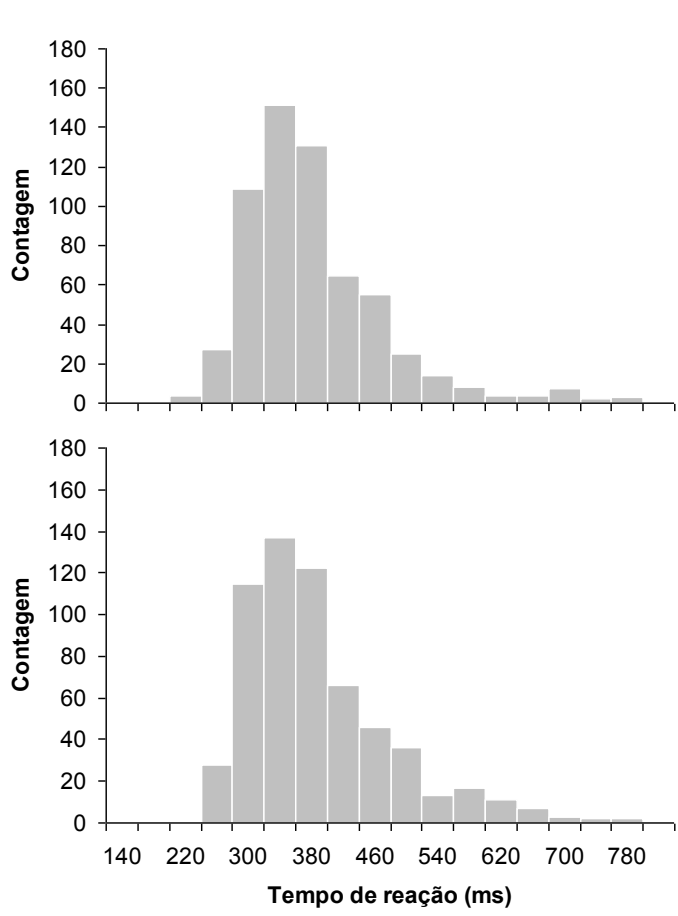

Direita abaixo
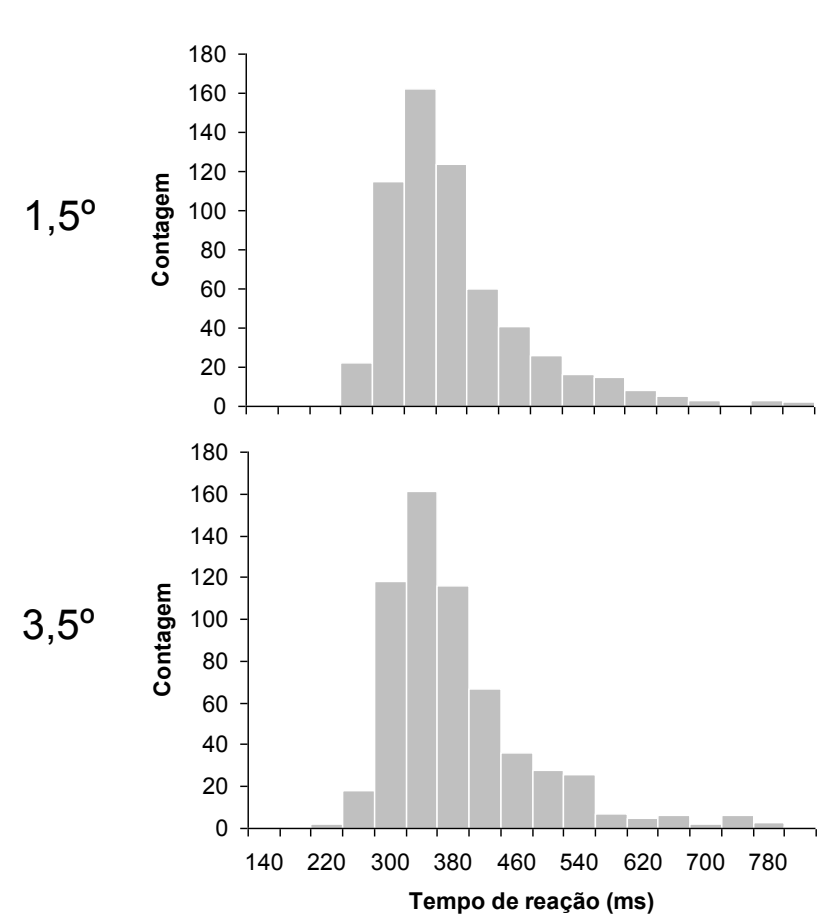

Figura 23. Quatro distribuições de tempo de reação bruto produzidas pela combinação do lado do campo visual em que o alvo foi apresentado abaixo do estímulo de fixação (esquerda abaixo ou direita abaixo) e o tamanho da dica das provas válidas $\left(1,5^{\circ}\right.$ e $3,5^{\circ}$ de ângulo visual).

\section{Tempo de reação manual da sessão experimental sem dicas}

Foram adotados os mesmos critérios para calcular e excluir o TRM da sessão experimental sem as dicas. Os participantes cometeram erros em apenas 3 provas sem alvo. Nenhuma prova foi excluída por apresentar TRM menor do que $150 \mathrm{~ms}$ e $13 \%$ das provas por apresentar TRM maior do que dois desvio padrão mais a média do TRM específico de cada localização em que o alvo foi apresentado.

Uma ANOVA $(p<0,05)$ de uma via para as medidas repetidas do TRM médio das respostas corretas das oito possíveis localizações em que o alvo foi apresentado (abaixo, acima, esquerda, direita, canto inferior esquerdo ou direito e canto superior esquerdo ou direito), revelou um efeito estatisticamente significativo para as localizações $\left(F(7,112)=2,88 ; p<0,01\right.$, parcial $\left.\eta^{2}=0,15\right)$. Comparações pareadas (teste post hoc de Newman-Keuls, $p<0,05)$ entre o TRM das oito localizações revelaram 
que o TRM foi em média $40 \mathrm{~ms}$ mais rápido quando o alvo foi apresentado à esquerda (361 ms) do estímulo de fixação do que no canto inferior esquerdo (401 ms) e uma tendência a ser mais rápido do que nas localizações abaixo (398 ms, $p=0,054)$, à direita (394 ms, $p=0,077)$, canto inferior direito (392 ms, $p=0,064)$ e canto superior direito (397 ms, p=0,052). Apesar de o TRM da localização acima (367 ms) ser em média 27 ms mais rápido do que o TRM das outras localizações (exceto a localização esquerda), as análises não revelaram diferença estatisticamente significativa. O TRM médio de cada localização é mostrado na Figura 24.

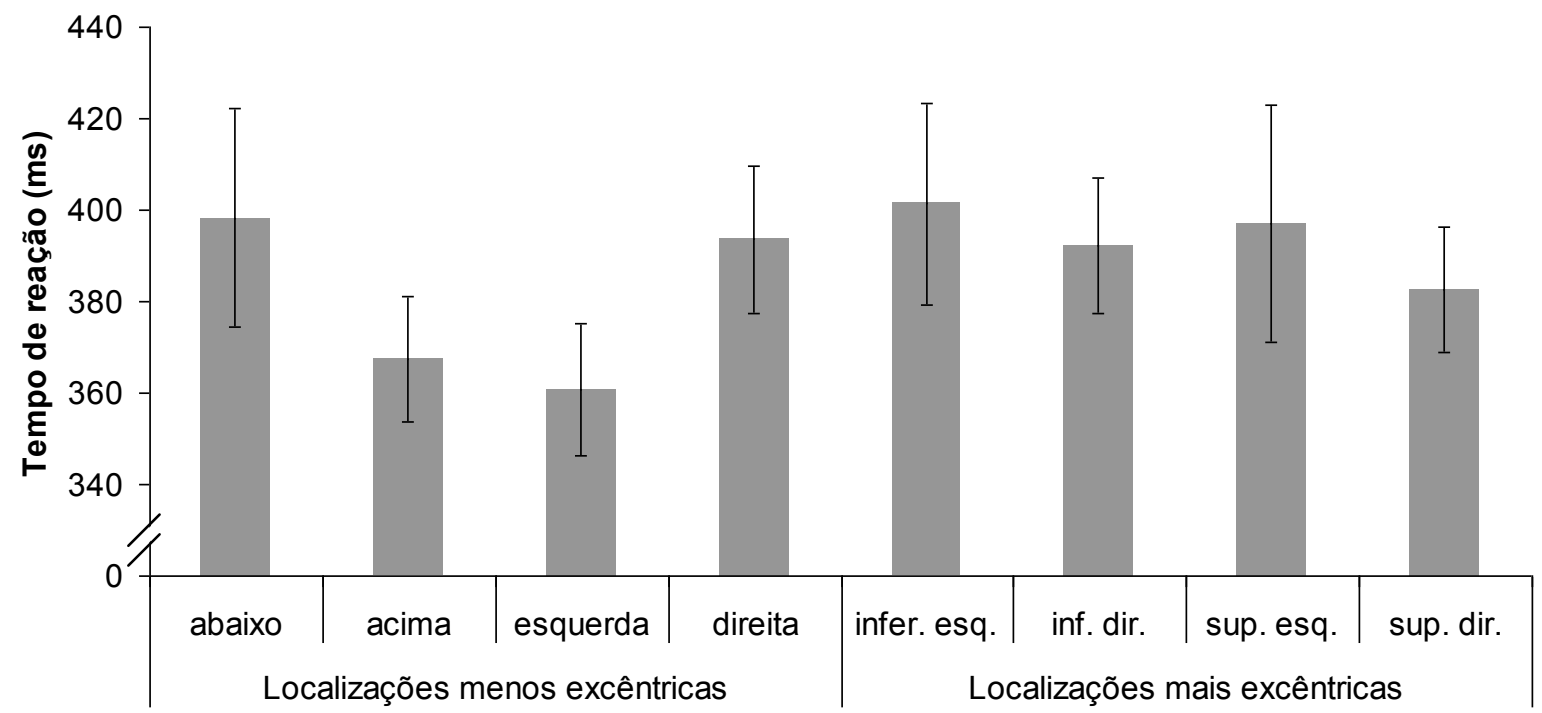

Figura 24. Tempo de reação manual médio da sessão experimental em que apenas o alvo foi apresentado em oito localizações diferentes em volta do estímulo de fixação. As localizações abaixo, acima, à esquerda e à direita do estímulo de fixação eram menos excêntricas do que as localizações posicionadas no canto inferior esquerdo, inferior direito, superior esquerdo e superior direito.

\section{Discussão}

Os resultados mostraram um desempenho melhor nas provas de dica válida com uma ou duas dicas em comparação às provas de dica inválida, inclusive em relação às provas de dica inválida em que o alvo foi apresentado entre as duas 
dicas. Esses resultados não sugerem que tenha ocorrido um foco único de atenção e não confirmam os resultados do Experimento 6. No entanto, quando as duas dicas foram apresentadas, o desempenho melhorou quando o alvo foi apresentado entre as duas dicas (localização acima ou abaixo do estímulo de fixação), comparado ao desempenho das provas em que o alvo foi apresentado fora, mas nos flancos das duas dicas (localização à esquerda ou à direita do estímulo de fixação). Essa vantagem, que foi de $29 \mathrm{~ms}$ em TRM, não parece ser explicada por algum ganho sensorial causado pelas diferentes excentricidades usadas, como revelou a análise da sessão sem as dicas (Figura 24). Essa análise mostrou que o desempenho foi igual entre todas as localizações com maior ou menor excentricidade com exceção da localização esquerda, onde o TRM foi significativamente mais rápido do que algumas localizações. Portanto, o ganho para detectar o alvo entre as duas dicas não pode ser atribuído ao fato de o alvo estar mais perto do centro da tela e, conseqüentemente, mais próximo da área abrangida pela fóvea. Além disso, a comparação entre as provas com uma e duas dicas para as localizações acima/abaixo do estímulo de fixação, mostrou uma vantagem estatisticamente significativa de $17 \mathrm{~ms}$ em TRM para o alvo apresentado entre as duas dicas (Figura 21). Como esses dois tipos de provas foram iguais, exceto pelo número de dicas, a vantagem para detectar o alvo nas localizações acima/abaixo do estímulo de fixação nas provas com duas dicas, só pode ser explicada pela distribuição da atenção pela área entre as dicas. A possibilidade de os participantes terem prestado atenção em uma localização por prova não parece explicar os resultados, já que a inspeção visual das distribuições do TRM das provas de dica válida com duas dicas, não sugere esse tipo de estratégia (Figuras 22 e 23). A possibilidade de o foco ter mudado rapidamente de localização indicada durante o longo período de tempo em 
que os estímulos permaneceram expostos até a resposta ser realizada, pode ter ocorrido, embora esse tipo de estratégia devesse ter produzido TRM's rápidos nas localizações intermediárias às duas dicas também, mas isso não ocorreu. Além disso, esse tipo de estratégia não parece ser tão vantajoso quando o alvo pode aparecer em localizações fora das localizações indicadas, aumentando a chance de prejudicar o desempenho se o alvo aparecer em um local distante daquele indicado.

Portanto, esses resultados sugerem que a região entre as duas dicas recebeu atenção simultaneamente com as duas localizações indicadas, mas que existiu ativação maior de recursos de atenção dentro das duas dicas. Os resultados parecem corroborar com os resultados encontrados por Awh e Pashler (2000). Eles verificaram que estímulos apresentados de maneira abrupta entre dicas periféricas não podem ser completamente ignorados, mesmo assim, a apresentação desses estímulos não excluiu a vantagem em processamento das áreas indicadas. Esse padrão de resultado foi interpretado como indícios de que os recursos de atenção possam ser divididos em forma de gradientes que produzem picos de ativação nos locais indicados, diminuindo nas áreas intermediárias às dicas. Assim, os resultados desse experimento seriam mais bem explicados por um modelo de gradiente de atenção espacial, onde um gradiente pode formar dois picos de ativação de recursos de atenção, correspondendo às localizações de dois alvos apresentados ao mesmo tempo e em locais diferentes do campo visual (Laberge \& Brown, 1989). Como essa proposta considera o foco de atenção como o pico de ativação dos recursos de atenção, o foco pode operar simultaneamente em mais de uma localização não adjacente, portanto, sugerindo que a atenção possa ser dividida.

A distribuição da atenção em gradiente também explicaria porque o efeito do tamanho da dica não foi verificado novamente neste estudo, pois o modelo de 
gradiente de distribuição da atenção não propõe bordas bem delimitadas para o foco de atenção, mas sugere uma diminuição gradual dos recursos de atenção conforme o distanciamento do local que recebe atenção. Outra possível explicação para o efeito do tamanho da dica não ter ocorrido é a divisão dos recursos de atenção, que ao serem orientados a dois locais ao mesmo tempo, perderiam a capacidade de se ajustar ao tamanho dessas áreas, como foi discutido no Experimento 4. Quando duas áreas são indicadas, apenas a orientação da atenção visual ocorreria. No entanto, isso não parece ter ocorrido em Castiello e Umiltà (1992), que encontraram o efeito do tamanho da dica em duas áreas indicadas simultaneamente de cada lado do campo visual. Isso pode ter ocorrido por causa da localização em que o alvo foi apresentado em cada estudo. No estudo de Castiello e Umiltà (1992) o alvo foi apresentado sempre nas mesmas localizações das dicas e isso não ocorreu neste e nos Experimentos 4 a 6 deste estudo, onde o alvo foi apresentado fora das dicas e em diferentes localizações (Experimento 7). A apresentação do alvo fora das dicas pode ter interferido no processo de focalização, que de acordo com Turatto et al (2000) ocorre depois do processo de orientação e pode ser controlado, pelo menos parcialmente (Benso et al., 1998; Greenwood \& Parasuraman, 2004; Yeshurun \& Carrasco, 2008). Assim, o sistema visual pode ter evitado ajustar o foco ao tamanho das dicas porque o alvo poderia aparecer fora das dicas nas provas de dica inválida e os participantes evitaram o ajuste na tentativa de melhorar o desempenho, pois o ajuste consome tempo (Castiello \& Umiltà, 1990) e recursos (Eriksen \& St. James, 1986). Embora a probabilidade de o alvo aparecer fora das dicas tenha sido menor do que a probabilidade de aparecer dentro, isso gerou certa incerteza, o que pode ter ativado algum sistema inibitório de atenção, evitando demandar muitos recursos de atenção para as duas áreas indicadas. Isso parece ser confirmado por 
Greenwood e Parasuraman (2004), que encontraram resultados mostrando que o foco de atenção pode não ser ajustado ao tamanho de áreas indicadas quando a incerteza sobre a localização de apresentação do alvo era grande. Em Castiello e Umiltà (1992) isso parece não ter ocorrido porque os participantes sabiam que o alvo seria apresentado sempre dentro de uma das duas dicas expostas e estudos mostram que dicas periféricas podem produzir um benefício ainda maior em desempenho se forem preditivas, ou seja, se informarem a localização do alvo em mais de $50 \%$ das provas, mesmo sendo expostas por mais de 500 ms antes do alvo (Maruff, Hay, et al., 1995; Maruff, Currie, et al., 1995). Outro estudo que manipulou o tamanho de duas dicas e obteve indícios de que tenha ocorrido o processo de focalização foi o de McCormick, et al. (1998), mas seus resultados indicaram a existência de um foco único de atenção, o que está perfeitamente de acordo com o efeito do tamanho da dica.

Por fim, os resultados desse estudo são contrários aos encontrados por McCormick et al. (1998) e isso parece ter ocorrido devido a localização em que os estímulos foram apresentados. Em McCormick et al. (1998) os estímulos foram alinhados com o meridiano horizontal do campo visual e a localização intermediária às duas dicas estava entre uma das dicas e o estímulo de fixação. Essa disposição dos estímulos parece favorecer um foco único de atenção, pois exige apenas um reajuste do seu tamanho para englobar todas essas localizações dispostas na linha horizontal que cruza o centro do campo visual. Porém, nos experimentos realizados no presente estudo os estímulos foram apresentados sempre no canto superior esquerdo e direito ou inferior esquerdo e direito, portanto fora da área central do campo visual, sendo uma situação um pouco mais complexa, que exigiu a orientação da atenção para essas áreas e não apenas a expansão do foco. 
Os resultados também foram diferentes daqueles obtidos no Experimento 6 para o desempenho das provas em que o alvo foi apresentado entre as duas dicas. No experimento anterior, apresentar o alvo entre as duas dicas ou dentro de uma delas produziu a mesma vantagem em desempenho enquanto nesse experimento apresentar o alvo entre as duas dicas produziu um custo em relação às provas em que o alvo foi apresentado dentro das dicas. Essa diferença só pode ser atribuída à apresentação do alvo nas duas novas localizações fora das dicas. Isso deve ter aumentado a incerteza espacial sobre a localização em que o alvo seria apresentado e, conseqüentemente, aumentou a área a ser monitorada. Um foco muito grande de atenção seria necessário para abranger toda essa área, consumindo muitos recursos de atenção, pois abarcaria uma região interveniente e irrelevante muito grande para a tarefa. Assim, a divisão da atenção ou sua distribuição em um gradiente com picos de ativação nos dois locais indicados parece ser mais eficiente. 
3. Discussão Geral 

O objetivo principal deste estudo foi investigar a distribuição da atenção visual sobre áreas não adjacentes do campo visual, indicadas por dicas espaciais periféricas. Em segundo lugar, verificar se o foco de atenção poderia se ajustar ao tamanho de uma dica usando uma tarefa de JOT. O ajuste do foco ao tamanho da dica permitiria testar se a focalização ocorreria em duas áreas indicadas, levantando evidências de que a atenção poderia ser orientada e ajustada simultaneamente ao tamanho de duas áreas não adjacentes como foi realizado por Castiello e Umiltà (1992). Esse ajuste ou focalização da atenção foi investigado por meio do efeito do tamanho da dica, demonstrado em tarefas de TR onde se observa um aumento gradual do tempo para detectar um alvo apresentado dentro da dica conforme o aumento do tamanho da dica. Esse aumento é interpretado como uma relação inversa entre a concentração de recursos de atenção dentro da área indicada e o tamanho dessa área (Eriksen \& Yeh, 1985; Eriksen \& St. James, 1986). No entanto, esse efeito parece ser observado apenas em condições específicas e com tarefas de TR (Benso et al., 1998; Castiello \& Umiltà, 1990, 1992; Eriksen \& St. James, 1986, Eriksen \& Yeh, 1985; Maringelli \& Umiltà, 1998; Mizuno et al., 1998; Turatto et al. 2000), não existindo, até onde é nosso conhecimento, relatos na literatura do efeito do tamanho da dica com outras tarefas como a de JOT. Essa tarefa seria usada para estudar a divisão do foco neste estudo, caso o feito do tamanho da dica fosse observado por meio da facilitação temporal encontrada com esse tipo de tarefa. Os Experimentos 1a, 1b, e 3c mostraram que em condições com apenas uma dica o efeito do tamanho da dica não ocorreu para o julgamento de ordem temporal com diferentes tipos de alvos, não ocorrendo também quando o intervalo entre a dica e os alvos foi manipulado. No entanto, os Experimentos 2a e 3a mostraram que esse efeito ocorreu quando uma tarefa de TRM foi solicitada e o Experimento $2 b$ quando 
os participantes deveriam realizar uma tarefa de TRS. O tempo de reação nessas tarefas aumentou conforme o aumento do tamanho da dica, sendo mais evidente para a tarefa de TRS quando a dica periférica foi exposta por $100 \mathrm{~ms}$ antes da apresentação do alvo, mas não sendo verificado quando a dica foi exposta por 500 ms. Por outro lado, na tarefa de TRM esse efeito parece ter sido mais acentuado nos 500 ms de exposição da dica do que nos 100 ms. Apesar de a seqüência de apresentação dos estímulos não ter sido idêntica entre a tarefa de JOT e as tarefas de TR, os resultados desses experimentos sugerem que possa existir uma dissociação entre esses dois tipos de tarefas para o efeito do tamanho da dica. Além disso, revela uma dinâmica temporal diferente para esse efeito quando a resposta foi manual e quando foi uma sacada dos olhos para o alvo. O efeito do tamanho da dica encontrado com a tarefa de TRM e com um intervalo de 500 ms de exposição da dica foi semelhante ao relatado na literatura e por esse motivo a tarefa de TRM foi usada nos experimentos subseqüentes para estudar a distribuição da atenção em duas áreas separadas do campo visual e na região entre essas duas áreas. Os resultados dos Experimentos 4 e 7 mostraram que apresentar os estímulos em lados opostos do campo visual pode levar a divisão da atenção visual, que ignoraria parcialmente a região entre as áreas indicadas. Porém, essa interpretação parece depender da quantidade de lugares em que o alvo possa aparecer em volta das áreas indicadas, pois os resultados do Experimento 6 mostraram que a apresentação do alvo entre duas dicas periféricas pode estar dentro de um foco único de atenção quando apenas essa localização é usada. A divisão do foco parece depender também da localização em que os estímulos foram apresentados em relação aos lados do campo visual, pois o Experimento 5 não encontrou evidências de divisão do foco de atenção quando os mesmos estímulos, com as mesmas 
distâncias entre o centro geométrico deles, foram apresentados do mesmo lado do campo visual. Juntos, os resultados dos Experimentos 4, 5, 6 e 7 corroboram com a proposta de que o debate sobre a divisão ou não do foco de atenção deve levar em consideração a localização em que os estímulos são apresentados em relação às metades do campo visual (Kraft et al., 2005).

Além disso, todos os experimentos, com a exceção do Experimento 2c, mostraram que a apresentação abrupta de uma moldura quadrada na periferia do campo visual, alterou o desempenho dos participantes, produzindo uma vantagem em latência temporal nas tarefas de JOT e de TR quando um alvo foi apresentado dentro da moldura. Esses resultados, juntamente com evidências comportamentais e neurofisiológicas de que estímulos de aparecimento abrupto podem capturar a atenção visual, sugerem que os diferentes paradigmas usados neste estudo alteraram a distribuição da atenção, que foi orientada para a moldura.

\subsection{Diferentes resultados entre tarefas para o efeito do tamanho da dica}

Os diferentes resultados obtidos nos Experimentos 1, 2 e 3 desse estudo, com a tarefa de JOT e as tarefas de TR para o efeito do tamanho da dica, podem ser explicados tanto por uma dissociação entre estes dois tipos de tarefa quanto por um ajuste mais flexível do foco ao tamanho da região em que os estímulos ocorreram. No entanto, os resultados desses experimentos não podem confirmar a possibilidade de uma dissociação para o efeito do tamanho da dica entre as duas tarefas, porque as provas em que a tarefa de JOT foi solicitada e as provas em que as tarefas de TR foram realizadas não foram totalmente iguais. Na tarefa de JOT dois alvos foram apresentados, um fora do local indicado e o outro dentro da dica na mesma prova, enquanto que nas provas de TR apenas um alvo foi apresentado por prova. Essa 
diferença entre os dois procedimentos usados em cada tipo de tarefa pode ter eliminado o efeito do tamanho da dica na tarefa de JOT, justamente por ter produzido um reajuste do tamanho do foco de atenção ou uma redistribuição da atenção para uma área maior em volta da moldura usada como dica. Isso pode ter ocorrido devido à apresentação de um alvo dentro e outro fora da dica em todas as provas. Assim, inicialmente, a apresentação abrupta da moldura pode ter capturado a atenção automaticamente, mas devido à moldura ter sido apresentada por mais tempo (500 ms), o processo de ajuste do foco ao tamanho da dica pode não ter ocorrido porque os recursos de atenção foram reajustados para abranger a área maior em volta da moldura ou áreas relevantes onde o outro alvo seria apresentado fora da moldura. De acordo com alguns estudos, isso seria possível, visto que o processo de ajuste ou focalização da atenção poderia ser parcialmente controlado pelo observador em situações onde o indivíduo não sabe exatamente onde o alvo será apresentado (Greenwood \& Parasuraman, 2004; Yeshurun \& Carrasco, 2008). Além disso, esse ajuste mais flexível pode ter ocorrido também nos Experimentos 4 a 7, onde a tarefa era de TRM e o efeito do tamanho da dica não ocorreu. Nestes experimentos, em metade das provas duas dicas foram apresentadas com a possibilidade de o alvo ser apresentado fora das dicas também, ou seja, o alvo poderia aparecer em um número maior de localizações e isso pode ter aumentado a incerteza espacial do participante sobre a localização do alvo. Assim, a apresentação das dicas pode ter orientado o foco de atenção para as áreas indicadas, mas pode não ter sido forte o suficiente para fazer com que o foco fosse ajustado ao seu tamanho, pois o sistema de atenção pode ter sido re-configurado para considerar uma área maior como relevante. Embora essa idéia pareça favorável a um foco único de atenção que se expanda em tamanho, ela pode ser 
complementada pela proposta de gradientes maiores de atenção nos locais indicados ou que as áreas indicadas tiveram prioridade em relação às outras não indicadas (Folk et al., 1992). Isso possibilitaria uma interpretação de que os recursos de atenção foram divididos sobre as duas áreas, porém com outras áreas próximas às dicas com uma relevância ou ativação menor de recursos de atenção.

O efeito do tamanho da dica também foi diferente entre as tarefas de TRM e TRS nos Experimentos 2a, 2b, 3a e 3b. Esse resultado é interessante por que as duas tarefas foram realizadas com a mesma estimulação sensorial, mudando apenas a forma como a resposta foi dada e a forma como a atenção foi orientada (implicitamente e explicitamente). Os resultados revelaram que o tamanho da dica afetou muito mais cedo o TRS do que o TRM. Esse resultado vai ao encontro de estudos revelando uma dissociação entre estes dois tipos de tarefas e pode ser tão interessante para o estudo do sistema visual quanto uma dissociação entre tarefas de JOT e TR, pois pode fornecer pistas sobre o controle dos movimentos de sacada dos olhos e vias neurais por onde a informação passa.

Classicamente os estudos têm comparado as diferenças entre TR e PSS obtidos em tarefas de JOT, revelando que tarefas de TR são mais afetadas pela manipulação dos estímulos do que as tarefas de JOT. Uma explicação para isso é de que respostas de TR e JOT partilham processamentos parciais da informação (Neumann, 1990, Tappe et al., 1994). Tappe et al. baseados em seus resultados e em modelos de "fluxo contínuo" de processamento da informação, ou seja, que o estágio motor é continuamente alimentado por uma resposta preliminar de uma análise sensorial (Eriksen \& Schultz, 1979; McClelland, 1979), concluíram que os sinais dos estímulos que chegam ao sistema visual devem divergir rapidamente, projetando-se diretamente para o sistema motor para uma resposta manual rápida 
ou permitindo processos paralelos de análise sensorial, posteriores e integrativos da informação, produzindo a experiência sensorial subjetiva ou em outras palavras, a representação consciente que é usada no JOT. Embora não se saiba exatamente o que sejam esses processos integrativos, diferenças entre respostas de TR e de JOT podem ser expressas em termos de processos de alimentação (feedforward) e realimentação (feedback) como discutido por Bompas e Sumner (2008). Eles propõem, assim como Lamme e Roelfsema (2000), que projeções de alimentação da informação que vem do meio externo até áreas especializadas de processamento da informação no sistema nervoso central, podem servir vários processos incluindo ações motoras. Conexões adicionais, de realimentação das áreas mais especializadas para áreas menos especializadas e vice versa, seriam necessárias para o estímulo ser conscientemente percebido. Resultados de um estudo com estimulação magnética transcraniana parecem confirmar essa proposta (PascualLeone \& Walsh, 2001). Bompas e Sumner sugerem que o envolvimento de projeções de realimentação para os julgamentos, mas não para respostas rápidas podem explicar as inconsistências entre TR e JOT de duas maneiras. Primeiro, porque as conexões de realimentação consomem tempo e podem misturar a diferença sensorial entre os sinais dos estímulos quando entram no sistema com um ruído, de maneira que qualquer diferença torna-se mais difícil de ser mensurada. Em segundo, porque as conexões de realimentação de áreas de alto nível do sistema nervoso podem corrigir as discrepâncias entre os diferentes sinais e permitir uma recuperação da sincronia entre eles. No entanto, outras explicações também são plausíveis. Miller e Schwarz (2006), por exemplo, desenvolveram e simularam um modelo de difusão com as mesmas observações sensoriais (inputs) e um mesmo sistema perceptual para os dois tipos de tarefas e concluíram que as dissociações 
entre os efeitos observados em tarefas de TR e JOT não representam, necessariamente, alguma diferença profunda nos mecanismos de percepção usados em cada uma dessas tarefas. Ao invés, dependem dos critérios usados pelos participantes para aperfeiçoar o desempenho em cada tarefa.

Nesse contexto, como apontam Jaskowski e Sobieralska (2004), dissociações entre TRM e TRS são interessantes, porque os dois tipos de respostas são respostas de reação motora rápida e nenhuma diferença deveria ser observada. Assim, os resultados podem apontar para outras vias de processamento específicas para a reação de sacadas dos olhos. Essa possibilidade parece ser suportada por resultados anatômicos e neurofisiológicos, demonstrando que sacadas realizadas de maneira automática, em resposta a estímulos de início abrupto apresentados na periferia do campo visual, são mediadas por vias neurais do córtex parietal posterior para o colículo superior, enquanto que sacadas realizadas de maneira voluntária, em resposta a dicas centrais, são mediadas por vias que seguem da área visual frontal para o tronco encefálico (Gaymard, Ploner, Rivaud, Vermersch \& Pierrot-Deseilligny, 1998). Uma explicação possível para a dissociação entre TRM e TRS sugerida por Jaskowski e Sobieralska (2004) é a de que realizar uma sacada em resposta a apresentação abrupta de um estímulo pode requerer um processamento mais simples, de maneira que as características do estímulo não são totalmente reconhecidas enquanto que uma resposta motora ativaria outra via que pode assemelhar-se a resposta realizada por movimentos voluntários de sacada dos olhos. Porém, mais informações e evidências precisam ser adicionadas a esta proposta.

O efeito do tamanho da dica encontrado mais cedo na tarefa de TRS, também revela que o ajuste do foco de atenção ao tamanho de uma dica pode ocorrer mais 
cedo do que foi estimado com tarefas de TRM (Castiello \& Umiltà 1990, 1992). Isso pode não ter relação alguma com essas diferentes vias neurais sugeridas para a resposta manual e motora dos olhos, mas ao invés, refletir diferenças entre a maneira como a atenção foi orientada nos dois tipos de tarefas, ou seja, na tarefa de TRM a atenção foi orientada de maneira implícita enquanto que na tarefa de TRS foi orientada de maneira explícita. Embora estudos com diferentes técnicas tenham obtido evidências de que o sistema óculo-motor e o sistema de atenção partilhem as mesmas áreas e rede neural para serem realizados (Eimer, Velzen, Gherri \& Press, 2007; Nobre, Gitelman, Dias \& Mesulam, 2000), diferentes resultados podem ser encontrados quando a atenção é deslocada de maneira implícita ou explícita, mostrando uma ativação maior de mais áreas quando uma sacada é realizada para um alvo do que quando apenas o deslocamento implícito da atenção ocorre. Existindo também evidências de que esses dois tipos de orientação ativem áreas corticais diferentes (Mort et al., 2003). Embora ainda se saiba pouco sobre a relação entre o sistema de atenção e o sistema-oculomotor, boa parte dos estudos consideram que o deslocamento da atenção para uma área relevante ocorra antes do que o deslocamento dos olhos, pois o destino dos movimentos dos olhos dependeria de informações sobre o local em que os olhos seriam destinados e essas informações seriam extraídas por um processamento preliminar, supostamente guiado pela atenção. Assim, é difícil saber se a atenção visual é deslocada ao mesmo tempo, juntamente ou depois dos movimentos dos olhos para uma determinada coordenada espacial, mas o efeito do tamanho da dica obtido em 100 ms para a tarefa de TRS pode ter ocorrido devido a ativação maior de áreas envolvidas tanto na orientação da atenção quanto na orientação dos olhos para um alvo. Enquanto que na orientação implícita, ou seja, quando a tarefa foi de TRM e os 
olhos permaneceram no ponto de fixação, uma ativação menor tenha ocorrido inicialmente, gerando o efeito do tamanho da dica apenas quando o intervalo entre dica e alvo foi mais longo (500 ms). Mas essas explicações precisam ser mais bem testadas, pois ocorreu uma grande quantidade de erros nos Experimentos $2 \mathrm{a}$ e $2 \mathrm{~b}$ e isso pode ter enviesado o desempenho dos participantes.

\subsection{Distribuição da atenção por áreas não adjacentes do campo visual}

O conjunto de resultados coletados nos Experimentos 4, 5, 6 e 7 deste estudo, realizados para investigar a distribuição da atenção em duas localizações indicadas e espacialmente separadas não parece ser explicado apenas por modelos que propõem a divisão da atenção ou modelos de foco único. Propostas que consideram a atenção como um sistema dinâmico, capaz de operar tanto com um foco único quanto com a divisão da atenção, como o modelo proposto por Kraft et al. (2005) e o modelo de gradiente de distribuição da atenção espacial com picos de ativação dos recursos nas áreas relevantes (Laberge \& Brown, 1989), parecem explicar melhor os resultados obtidos. Primeiro, porque os resultados encontrados nos Experimentos 4 e 7, onde as dicas periféricas foram apresentadas em lados opostos do campo visual, sugerem que a atenção tenha sido dividida. Isso é mais evidente no Experimento 7 onde os diferentes desempenhos entre as condições de dica válida e inválida com duas dicas não pode ser atribuído ao posicionamento do alvo fora de um foco único de atenção (Experimento 6), nem às diferentes excentricidades usadas. Os resultados do Experimento 5, ao contrário, sugerem a existência de um foco único de atenção quando as dicas foram apresentadas praticamente do mesmo lado do campo visual. Embora tenham existido várias diferenças entre este estudo e o estudo de Kraft et al. (2005) quanto ao 
procedimento, localizações e estímulos usados, esses resultados parecem apontar na mesma direção dos obtidos por Kraft et al. Eles usaram duas dicas centrais para apontar ao mesmo tempo duas de quatro localizações onde dois alvos foram apresentados junto com dois estímulos competidores. A tarefa foi comparar a identidade dos alvos que poderiam ser apresentados do mesmo lado do campo visual ou em lados opostos. A dificuldade da tarefa foi manipulada por meio de mudanças nas características dos alvos. Eles verificaram um desempenho melhor para alvos adjacentes do que para alvos separados dentro do mesmo lado do campo visual quando a tarefa solicitada exigia pouco carregamento do sistema, ou seja, quando a tarefa foi classificada como fácil. O desempenho também foi similar tanto para alvos adjacentes quanto separados quando apresentados em lados opostos do campo visual. Porém, quando a tarefa solicitada foi difícil, o desempenho foi sempre melhor para estímulos apresentados em lados diferentes, indicando uma vantagem bilateral de campo. Os resultados foram interpretados como indícios de que os recursos de atenção foram mais restritos dentro de um único lado do campo visual comparado aos dois lados. Baseados nestes resultados e em diferentes estudos que investigaram movimentos oculares (Corbetta et al., 1998; Sereno \& Kosslyn, 1991) e pacientes que tiveram o corpo caloso seccionado (Banich, 1998; Holtzmann, 1981; Luck et al., 1989; Mangun et al. 1994), além de estudos que mostram uma vantagem bilateral de campo (Brown, Jeeves, 1993; Sereno \& Kosslyn, 1991), eles sugeriram um modelo onde a atenção pode ser dividida entre lados oposto do campo visual, mas formar um foco único dentro de apenas um lado. Além disso, o modelo prevê que quando a atenção é dividida entre campos opostos, ocorre um aumento na quantidade de recursos de atenção. De acordo com a sua proposta, isso ocorreria porque cada hemisfério cerebral seria capaz de controlar 
dois sistemas parcialmente independentes de atenção, interligados por processos óculo-motor. Eles sugeriram também dois estágios de processamento de acordo com o modelo de Lavie (1995): um estágio inicial, onde a atenção pode estar em um foco único dentro de cada lado do campo visual e um posterior, que selecionaria os estímulos de acordo com as características da tarefa. Quando os estímulos são apresentados em lados opostos do campo visual e os dois hemisférios estão ativos, a informação pode ser processada mais eficientemente, pois teria mais recursos de atenção disponíveis. Assim, esse modelo parece mais adequado para explicar os resultados obtidos neste estudo, sugerindo que a habilidade para dividir a atenção visual pode depender da localização em que os estímulos ocorrem em relação ao lado do campo visual.

Além disso, os resultados do Experimento 7 mostraram que apesar de existir uma vantagem maior para as localizações indicadas, o desempenho não foi uniforme entre as localizações apresentadas fora das provas com duas dicas. O desempenho em TR foi melhor nas localizações entre as duas dicas do que nas localizações que as flanqueavam. Embora esses resultados não demonstrem uma diminuição gradual do desempenho em função da distância, pois as localizações do estímulo apresentado fora das dicas foi sempre a mesma, eles sugerem que as áreas indicadas não são como ilhas cercadas por completa ausência de processamento dos estímulos (Awh \& Pashler, 2000). Assim, a apresentação das duas dicas pode ter gerado um gradiente de processamento que atingiu um pico em cada localização indica, declinando nas localizações intervenientes e diminuindo ainda mais fora da zona entre as duas dicas. Essa interpretação encontra respaldo em outros resultados obtidos no estudo de Awh e Pashler e que são muito semelhantes aos encontrados no Experimento 7. Eles investigaram a possibilidade 
de a atenção ser dividida quando duas localizações não adjacentes foram indicadas por dicas periféricas. As dicas foram expostas por um período longo de tempo (750 ms) antes de dois alvos aparecerem nos dois locais indicados ou em duas localizações fora do local indicado (i.e., uma localização entre as duas localizações indicadas e outra fora dessa área). A tarefa foi identificar os dois alvos e os resultados mostraram um desempenho melhor para identificar os alvos nas localizações indicadas do que na localização interveniente e um resultado melhor ainda quando comparado à localização fora dessa área. Além disso, o desempenho foi melhor para a localização entre as duas dicas do que para a localização distante. Os resultados também foram replicados em outros experimentos do estudo, inclusive quando apenas um alvo foi apresentado nas diferentes localizações (Experimento 1a), condição semelhante a do Experimento 7 do presente estudo. Além destes resultados, Awh e Pashler verificaram que quando as duas localizações foram indicadas de cada lado do campo visual (i.e., esquerda e direita) o desempenho foi melhor do que quando as duas localizações foram indicadas do mesmo lado (i.e., acima e abaixo, mas do lado esquerdo ou do lado direito do centro da tela). Embora as duas situações tenham sugerido a divisão da atenção, eles realizaram um controle para verificar se essa diferença poderia ser atribuída a uma vantagem bilateral de campo e encontraram resultados favoráveis a esta hipótese. Silva e Ribeiro-do-Valle (2008), também demonstraram que a atenção pode ser dividida do mesmo lado do campo visual, mas de maneira automática, corroborando com resultados de Hahn e Kramer (1998), enquanto que em Awh e Pashler essa divisão pode ser considerada voluntária pelo longo tempo de exposição das dicas periféricas. Como apontado por Silva e Ribeiro-do-Valle, esses resultados podem 
indicar que o mecanismo de atenção de cada hemisfério pode controlar pelo menos dois focos independentes de facilitação em cada lado do campo visual. No entanto, os resultados dos Experimentos 4, 5 e 7 deste estudo parecem indicar que seja mais fácil dividir a atenção quando os eventos ocorrem simultaneamente de cada lado do campo visual do que do mesmo lado. Assim, a conclusão de Awh e Pashler de que a divisão ou não da atenção em um mesmo lado do campo visual deve ser relativa e não absoluta, parece mais adequada explicar os diversos resultados obtidos.

Por outro lado, os resultados do Experimento 6 mostraram que em algumas situações pode ser mais fácil manter um foco único de atenção, mesmo que as localizações indicadas ocorram em lados apostos. Este experimento foi o único a mostrar um aumento gradual do TRM conforme o aumento do tamanho da dica, quando duas dicas foram apresentadas. Esse efeito, juntamente com o desempenho igual para as provas em que o alvo foi apresentado dentro e entre as duas dicas, sugere que o foco de atenção foi único e que se expandiu para abarcar tanto as dicas quanto a região intermediária. Embora os resultados sugiram que o ajuste não tenha ocorrido quando apenas uma dica foi apresentada, os resultados são semelhantes aos encontrados por McCormick, et al. (1998). Isso pode ter ocorrido por que em circunstancias onde existam poucos locais para um evento ocorrer, ou seja, em uma área relativamente pequena a ser monitorada, seja mais fácil manter um foco único sobre estas áreas do que em situações onde a área é muito grande. Em condições onde a área é grande, dividir a atenção seja melhor para o desempenho, evitando despender recursos de atenção em áreas intervenientes e irrelevantes para a tarefa (McMains \& Somers, 2005). 
Embora o presente estudo tenha assumido que a atenção visual possa ser destinada principalmente a localizações espaciais, existem também evidências de que a atenção possa ser destinada a objetos ao invés de localizações (Baylis \& Driver, 1993; Duncan, 1984; Gibson, 1994; Kahneman, Treisman \& Gibbs, 1992; Kramer \& Jacobson, 1991). Essas evidências surgem de diferentes paradigmas experimentais. Duncan (1984), por exemplo, mostrou que é mais fácil julgar duas propriedades de um mesmo objeto do que julgar duas propriedades de objetos diferentes, mesmo que a distância espacial entre esses objetos fosse a mesma. Outros resultados têm mostrado que um objeto em movimento pode capturar a atenção, que seguiria este objeto (Driver \& Baylis, 1989). Assim, a atenção pode ser dividida em regiões não contíguas do espaço quando objetos com características semelhantes ocorrerem um uma cena.

Apesar de essa proposta não excluir a possibilidade de a atenção ser destinada a localizações espaciais, ela não parece ser uma alternativa para explicar esses resultados porque o paradigma usado nos experimentos deste estudo foi diferente do usado nos estudos que investigam a seleção de objetos. Isto é, os participantes realizaram a detecção de um alvo apresentado em diferentes localizações indicadas por dicas espaciais e não um julgamento das propriedades de dois objetos apresentados na mesma localização. Além disso, nenhum estímulo foi apresentado em movimento.

Finalmente, a discussão sobre a capacidade de dividirmos ou não a atenção visual parece ganhar maior complexidade, passando-se a questionar quais fatores ou situações contribuem para a divisão ou não da atenção. Estudos que utilizaram a técnica de fMRI indicam que em determinadas situações seja até vantajoso dividir a 
atenção dependendo do tamanho da área a ser monitorada (McMains \& Somers, 2005). E estudos e propostas que sugiram uma distribuição mais flexível em relação às localizações em que os eventos ocorrem parece ganhar maior respaldo (Kraft et al., 2005; Awh \& Pashler, 2000). As diferenças no desempenho nestas duas tarefas sugerem um tema promissor para futuras investigações.

\section{Conclusão}

As evidências encontradas neste estudo sugerem que a atenção visual pode ser dividida em mais de uma localização não adjacente. A habilidade para dividirmos a atenção visual sobre áreas não adjacentes pode depender das localizações onde os eventos ocorrem em relação ao lado do campo visual, assim como do tamanho da área a ser processada pelo sistema de atenção. Além disso, não encontramos evidências de que a manipulação do tamanho de uma moldura afetasse a latência temporal em uma tarefa de JOT, afetando apenas o TR em tarefas de detecção simples de um alvo. 



\section{REFERÊNCIAS BIBLIOGRÁFICAS}

Arguin, M., Lassonde, M., Quattrini, A., Del Pesce, M., Foschi, N., \& Papo I. (2000). Divided visuo-spatial attention systems with total and anterior callosotomy. Neuropsychologia, 38, 283-291.

Awh, E., \& Pashler, H. (2000). Evidence for split attentional foci. Journal of Experimental Psychology: Human Perception \& Performance, 26, 834-846.

Bahcall, D.O., \& Kowler, E. (1999). Attentional interference at small spatial separations. Vision Research, 39, 71-86.

Banich, M.T. (1998). The missing link: the role of interhemispheric interaction in attentional processing. Brain and Cognition, 36(2), 128-57.

Baylis, G.C., \& Driver, J. (1993). Visual attention and objects: evidence for hierarchical coding of location. Journal of Experimental Psychology: Human Perception \& Performance, 19, 451-470.

Benso, F., Turatto, M., Mascetti, G.G., \& Umiltà, C. (1998). The time course of attention focusing. European Journal of Cognitive Psychology, 10, 373-388.

Bichot, N.P., Cave, K.R., \& Pashler, H. (1999). Visual selection mediated by location: Feature-based selection of noncontiguous locations. Perception \& Psychophysics, 61, 403-423.

Bompas, A., \& Sumner, P. (2008). Sensory sluggishness dissociates saccadic, manual, and perceptual responses: an S-cone study. Journal of Vision, 8, 1-13.

Brefczynski, J.A., \& DeYoe E.A. (1999). A physiological correlate of the 'spotlight' of visual attention. Nature Neuroscience, 2, 370-374.

Brown, W.S., \& Jeeves, M.A. (1993). Bilateral visual field processing and evoked potential interhemispheric transmission time. Neuropsychologia, 31(12), 1267-81.

Castiello, U., \& Umiltà, C. (1990). Size of the attentional focus and efficiency of processing. Acta Psychologica, 73, 195-209.

Castiello, U., \& Umiltà, C. (1992). Splitting focal attention. Journal of Experimental Psychology: Human Perception \& Performance, 3, 837-848.

Cavallet, M., Galera, C., Von Grünau, M., \& Afroditi, P. (no prelo). Distribution of visual attention within a cued area: Evidence based on temporal order judgments. Psicologia: Reflexão e Crítica, 24(3).

Cheal, M., \& Lyon, D.R. (1991). Central and peripheral precuing of forced-choice discrimination. Q. J. Exp. Psychol. 43A, 859-880.

Colegate, R., Hoffman, J.E., \& Eriksen, C.W. (1973). Selective encoding from multielement visual displays. Perception \& Psychophysics, 14, 217-224. 
Driver, J., \& Baylis, G. C. (1989). Movement and visual attention: The spotlight metaphor breaks down. Journal of Experimental Psychology: Human Perception \& Performance, $15,448-456$.

Duncan, J. (1984). Selective attention and the organization of visual information. Journal of Experimental Psychology: General, 113, 501-517.

Egeth, H.E., \& Yantis, S. (1997). Visual attention: control, representation, and time course. Annual Rev. Psychol., 48, 269-297.

Egly, R., \& Homa, D. (1984). Sensitization of the visual field. Journal of Experimental Psychology: Human Perception \& Performance, 10, 778-793.

Eimer, M., Van Velzen, J., Gherri, E., \& Press, C. (2007). ERP correlates of shared control mechanisms involved in saccade preparation and in covert attention. Brain Research, 1135, 154-166.

Eriksen, C.W., \& Collins, J.F. (1969). Visual perceptual rate under two conditions of search. Journal of Experimental Psychology, 80, 489-492.

Eriksen, C.W., \& Hoffman, J.E. (1972). Temporal and spatial characteristics of selective encoding from visual displays. Perception \& Psychophysics, 12, 201204.

Eriksen C.W., Pan, K., \& Botella, J. (1993). Attentional distribution in visual space. Psychological Research,56, 5-13.

Eriksen, C.W., \& Schultz, D.W. (1979). Information processing in visual search: A continuous flow conception and experimental results. Perception \& Psychophysics, 25, 249-263.

Eriksen, C.W., \& St. James, J.D. (1986). Visual attention within and around the field of focal attention: A zoom lens model. Perception \& Psychophysics, 40, 225-240.

Eriksen, C. W., \& Yeh, Y. (1985). Allocation of attention in the visual field. Journal of Experimental Psychology: Human Perception \& Performance, 11, 583-597.

Fischer, B. (1998). Attention in Saccades. In: R.D. Wright (Ed.) Visual Attention, (pp. 289-305). New York: Oxford University Press.

Folk, C.L., Remington, R.W., \& Johnston, J.C. (1992). Involuntary covert orienting is contingent on attentional control settings. Journal of Experimental Psychology: Human Perception \& Performance, 18, 1030-1044.

Galera, C., Cavallet, M., Von Grunau, M., \& Panagopoulos, A. (2006). Características atentivas reveladas por dicas múltiplas locais e globais. Psicologia: Teoria e Pesquisa, 22, 327-334.

Galera, C., Von Grünau, M., \& Panagopoulos, A. (2005). Automatic focusing of attention on object size and shape. Psicológica, 26, 147-160. 
Gaymard, B., Ploner, C.J., Rivaud, S., Vermersch, A.I., \& Pierrot-Deseilligny, C. (1998). Cortical control of saccades. Experimental Brain Research, 123, 159-163.

Gibson, B.S. (1994). Visual attention and objects: one versus two or convex versus concave? Journal of Experimental Psychology: Human Perception \& Performance, 20, 203-207.

Greenwood, P.M., \& Parasuraman, R. (1999). Scale of attentional focus in visual search. Perception \& Psychophysics, 61, 837-859.

Greenwood, P.M., \& Parasuraman, R. (2004). The scaling of spatial attention in visual search and its modification in healthy aging. Perception \& Psychophysics, $\underline{66}, 3-22$.

Greenwood, P.M., Parasuraman, R., \& Alexander, G.E. (1997). Controlling the focus of spatial attention during visual search: Effects of advanced aging and Alzheimer disease. Neuropsychology, 11, 3-12.

Hahn, S., \& Kramer, A. F. (1995). Attentional flexibility and aging: you don't need to be 20 years of age to split the beam. Psychology and Aging, 10, 597-609.

Hahn, S., \& Kramer, A. F. (1998). Further evidence for the division of attention among non-contiguous locations. Visual Cognition, 5, 217-256.

Heinze, H.J., Luck, S.J., Münte, T.F., Gös, A., Mangun, G.R., \& Hillyard, S.A. (1994). Attention to adjacent and separate positions in space: an electrophysiological analysis. Percept Psychophysics, 56(1), 42-52.

Hikosaka, O., Miyauchi, S., \& Shimojo, S. (1993). Focal visual attention produces illusory temporal order and motion sensation. Vision Research, 33, 1219-1240.

Holtzmann, J.D. (1981). Interactions between cortical and subcortical visual areas: evidence from human commissurotomy patients. Visual Research, 24, 801-813.

Hughes, H.C., \& Kesley, J.V. (1984). Response-dependent effects on near-threshold detection performance: Saccades versus manual responses, Perception \& Psychophysics, 35, 543-546.

Humphreys, G.W., \& Bruce, V. (1989). Visual Cognition. Hillsdale, NJ: Erlbaum.

Jaskowski, P. (1992). Temporal order judgment and reaction time for short and long stimuli. Psychological Research, 54, 141-145.

Jaskowski, P. (1993). Temporal-order judgmente and reaction time to stimuli of different rise times. Perception, 22, 963-970.

Jaśkowski, P., \& Sobieralska, K. (2004). Effect of stimulus intensity on manual and saccadic reaction time. Perception and Psychophysics, 66, 535-544. 
Juola, J.F., Crouch, T., \& Cocklin, T. (1987). Voluntary control of attention near the fovea. Acta Psychologica, 63, 207-217.

Juola, J.F., Bouwhuis, D.G., Cooper, E.E., \& Warner, C.B. (1991). Control of attention around the fovea. Journal of Experimental Psychology: Human Perception \& Performance, 17, 125-141.

Jonides, J., \& Yantis, S. (1988). Uniqueness of abrupt visual onset in capturing attention. Perception \& Psychophysics, 43, 346-354.

Jonides, J. (1981). Voluntary versus automatic control over the mind's eye's movement. In J.B.Long \& A.D. Baddeley (Eds.), Attention and Performance IX, (pp. 187-203). Hillsdale, NJ: Erlbaum.

Jonides, J. (1983). Further toward a model of the mind's eye's movement. Bulletin of the Psychonomic Society, 21, 247-250

Kahneman, D., Treisman, A., \& Gibbs, B. (1992). The reviewing of object files: Object-specific integration of information. Cognitive Psychology, 24, 175-219.

Kastner, S., De Weerd, P., Desimone, R., \& Ungerleider, L.G. (1998). Mechanisms of directed attention in the human extrastriate cortex as revealed by functional MRI. Science, 282, 108-111.

Kraft, A., Müller, N.G., Hagendorf, H., Schira, M.M., Dick, S., Fendrich, R.M., \& Brandt, S.A. (2005). Interactions between task difficulty and hemispheric distribution of attended locations: implications for the splitting attention debate. Brain Research. Cognitive Brain Research, 24(1),19-32.

Kramer, A. F., \& Hahn, S. (1995). Splitting the beam: Distributions of attention over noncontiguous regions of the visual field. Psychological Science, 6, 381-385.

Kramer, A. F., \& Jacobson, A. (1991). Perceptual organization and focused attention: The role of objects and proximity in visual processing. Perception \& Psychophysics, 50, 267-284.

Kröse, B.J., \& Julesz, B. (1989). The control and speed of shifts of attention. Vision Research, 29, 1607-1619.

LaBerge, D. (1983). Spatial extent of attention to letters and words. Journal of Experimental Psychology: Human Perception \& Performance, 9, 371-379.

LaBerge, D., \& Brown, V. (1989). Theory of attentional operation in shape identification. Psychological Review, 96, 101-124.

Laberge, D., Carlson, R.L., Williams, J.K., \& Bunney, B.G. (1997). Shifting attention in visual space: tests of moving-spotlight models versus an activity-distribution model. Journal of Experimental Psychology: Human Perception \& Performance, $\underline{23}, 1380-1392$. 
Lambert, A., Spencer, M., \& Hockey, R. (1991). Peripheral visual changes and spatial attention. Acta Psychologica (Amst), 76, 149-163.

Lamme, V.A., \& Roelfsema, P.R. (2000). The distinct modes of vision offered by feedforward and recurrent processing. Trends in Neurosciences, 23, 571-579.

Lavie, N. (1995). Perceptual load as a necessary condition for selective attention. Journal of Experimental Psychology: Human Perception \& Performance, 21, 451468.

Luck, S.J., Hillyard, S.A., Mangun, G.R., \& Gazzaniga, M.S. (1989). Independent hemispheric attentional systems mediate visual search in split-brain patients. Nature, 342, 543-545.

Mangun, G.R., Luck, S.J., Plager, R., Loftus, W., Hillyard, S.A., Handy, T., Clark, V.P., \& Gazzaniga, M.S. (1994). Monitoring the visual world: hemispheric asymmetries and subcortical processes in attention. Journal of Cognitive Neuroscience. 6, 267-275.

Maringelli, F., \& Umiltà, C. (1998). The control of the attentional focus. European Journal of Cognitive Psychology, 10, 225-246.

Maruff, P., Currie, J., McArthur, C., \& Malone, V. (1995). Asymmetries in the orienting of covert visual attention in Alzheimer's disease. Brain, 118, 1421-1426.

Maruff, P., Hay, D., Malone, V., \& Currie, J. (1995). Asymmetries in the covert orienting of visual spatial attention in schizophrenia. Neuropsychologia, 33, 12051223.

Maruff, P., Yucel, M., Danckert, J., Stuart, G., \& Currie, J. (1999). Facilitation and inhibition arising from the exogenous orienting of covert attention depends on the temporal properties of spatial cues and targets. Neuropsychologia, 37, 731-744.

Masland, R.H. (2001). The fundamental plan of the retina. Nature Neuroscience, 4 , 877-886.

McClelland, J.L. (1979). On the time relations of mental processes: An examination of systems of processes in cascade. Psychological Review, 86, 287-330.

McCormick, P.A., \& Klein, R. (1990). The spatial distribution of attention during covert visual orienting. Acta Psychologica, 75, 225-242.

McCormick, P.A., Klein, R.M., \& Johnston, S. (1998). Splitting versus sharing focal attention: comment on Castiello and Umiltà (1992). Journal of Experimental Psychology: Human Perception and Performance, 24(1), 350-357.

McDonald, J.J., Teder-Sälejärvi, W.A., Di Russo, F., \& Hillyard, S.A. (2005). Neural basis of auditory-induced shifts in visual time-order perception. Nature Neuroscience, 8, 1197-1202. 
McMains, S.A., \& Somers, D.C. (2004). Multiple spotlights of attentional selection in human visual cortex. Neuron, 42, 677-686.

McMains, S.A., \& Somers, D.C. (2005). Processing efficiency of divided spatial attention mechanisms in human visual cortex. The Journal of Neuroscience, 25 , 9444-9448.

Miller, J., \& Schwarz, W., (2006). Dissociations between reaction time and temporal order judgments: A diffusion model approach. Journal of Experimental Psychology: Human Perception and Performance, 32, 394-412.

Mizuno, M., Umiltà, C., \& Sartori, G. (1998). Deficits in the control of the attentional focus in chronic schizophrenics. Cortex, 34, 263-270.

Mort, D.J., Perry, R.J., Mannan, S.K., Hodgson, T.L., Anderson, E., Quest, R., McRobbie, D., McBride, A., Husain, M., \& Kennard, C. (2003). Differential cortical activation during voluntary and reflexive saccades in man. Neuroimage, 18, 231246.

Motter, B.C. (1993). Focal attention produces spatially selective processing in visual corticalareas V1, V2 and V4 in the presence of competing stimuli. Journal of Neurophysiology, 70, 909-919.

Müller, N.G., Bartelt, O.A., Donner, T.H., Villringer, A., \& Brandt, S.A. (2003). A physiological correlate of the "Zoom Lens" of visual attention. The Journal of Neuroscience, 23, 3561-3565.

Müller, H.J., \& Findlay, J.M. (1987). Sensitivity and criterion effects in the spatial cuing of visual attention. Perception \& Psychophysics, 42, 383-399.

Müller, H.J., \& Findlay, J.M. (1988). The effect of visual attention on peripheral discrimination thresholds in single and multiple element displays. Acta Psychologica, 69, 129-155.

Müller, M.M., \& Hübner, R. (2002). Can the spotlight of attention be shaped like a doughnut? Psychological Science, 13, 119-124.

Müller, N.G., \& Kleinschmidt, A. (2004). The attentional 'spotlight's' penumbra: center-surround modulation in striate cortex. Neuroreport, 29, 977-980.

Müller, M.M., Malinowski, P., Gruber, T., \& Hillyard, S.A. (2003). Sustained division of the attentional spotlight. Nature, 424, 309-312.

Müller, N.G., Mollenhauer, M., Rösler, A., \& Kleinschmidt, A. (2005). The attentional field has a Mexican hat distribution. Vision Research, 45, 1129-1137.

Müller, H.J., \& Rabbitt, P.M.A. (1989). Reflexive and voluntary orienting of visual attention: time course of activation and resistance to interruption. J. Exp. Psychol.: Hum. Percept. Perform., 15, 315-330. 
Nakayama, K., \& Mackeben, M. (1989). Sustained and transient components of focal visual attention. Visual Research, 29, 1631-1647.

Neumann, O., \& Esselmann, U. (1992). Visual attention, response latency, and temporal order judgement. International Journal of Psychology, 27, 13.

Neumann, O., Esselmann, U., \& Klotz, W. (1993). Differential effects of visual spatial attention on response latency and temporal orer judgment. Psychological Research, 56, 26-34.

Nobre, A.C., Gitelman, D.R., Dias, E.C., \& Mesulam, M.M. (2000). Covert visual spatial orienting and saccades: overlapping neural systems. Neuroimage, 11, 210-216.

Noesselt, T. Hillyard, S.A., Woldorff, M.G., Schoenfeld, A., Hagner, T., Jancke, L., Tempelmann, C., Hinrichs, H., \& Heinze, H.J. (2002). Delayed striate cortical activation during spatial attention. Neuron, 35, 575-587.

Palmer, S.E. (1999). Vision Science: Photons to Phenomenology. MIT Press, Cambridge.

Pan, K., \& Eriksen, C.W. (1993). Attentional distribution in the visual field during same-different judgments as assessed by response competition. Percept Psychophysics, 53(2), 134-44.

Panagopoulos, A., von Grünau, M.W., \& Galera, C. (2004). Attentive mechanisms in visual search. Spatial Vision, 17, 353-371.

Panagopoulos A., von Grünau, M.W. Galera, C., Ivan, L., \& Cavallet, M. (2006). Does the strength of the attentional focus depend on the size of the cued area? Vision Sciences Society: $6^{\text {th }}$ Annual Meeting.

Park, J., Schlag-Rey, M., \& Schlag, J. (2003). Spatial localization precedes temporal determination in visual perception. Vision Research, 43, 1667-1674.

Pascual-Leone, A., \& Walsh, V. (2001). Fast backprojections from the motion to the primary visual area necessary for visual awareness. Science, 292, 510-512.

Pashler, H., Johnston, J.C., \& Ruthruff, E. (2001). Attention and performance. Annual Review of Psychology, 52, 629-651.

Posner, M. I. (1980). Orienting of attention. Quarterly Journal of Experimental Psychology, 32, 3-25.

Posner, M.I., \& Cohen, Y. (1984). Components of visual orienting. In Bouma, H., \& Bouwhuis, D.G. (eds). Attention and performance $X$, (pp 531-556). Erlbaum, Hillsdale, NJ.

Posner, M. I., Snyder, C. R. R., \& Davidson, B. J. (1980). Attention and the detection of signals. Journal of Experimental Psychology: General, 109, 160-174. 
Pratt, J., \& Abrams, R.A. (1995). Inhibition of return to successively cued spatial locations. Journal of Experimental Psychology: Human Perception \& Performance, 21, 1343-1353.

Rafal RD, Calabresi PA, Brennan CW, \& Sciolto TK. (1989). Saccade preparation inhibits reorienting to recently attended locations. Journal of Experimental Psychology: Human Perception \& Performance, 15, 673-685.

Remington, R.W., Johnston, J.C., \& Yantis, S. (1992). Involuntary attention capture by abrupt onsets. Perception \& Psychophysics, 51, 279-290.

Roufs, J.A.J. (1974). Dynamic properties of vision-V. Perception lag and reaction time in relation to flicker and flash thresholds. Vision Research, 14, 853-869.

Scharlau, I. (2004a). Evidence against response bias in temporal order tasks with attention manipulation by masked primes. Psychological Research, 68, 224-236.

Scharlau, I. (2004b). Evidence for split foci of attention in a priming paradigm. Perception \& Psychophysics, 66, 988-1002.

Schneider, K.A., \& Bavelier, D. (2003). Components of visual prior entry. $\underline{\text { Cognitive }}$ Psychology, 47, 333-366.

Serences, J.T., \& Yantis, S. (2006). Selective visual attention and perceptual coherence. Trends in Cognitive Sciences, 10(1), 38-45.

Sereno, A.B., \& Kosslyn, S.M. (1991). Discrimination within and between hemifields: a new constraint on theories of attention. Neuropsychologia, 29(7), 659-75.

Shore, D.I., Spence, C., \& Klein, R.M. (2001). Visual prior entry. Psychological Science, 12, 205-212.

Shulman, G.L., Sheehy, J.B., \& Wilson, J. (1986). Gradients of spatial attention. Acta Psychologica, 61, 167-181.

Silva, P.S., \& Ribeiro-do-Valle, L.E. (2008). Evidence for divided automatic attention.Brazilian Journal of Medical and Biological Research, 41, 159-169.

Spence, C., \& Parise, C. (2009). Prior-entry: A review. Consciousness and Cognition, $\underline{19}, 364-379$.

Stelmach, L.B., \& Herdman, C.M. (1991). Directed attention and perception of temporal order. Journal of Experimental Psychology: Human Perception and Performance, $17,539-550$.

Sternberg, S., \& Knoll, R.L. (1973). The perception of temporal order: fundamental issues and a general model. Em: Kornblum, S. (Editor), Attention and Performance IV. Academic Press, New York, NY, USA, 629-685. 
Tappe, T., Niepel, M., \& Neumann, O. (1994). A dissociation between reaction time to sinusoidal gratings and temporal-order judgment. Perception, 23, 335-347.

Theeuwes, J. (1995). Abrupt luminance change pops out; abrupt color change does not. Perception \& Psychophys, 57, 637-644.

Titchener, E.B. (1908). Lectures on the elementary psychology of feeling and attention. New York: Macmillan.

Turatto M., Benso F., Facoetti A., Galfano G., Mascetti G.G., \& Umiltà C. (2000). Automatic and voluntary focusing of attention. Perception \& Psychophysics, 62, 935-952.

Vecera, S.P., \& Rizzo, M. (2003). Spatial attention: normal processes and their breakdown. Neurologic Clinics of North America, 21, 575-607.

Vibell, J., Klinge, C., Zampini, M., Spence, C., \& Nobre, A.C. (2007). Temporal order is coded temporally in the brain: early event-related potential latency shifts underlying prior entry in a cross-modal temporal order judgment task. Journal of Cognitive neuroscience, 19, 109-120.

Von Grünau, M., \& Faubert, J. (1994). Intraattribute and interattribute motion induction. Perception, 23, 913-928.

Weichselgartner, E., \& Sperling, G. (1987). Dynamics of automatic and controlled visual attention. Science, 6 , 778-780.

Whelan, R. (2008). Effective analysis of reaction time data. The Psychological Record, 58, 475-482.

Wright, R. D. (1994). Shifts of visual attention to multiple simultaneous location cues. Canadian Journal of Experimental Psychology, 48, 205-217

Wright, R. D., \& Ward, L. M. (1998). The control of visual attention. In Wright, R.D. (Ed.), p. 132-186, Visual Attention, New York: xford University Press.

Yantis, S., \& Hillstrom, A.P. (1994). Stimulus-driven attentional capture: evidence from equiluminant visual objects. Journal of Experimental Psychology: Human Perception and Performance, 20 (1), 95-107.

Yantis, S., \& Jones, E. (1991). Mechanisms of attentional selection: temporally modulated priority tags. Perception \& Psychophysics, 50, 166-178.

Yantis, S., \& Jonides, J. (1984). Abrupt visual onset and selective attention: Evidence from visual search. Journal of Experimental Psychology: Human Perception \& Performance, 10, 601-621.

Yantis, S., \& Jonides, J. (1990). Abrupt visual onsets and selective attention: Voluntary versus automatic allocation. Journal of Experimental Psychology: Human Perception \& Performance, 16, 121-134. 
Yeshurun, Y., \& Carrasco, M. (2008). The effects of transient attention on spatial resolution and the size of the attentional cue. Perception \& Psychophysics, 70, 104-113.

Zampini, M., Shore, D.I., \& Spence, C. (2005). Audiovisual prior entry. Neuroscience Letters, 381, 217-222.

Zimba, L.D., \& Hughes, H.C. (1987). Distractor-target interactions during directed visual attention. Spatial Vision, 2, 117-149. 
Apêndices 



\section{APÊNDICE A - Termo de Consentimento Livre e Esclarecido}

Título do estudo: Características da distribuição automática da atenção visual sobre figuras geométricas não-adjacentes

Pesquisador: (1) Mikael Cavallet, mikael@pg.ffclrp.usp.br, (16) 3602-4393, Rua Antônio Seron, 328, Centro. CEP 14160-520. Sertãozinho-SP.

Orientador: César Aléxis Galera, algalera@usp.br, (16) 3602-3760, Avenida Cândido Pereira Lima, 155, Jardim Recreio. CEP 14040-250. Ribeirão Preto-SP.

1) Eu, Mikael Cavallet, estou Ihe convidando a participar deste estudo sobre atenção visual humana, cujo objetivo é investigar a distribuição automática da atenção pelo campo visual, com a justificativa de compreender mecanismo de seleção da informação visual e o funcionamento da atenção visual. O estudo não Ihe fornecerá nenhum benefício direto, mas os dados obtidos podem ser úteis para contribuir com o conhecimento que esta pesquisa procura esclarecer.

2) O procedimento será sentar-se em frente à tela de um monitor e julgar a ordem em que estímulos são apresentados na tela. Caso você concorde em participar, sua tarefa será identificar em cada prova qual de duas letras $(F, J)$ apresentadas em seqüência muito rápida apareceu primeiro. Sua resposta será dada no teclado do computador e as respostas corretas e erradas serão registradas para análise.

3) O estudo não oferece quaisquer riscos a sua saúde física ou mental.

4) Informo que a sua privacidade será respeitada, ou seja, seu nome ou qualquer outro dado ou elemento que possa, de qualquer forma, Ihe identificar, será mantido em sigilo.

5) Você também pode se recusar a participar do estudo, ou retirar seu consentimento a qualquer momento, sem precisar justificar.

6) Caso você concorde em participar, manifeste seu livre consentimento assinando este termo.

Nome:

Assinatura:

Data:

Endereço:

Confirmo ter explicado a natureza e objetivos desse estudo ao voluntário acima.

Nome do Pesquisador: Assinatura: 


\section{APÊNDICE B - Termo de Consentimento Livre e Esclarecido}

\section{Consent Form to Participate in Vision Lab Research}

I agree to participate in the research experiment being conducted by Mikael Cavallet of the Vision Lab of Department of Psychology at Concordia University for his Doctorate $(\mathrm{PhD})$ Thesis, in collaboration with Aaron Johnson and supervised under Dr. Michael von Grünau.

\section{Purpose}

I am aware that the purpose of this project is to determine the role of eye movement in focusing on a stationary target during tasks of temporal order judgment (TOJ), reaction time (RT) and saccade reaction time (SRT). I have also been informed that the research is being conducted in order to fulfill the requirements for his PhD Thesis.

\section{Procedures}

I have been informed that this research project will require me to sit on a chair with a head rest while fixating on different visual conditions in a dark room. I am also aware that an eye tracker will record my eyes movements during the course of the experiment in order for my eye movements to be analyzed.

The experiment will last about 45 minutes and a short break will be provided. I have been informed that any of my data recorded in this study will be kept strictly confidential and will not be linked with my name. The only tasks that will be asked of me are the ones that are listed above.

\section{Risks and Benefits}

I am aware that any video captures taken during the study are strictly confidential and that the computer where the experiment will be carried out stay in a locked room and is assessed just by members of the Vision Lab. I have also been informed that the monitor luminance has a safety threshold for my eyes, but that the eye tracker and the luminance may provide some discomfort.

\section{Conditions of Participation}

- I understand that I am free to decline participation in this experiment at any time.

- I understand that I am free to withdraw from participating in this experiment at anytime without any negative consequences. 
- I understand that my participation in this study is confidential.

- I understand that the data from this study may be published.

- I understand the purpose of this study and know that there is no hidden motive of which I have not been informed.

I HAVE CAREFULLY STUDIED THE ABOVE AND UNDERSTAND THIS AGREEMENT. I FREELY CONSENT AND AGREE TO PARTICIPATE IN THIS STUDY.

NAME (please print)

SIGNATURE

WITNESS SIGNATURE

DATE 

Anexos 

ANEXO A - Declaração do Comitê de Ética em Pesquisa - CEP do Departamento de Psicologia e Educação da Faculdade de Filosofia, Ciências e Letras de Ribeirão Preto

UNIVERSIDADE DE SÁO PAULO

FACULDADE DE FILOSOFIA, CIÊNCIAS E LETRAS DE RIBEIRÃO PRETO

COMITE DE ETICAEM PESQUISA - CEP

Of.CEtP/FFCLRP-USP. 088/2008-1/10/2008

Senhor(a) Pesquisador(a):

Comunicamos a V. Sa. que o trabaho intitulado "CARACTERISTICAS DA DISTRIBUIÇĀo AUTOMÁTICA DA ATENÇÃo VISUAL SOBRE FIGURAS GEOMÉTRICAS NÃO-ADJACENTES" foi re-analisado pelo Comitê de Ética em Pesquisa da FFCLRP-USP, em sua $75^{\circ}$ Reuniâo Ordinária realizada em 1\%10/2008, e enquadrado na categoria: APROVADO, de acordo com o Processo CEP-FFCLRP n ${ }^{\circ}$ 400/2008 - 2008.1.1281.59.2

Atenciosamente,

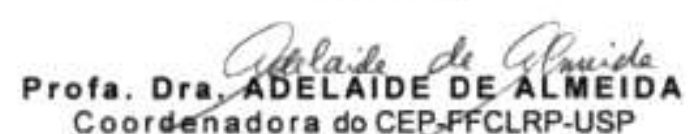

Coordenadora do CEP.FFCLRP-USP

llustrissimo Senhor

MIKAEL KAVALLET

Aluna do programa de Pós-Graduaçăo em Psicologia

Desta FFCLRP-USP

c.c: Prof. CESAR ALEXIS GALERA

Docente do Departamento de Psicologia e Educaçăo

Desta FFCLRP.USP 
ANEXO B - Declaração do Comitê de Ética em Pesquisa da Universidade Concórdia de Montreal

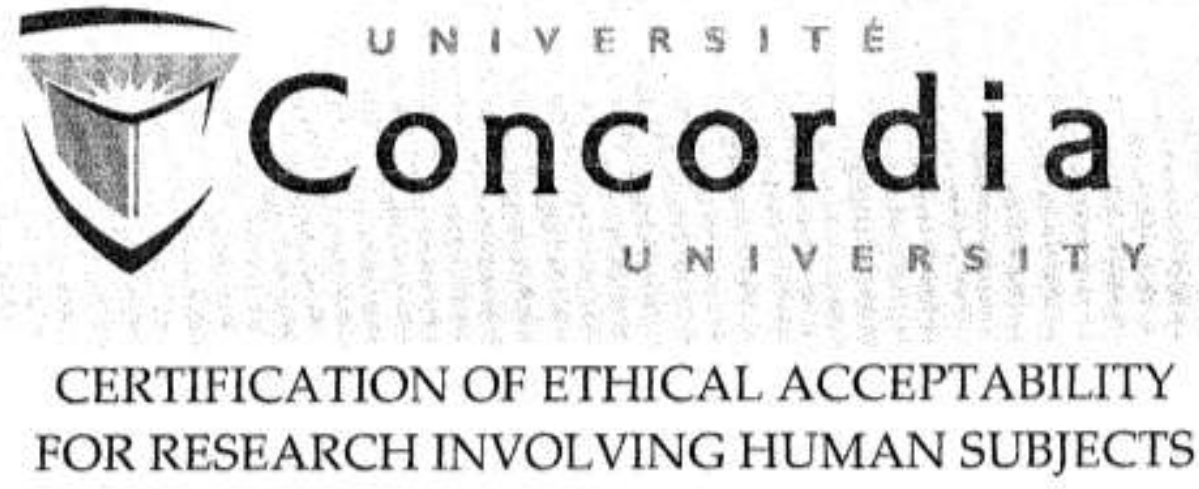

Name of Applicant:

Dr. Michael von Grunau

Department:

Psychology

Agency:

NSERC

Title of Project:

Psychophysical investigations of human motion and attention systems

Certification Number: $\quad$ UH2006-049-4 (Annual Report)

Valid From: Feb $4^{\text {th }} 2010$

to: Feb $4^{\text {th }} 2011$

The members of the University Human Research Ethics Committee have examined the application for a grant to support the above-named project, and consider the experimental procedures, as outlined by the applicant, to be acceptable on ethical grounds for research involving human subjects.

Dr. James Pfaus, Chair, University Human Research Ethics Committee 